PEDRO AUGUSTO SAMPAIO ROCHA FILHO

\title{
Cefaléia pós-craniotomia em pacientes submetidos à cirurgia para clipagem de aneurismas cerebrais
}

Tese apresentada ao Departamento de Neurologia da Faculdade de Medicina da Universidade de São Paulo para obtenção do título de Doutor em Ciências

Área de concentração: Neurologia

Orientador: Prof. Dr. José Luiz Dias Gherpelli

\section{São Paulo




\section{FICHA CATALOGRÁFICA}

Preparada pela Biblioteca da

Faculdade de Medicina da Universidade de São Paulo

Creprodução autorizada pelo autor

Rocha Filho, Pedro Augusto Sampaio

Cefaléia pós-craniotomia em pacientes submetidos à cirurgia para clipagem de aneurismas cerebrais / Pedro Augusto Sampaio Rocha Filho. -- São Paulo, 2006. Tese(doutorado)--Faculdade de Medicina da

Universidade de São Paulo.

Departamento de Neurologia.

Área de concentração: Neurologia.

Orientador: José Luiz Dias Gherpelli.

Descritores:

1.CEFALÉIA/classificação

2.CRANIOTOMIA 3.DOR PÓS-OPERATÓRIA

4.MEDIÇÃO DA DOR 5.SÍNDROME DA

DISFUNÇÃO DA ARTICULAÇÃO

TEMPOROMANDIBULAR

6.ANEURISMA

INTRACRANIANO 7.QUALIDADE DE VIDA

USP/FM/SBD-028/06 
Dedico esta tese:

A minha mãe e meu pai, que sempre valorizaram a formação e educação dos filhos e são os principais responsáveis pelo que sou hoje.

A minha tia Suzy, minha segunda mãe.

A Dona Clara, minha terceira mãe, que tornou mais suportável a ausência da minha família enquanto estava morando em São Paulo. 


\section{AGRADECIMENTOS}

Ao Dr. Getúlio Daré Rabello, para mim um modelo de médico e neurologista, por ter-me acolhido no ambulatório de cefaléia, por ter sido um amigo durante esses anos. Obrigado pelas argutas observações feitas.

Ao Dr. José Luiz Dias Gherpelli, pelas orientações dadas e pela paciência nos meus momentos de ansiedade.

Ao Centro de Estatística Aplicada do Instituto de Matemática e Estatística da USP, nas pessoas de Cristiane Karcher e dos professores Carlos Alberto de Bragança Pereira e Júlio da Motta Singer, pela análise estatística deste estudo.

A Creusa Maria Roveri Dal Bo, pela análise estatística deste estudo.

Ao Dr. José Tadeu Tesseroli de Siqueira e a Fábio José Condino Fujarra, pelas avaliações odontológicas realizadas.

A meu pai, pelas sugestões pertinentes em relação à língua portuguesa.

À Equipe de Neurocirurgia Vascular que abriu as portas do Serviço para a realização deste estudo.

Aos Residentes de Neurocirurgia e ao corpo de enfermagem da enfermaria de neurocirurgia, pela colaboração com o projeto, deixando-me informado das novas internações e da programação cirúrgica.

A Ivete, voluntária do Hospital das Clínicas, pela ajuda na organização dos pacientes durante $o$ atendimento. 
A Ida Fortini, Dalva Carrocini e Antonio Cezar Ribeiro Galvão pelos ensinamentos neurológicos, psiquiátricos, e sobre cefaléias.

A Marcelo Calderaro, pelo estímulo dado durante este trabalho.

A Josie Haydée Lima Ferreira, por ter sido minha presença em São Paulo quando já estava no Recife. 
Esta tese está de acordo com:

Referências: adaptado de International Commitee of Medical Journals Editors (Vancouver)

Universidade de São Paulo. Faculdade de Medicina. Serviço de Biblioteca e Documentação. Guia de apresentação de dissertações, teses e monografias. Elaborado por Anneliese Carneiro da Cunha, Maria Júlia de A. L. Freddi, Maria F. Crestana, Marinalva de Souza Aragão, Suely Campos Cardoso, Valéria Vilhena. São Paulo: Serviço de Biblioteca e Documentação; 2004.

Abreviaturas dos títulos dos periódicos de acordo com List of Journals Indexed in Index Medicus. 


\section{SUMÁRIO}

Resumo

Summary

1 INTRODUÇÃO

2 REVISÃO DA LITERATURA

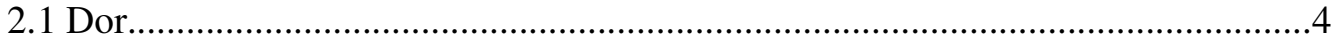

2.2 Cefaléia causada por aneurismas.................................................................6

2.3 Principais craniotomias utilizadas para o tratamento de aneurismas

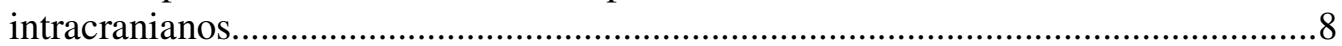

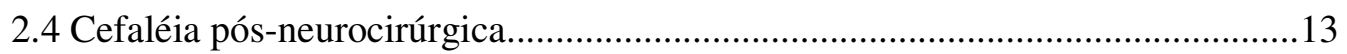

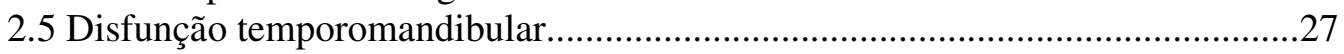

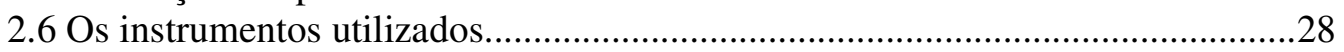

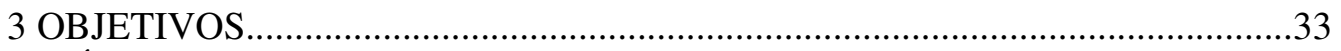

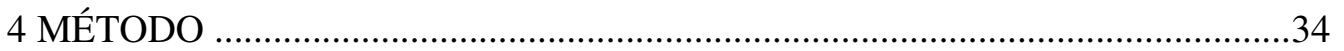

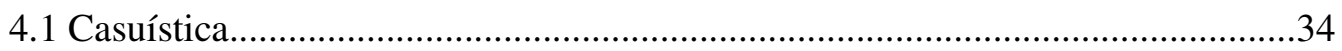

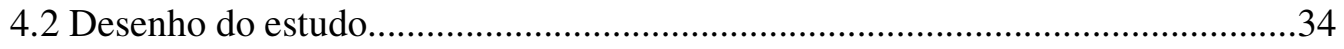

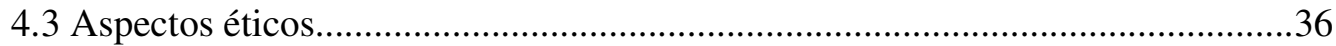

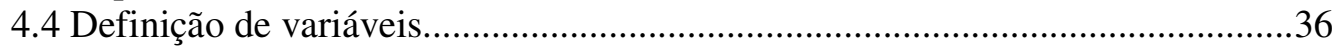

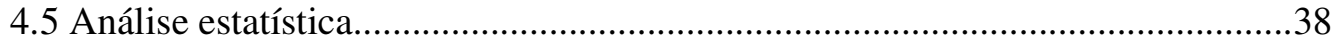

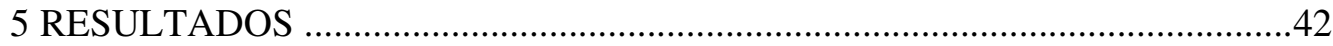

5.1 Caracterização da amostra e dados sobre o seguimento...................................42

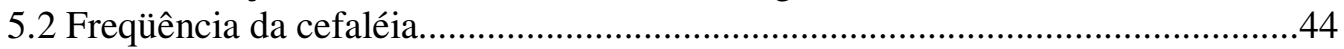

5.3 Relação entre frequiência de cefaléia e os sintomas depressivos,

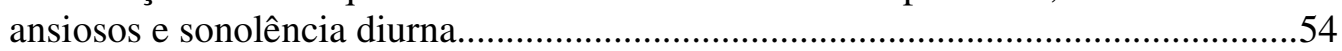

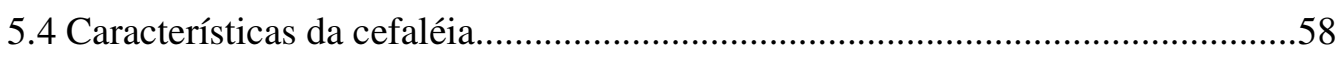

5.5 Disfunção temporomandibular e presença de cefaléia após a craniotomia.........69

5.6 Qualidade de vida.................................................................................... 71

5.7 Cefaléia pós-craniotomia segundo a classificação da IHS..................................73

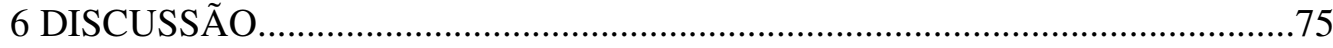

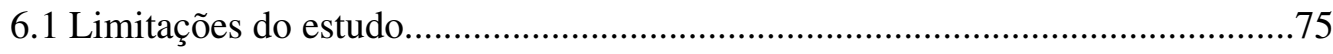

6.2 Freqüência de cefaléia..............................................................................77

6.3 Características da cefaléia pós-craniotomia....................................................... 81

6.4 Relação entre freqüência de cefaléia e os sintomas depressivos, ansiosos e

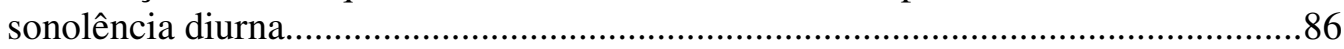

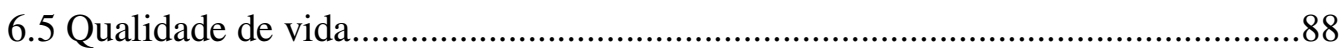

6.6 Disfunção temporomandibular e presença de cefaléia após a craniotomia..........92

6.7 Cefaléia pós-craniotomia segundo a classificação da IHS...................................94

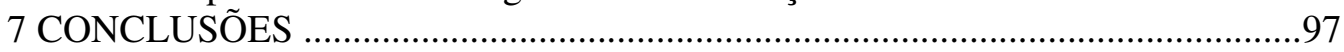

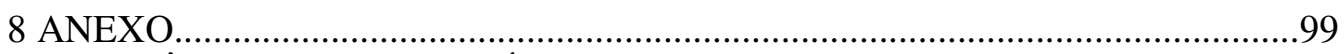

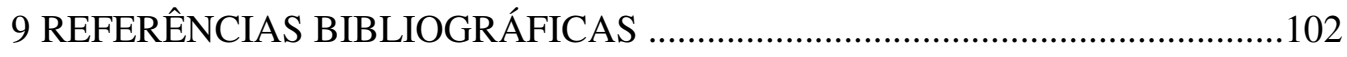




\section{RESUMO}

Rocha Filho PAS. Cefaléia pós-craniotomia em pacientes submetidos à cirurgia para clipagem de aneurismas cerebrais [tese]. São Paulo: Faculdade de Medicina, Universidade de São Paulo; 2006. 123 p.

INTRODUÇÃO: A cefaléia pós-craniotomia pode causar grande repercussão na vida de quem dela sofre. No entanto, a literatura sobre o assunto carece de estudos prospectivos sobre essa condição. Neste trabalho foram estudados o comportamento e características da cefaléia nos primeiros seis meses após craniotomia. MÉTODOS: Pacientes com aneurismas cerebrais, internados no Hospital das Clínicas da Faculdade de Medicina da Universidade de São Paulo, foram avaliados entre 17/10/2002 e 02/10/2003 no pré-operatório e seguidos por seis meses. Foram utilizados questionários semi-estruturados, diários de cefaléia e as escalas Hospital Anxiety and Depression Scale (ansiedade e depressão), Epworth (sonolência diurna), SF-36 (qualidade de vida) e McGill. Cirurgiões-dentistas avaliaram a presença de disfunção temporomandibular no pós-operatório. RESULTADOS: Foram incluídos 79 pacientes com idade média de 45,3 anos, 64,6\% do sexo feminino, e 72 concluíram o seguimento. Foram realizadas 87 craniotomias $(89,7 \%$ pterionais, $4,6 \%$ frontais e 5,8\% fronto-órbito-zigomáticas). A cefaléia pós-cirúrgica ocorreu em 91,1\% dos casos, a maioria com início precoce (mediana $=4$ dias) $\mathrm{e}$ significativamente mais precoce naqueles com cefaléia e hemorragia subaracnóidea na avaliação pré-operatória. Houve mudanças de diagnósticos, lado e local da cefaléia do pré para o pós-operatório que se mantiveram por todo este período. A freqüência de cefaléia: aumentou em média 14 dias (mediana=1) no primeiro trimestre do pós-operatório em relação ao trimestre anterior à cirurgia e continuou em média, 6,9 dias (mediana=0) mais alta no segundo trimestre; diminuiu em média 7,9 dias (mediana=1) dos primeiros para os últimos 3 meses de acompanhamento. Esse comportamento não sofreu influência da hemorragia subaracnóidea. Houve correlação positiva da freqüência de cefaléia com a intensidade dos sintomas depressivos e ansiosos. A cefaléia no segundo trimestre do pós-operatório relacionou-se significativamente à disfunção temporomandibular. A incidência de cefaléia pós-craniotomia baseada nos critérios da International Headache Society foi de 40\% (aguda: 11,0\%; crônica: 30,2\%). O índice total de dor baseado na escala de McGill teve correlação positiva com a ansiedade e menores escores na craniotomia pterional; e houve maior número de descritores marcados pelas mulheres. Os escores da SF-36 foram significativamente menores que os da população urbana brasileira; maiores intensidades de ansiedade e craniotomia frontal associaram-se com escores significativamente menores no domínio dor; maiores freqüências de cefaléia associaram-se com escores significativamente menores nos domínios dor e aspectos sociais. CONCLUSÕES: A cefaléia que ocorreu após craniotomia teve incidência alta, início precoce, características diferentes e maior freqüência que a cefaléia prévia e esteve associada à disfunção temporomandibular, a sintomas depressivos e ansiosos e à significativa repercussão sobre a qualidade de vida. Sua frequiência diminuiu com o tempo. A dor foi mais intensa nas mulheres, nos mais ansiosos, e nos submetidos a craniotomias frontais e fronto-órbito-zigomáticas.

Descritores: Cefaléia/classificação; Craniotomia; Dor pós-operatória; Medição da dor; Síndrome da disfunção da articulação temporomandibular; Aneurisma intracraniano; Qualidade de vida. 


\section{SUMMARY}

Rocha Filho PAS. Post-craniotomy headache after surgery for treatment of cerebral aneurysms [thesis]. São Paulo: "Faculdade de Medicina, Universidade de São Paulo"; 2006. 123p.

INTRODUCTION: Post-craniotomy headache can cause a great repercussion on the quality of life of those who suffer it. However, literature on this subject lacks prospective studies on this condition. We studied the behavior and characteristics of the headache on the first six months after craniotomy. METHODS: Patients with cerebral aneurysms were evaluated at the Clinics Hospital of the University of São Paulo Medical School, between 10/17/2002 and 10/02/2003 in the pre-surgical period, and followed during six months after the surgery. We used semi-structured interviews, headache diaries, Hospital Anxiety and Depression Scale, Epworth Sleepiness Scale, SF-36 and McGill Pain Questionnaire. Dentists evaluated the presence of temporomandibular disorder in the post-surgical period. RESULTS: 79 patients were included, with a mean age of 45.3 years, $64.6 \%$ were female, and 72 concluded the follow-up. 87 craniotomies were performed (pterional: $89.7 \%$; frontal: 4.6\%; orbitozygomatic: $5.8 \%$ ). Post-craniotomy headache was observed in $91.1 \%$, early in the post-surgical period (4 days), being significantly more precocious in those with headache caused by subarachnoid hemorrhage in the pre-surgical evaluation. There were changes in the headache diagnosis, side and sites, after surgery that did not change during the follow-up period. The frequency of the headache had an average increase of 14 days (median=1) on the first trimester of the pos-surgical period, compared to the trimester before surgery and continued at a rate of 6.9 days (median=0) higher on the second trimester. There was an average decrease of 7.9 days (median=1) from the first to the last three months of follow-up. The presence of subarachnoid hemorrhage did not influence headache frequency. There was a positive relation between headache frequency and depressive and anxiety symptoms. The headache on the second trimester of the post-surgical period was significant related to temporomandibular disorder. Post-craniotomy headache based on the International Headache Society criteria was observed in $40 \%$ of the patients (acute in 11.0\%; chronic in 30.2\%). McGill Pain Questionnaire: PRI was positively and significantly related to the intensity of the anxiety and had lower scores in the pterional approach; the number of words chosen was higher in women. SF-36: the scores were significantly lower than the ones found on a large Brazilian urban sample. The presence of anxiety and frontal craniotomy were associated with significant lower scores on bodily pain domain, and higher headache frequencies were significantly associated with lower scores on bodily pain and social functioning. CONCLUSIONS: post-craniotomy headache had a high incidence, an early beginning, different features and a higher frequency than previous headaches and was associated with temporomandibular disorder, depressive and anxiety symptoms and with a significant repercussion on quality of life. Its frequency decreased with time. Pain was more intense in women, anxious persons and in those with frontal and orbitozygomatic approach.

Keywords: Headache/classification; Craniotomy; Pain/postoperative; Pain measurement; Temporomandibular joint dysfunction syndrome; Intracranial aneurysm; Quality of life. 


\section{1 - INTRODUÇÃO}

A classificação de cefaléia da International Headache Society (IHS) ${ }^{1}$ divide as cefaléias em três grupos:

a) primárias (cefaléias-doença), que são compostas de quatro subgrupos (migrânea; cefaléia do tipo tensional; cefaléia em salvas e outras cefaléias trigêmino-autonômicas; e outras cefaléias primárias).

b) secundárias (cefaléias-sintoma), que são compostas de oito subgrupos.

c) grupo representado pelas neuralgias cranianas, dor facial primária e central e outras cefaléias.

As cefaléias secundárias freqüentemente têm as mesmas características das primárias, devendo, para serem classificadas como tal, ter relação temporal estabelecida com a lesão orgânica.

As cefaléias pós-craniotomia constituem um importante grupo de cefaléias secundárias, e freqüentemente são um desafio para neurocirurgiões e neurologistas.

As cefaléias pós-craniectomia e pós-craniotomia da fossa posterior são mais estudadas do que as relacionadas às cirurgias supratentoriais. No entanto, os estudos realizados são geralmente de tipo coortes retrospectivos ou transversais, o que limita as conclusões quanto à relação temporal entre a cirurgia e a cefaléia, bem como quanto à evolução temporal da mesma. Outro fato que deve ser destacado é que, nesses estudos, a presença de cefaléia primária prévia, importante variável de confusão, não é controlada. Apesar das limitações destes estudos, este tipo de cefaléia parece ter incidência importante, sendo as mais elevadas geralmente encontradas quando o acesso cirúrgico adotado é suboccipital, nestes sendo 
freqüentemente maiores que $40 \%{ }^{2-10}$. Essas cefaléias podem causar importante repercussão na vida do indivíduo, interferindo nas suas atividades diárias e nos seus trabalhos $4,6,11-13$.

A cefaléia pós-craniotomia supratentorial é pouco estudada, não havendo nenhum estudo prospectivo a respeito. Após lobectomia temporal anterior para tratamento de epilepsia de difícil controle, verificou-se que 5,6\% dos pacientes persistiam com cefaléia entre dois meses e 1 ano após o procedimento e 11,9 \% referiam dor por mais de um ano. Após 12 meses, 4\% dos pacientes tinham cefaléias que não eram controladas pelos medicamentos prescritos por seus médicos e 3,2 \% necessitavam de medicamentos para controle da dor ${ }^{14}$. Em outro estudo em que foram incluídos pacientes com tumores cerebrais, epilepsia e hemorragia intracraniana, encontrou-se incidência de 19\% de cefaléia pós-neurocirúrgica entre os que não tinham cefaléia prévia à cirurgia ${ }^{15}$.

O nosso interesse pelo assunto surgiu inicialmente da constatação, através da prática ambulatorial, de que este tipo de cefaléia pode constituir um problema clínico importante. Posteriormente, verificamos a lacuna na literatura de estudos com desenhos que permitissem definir a relação causal entre a craniotomia e a cefaléia, bem como a evolução temporal desta. A maioria dos estudos que trata do assunto foi feita com pacientes que se submeteram a cirurgias para tratamento de tumores, os quais, por si só, podem causar cefaléia.

O modelo de craniotomia para tratamento de epilepsia não nos parece adequado porque para o tratamento desse grupo de doenças usam-se medicamentos que podem interferir na evolução da cefaléia, além das crises epilépticas poderem causar cefaléia. 
O modelo mais adequado nos pareceu ser o da craniotomia para tratamento de aneurismas cerebrais. Esta doença não é progressiva e, em geral, é considerada curada após o tratamento cirúrgico. Outro fator levado em consideração foi o grande volume cirúrgico do Serviço de Neurocirurgia do Hospital das Clínicas da Faculdade de Medicina da Universidade de São Paulo, referência para o tratamento de aneurismas, recebendo pacientes de vários locais. Esse serviço tem também um ambulatório de seguimento pós-operatório estruturado, o que facilita a realização de pesquisa científica. 


\section{2 - REVISÃO DA LITERATURA}

\subsection{Dor}

Dor é uma experiência sensitiva e emocional desagradável associada a uma lesão tecidual real ou potencial, ou descrita nos termos de tal lesão ${ }^{16}$.

Os estímulos dolorosos são percebidos através de terminações periféricas (nociceptores) de neurônios sensitivos primários cujos corpos celulares encontram-se nos gânglios das raízes dorsais da medula espinal ou no gânglio trigeminal. Os nociceptores localizados na pele e tecido subcutâneo são ativados por variações térmicas (nociceptores térmicos), pressóricas (nociceptores mecânicos), ou pela combinação de várias formas de estímulos (nociceptores polimodais).

Os estímulos veiculados pelos nociceptores térmicos e mecânicos são conduzidos por fibras A $\delta$ mielinizadas que conduzem sinais a uma velocidade de 5$30 \mathrm{~m} / \mathrm{s}$, enquanto que os estímulos provenientes dos nociceptores polimodais o são por fibras $\mathrm{C}$, amielínicas que os conduzem a velocidades em geral menores que 1 $\mathrm{m} / \mathrm{s}$. As vísceras possuem nociceptores "silenciosos" que geralmente não são ativados por estímulos nociceptivos comuns, até que seus limiares sejam dramaticamente reduzidos por insultos químicos ${ }^{17}$.

A transmissão sináptica entre os nociceptores e os neurônios da coluna dorsal da medula é feita através do glutamato e de polipeptídios (entre estes a substância P). O glutamato, por ter um mecanismo específico de recaptação através das células gliais, atua nos neurônios pós-sinápticos que estão mais próximos. Os polipeptídios não apresentam sistema específico de recaptação, podendo difundir-se a distâncias 
consideráveis e influenciar outros neurônios pós-sinápticos, além de poderem prolongar a ação do glutamato ${ }^{17}$.

A aplicação de estímulos repetitivos determina o fenômeno da "sensibilização periférica" que faz com que receptores que inicialmente não respondiam aos estímulos, passem a responder. Este fenômeno é comumente observado após uma lesão e é mediado através da ação de várias substâncias que são liberadas pelas células e tecidos vizinhos à lesão (bradicinina, histamina, prostaglandinas, leucotrienos, acetilcolina, serotonina e substância P), baixando o limiar de ativação dos nociceptores ${ }^{17}$.

Como conseqüência do fenômeno de "sensibilização periférica", ocorre um aumento progressivo da despolarização de neurônios do corno posterior da medula, conseqüente à abertura dos canais iônicos pós-sinápticos mediados por receptores de glutamato tipo N-metil-D-aspartato (NMDA). Isso determina a indução de genes que codificam fatores de transcrição (como o c-fos), aumento na expressão de polipeptídios e outros neurotransmissores, assim como de seus receptores os quais presumivelmente levam a mudanças das propriedades fisiológicas desses neurônios 17. Esse processo conhecido como "sensibilização central" manifesta-se por uma expansão do campo nociceptivo, por um aumento da freqüência dos potenciais de ação espontâneos e por uma resposta exagerada a estímulos mecânicos e térmicos dos neurônios da coluna dorsal da medula ${ }^{18}$.

Ray e Wolff realizaram estimulações mecânicas, químicas, térmicas e elétricas durante neurocirurgias, constatando que os pacientes referiam dor quando as seguintes estruturas eram estimuladas: couro cabeludo, gálea, músculos e suas fáscias, periósteo, artérias extracranianas, troncos principais das artérias durais, seios 
durais, artéria carótida interna, artéria cerebral média (até 1-2 cm da sua origem), artéria cerebral anterior (do início até um cm após o joelho do corpo caloso), artéria pontina principal, artéria auditiva interna, artéria cerebelar póstero-inferior, tenda do cerebelo e o IX, X e XI nervos cranianos. A estimulação dos ossos do crânio, veias diplóicas, veias extracranianas, foice do cérebro, pia-aracnóide e parênquima cerebral não provocaram dor. A estimulação da dura-máter produziu dor quando estimulada no teto da órbita, esfenóide, dorso da sela, apófise clinóide anterior, fossa anterior e posterior, e foi insensível na convexidade do cérebro (com exceção das margens dos seios durais e ao longo do trajeto da artéria meníngea média) e na fossa média ${ }^{19}$. A inervação do couro cabeludo e dura-máter é feita basicamente pelo nervo trigêmeo e três primeiras raízes cervicais ${ }^{20,21}$.

\subsection{Cefaléia causada por aneurismas}

A prevalência de aneurismas intracranianos na população varia, conforme o desenho do estudo e método diagnóstico utilizado. Uma revisão sistemática que abrangeu 23 estudos e um total de 56.306 pacientes estudados por uma outra razão que não hemorragia subaracnóidea, encontrou as menores taxas de prevalências, em estudos retrospectivos baseados em dados de autópsias $(0,4 \%)$ e as maiores, em estudos prospectivos baseados em dados angiográficos $(6 \%)^{22}$.

A incidência da hemorragia subaracnóidea (HSA) é de 10,5/100.000 pessoas por ano, tendo as mulheres um risco 1,6 vezes maior que os homens ${ }^{23}$, sendo o pico de incidência do sangramento na sexta década ${ }^{24-26}$. Aproximadamente $85 \%$ das HSA espontâneas são causadas por aneurismas saculares intracranianos ${ }^{24,27-29}$. 
A cefaléia é o principal sintoma diagnóstico da HSA. Ela está presente na grande maioria dos casos ${ }^{30-36}$, sendo em geral de início súbito e de forte intensidade 30, 32, 35, 37-39. A cefaléia pode ser o único sintoma, ou pode ser acompanhada por náuseas/ vômitos, perda transitória da consciência, crises epilépticas, rebaixamento do nível de consciência, rigidez de nuca e sinais neurológicos focais ${ }^{30,32,34,35,39}$.

O tempo de duração dessa cefaléia é uma questão pouco estudada. Dos 240 pacientes incluídos no Alianza-Barcelona Stroke Registry, um banco de dados de doenças cérebro-vasculares, sete apresentaram HSA. O tempo médio de duração da cefaléia nesses pacientes foi de 86,5 horas ${ }^{40}$. A International Headache Society, na sua classificação de cefaléias, admite que a cefaléia conseqüente à HSA pode perdurar por até um mês ${ }^{1}$. Isto reflete a concepção de que essas cefaléias têm duração limitada.

Além da cefaléia causada no momento da HSA, são descritas também cefaléias sentinelas, nos dias ou semanas que precedem o sangramento, com padrão semelhante à cefaléia que levou ao diagnóstico deste. Uma revisão sistemática recente verificou que estas cefaléias ocorrem em 10 a $43 \%$ desses pacientes ${ }^{41}$. Acredita-se que a cefaléia sentinela seja causada por um pequeno sangramento não detectado, trombose ou expansão da parede do aneurisma ${ }^{42-45}$. Além desses períodos, é raro que o aneurisma cause cefaléia, sendo isso descrito de forma anedótica $^{46-55}$. 


\subsection{Principais craniotomias utilizadas para o tratamento de aneurismas} intracranianos

Craniotomia é um termo que designa a abertura cirúrgica do crânio ${ }^{56}$. As craniotomias podem ser divididas em supratentoriais e infratentoriais, de acordo com o compartimento craniano acessado ${ }^{56}$. Nesta seção discorreremos brevemente sobre as principais craniotomias utilizadas para o tratamento de aneurismas intracranianos.

2.3.1 Craniotomias frontal e bi-frontal: usada principalmente para o tratamento de aneurismas das artérias pericalosas ${ }^{57}$. Permite também o acesso a lesões do terceiro ventrículo e ventrículos laterais, gânglios basais e tálamo através da dissecação da fissura inter-hemisférica ${ }^{58}$. A incisão na pele é feita $1-2 \mathrm{~cm}$ anterior à sutura coronal. É rodado um retalho de pele sobre o rebordo orbitário ${ }^{57}$. Essa craniotomia é feita na altura da sutura coronal e paralela ao seio sagital ${ }^{58}$.

2.3.2 Craniotomia pterional (fronto-temporo-esfenoidal): é um dos acessos mais utilizados em neurocirurgia. Permite a abordagem de diferentes lesões localizadas nas cisternas basais e porção superior do compartimento infratentorial, possibilitando uma exposição cirúrgica máxima com mínima retração cerebral. Esse procedimento é feito com o paciente em posição supina. Uma incisão curva é feita na pele, começando na porção superior do arco zigomático $(<1 \mathrm{~cm}$ na frente do trágus), estendendo-se superiormente até a linha temporal anterior e, a partir daí, dirigindo-se anteriormente para a linha média, atrás da linha do cabelo. A artéria temporal superficial pode ser dissecada e preservada na maioria dos casos. A fáscia do músculo temporal é mantida intacta durante a incisão da pele. Quando a incisão alcança a linha temporal anterior, esta é aprofundada para incluir o pericrânio que é refletido anteriormente com o retalho da pele. A partir deste ponto, é necessário 
dissecar os tecidos moles que recobrem o arco zigomático para expor o processo zigomático do osso frontal. Essa dissecação é realizada de maneira a evitar a lesão do ramo frontal do nervo facial. A craniotomia é então realizada, permitindo o acesso à porção lateral do cérebro através da remoção do osso frontal, da parte escamosa do osso temporal e da asa maior do esfenóide. Após a realização da craniotomia, broca$\mathrm{se}^{*}$ o teto da órbita e a asa do esfenóide. Após exposição da fissura orbital superior, a brocagem prossegue medialmente, na asa menor do esfenóide. Abre-se então a duramáter.

Figura $1 * *$ - Craniotomia pterional: A - Posicionamento do paciente; B Dissecação interfascial do músculo temporal; C - Local da craniotomia; D - Abertura

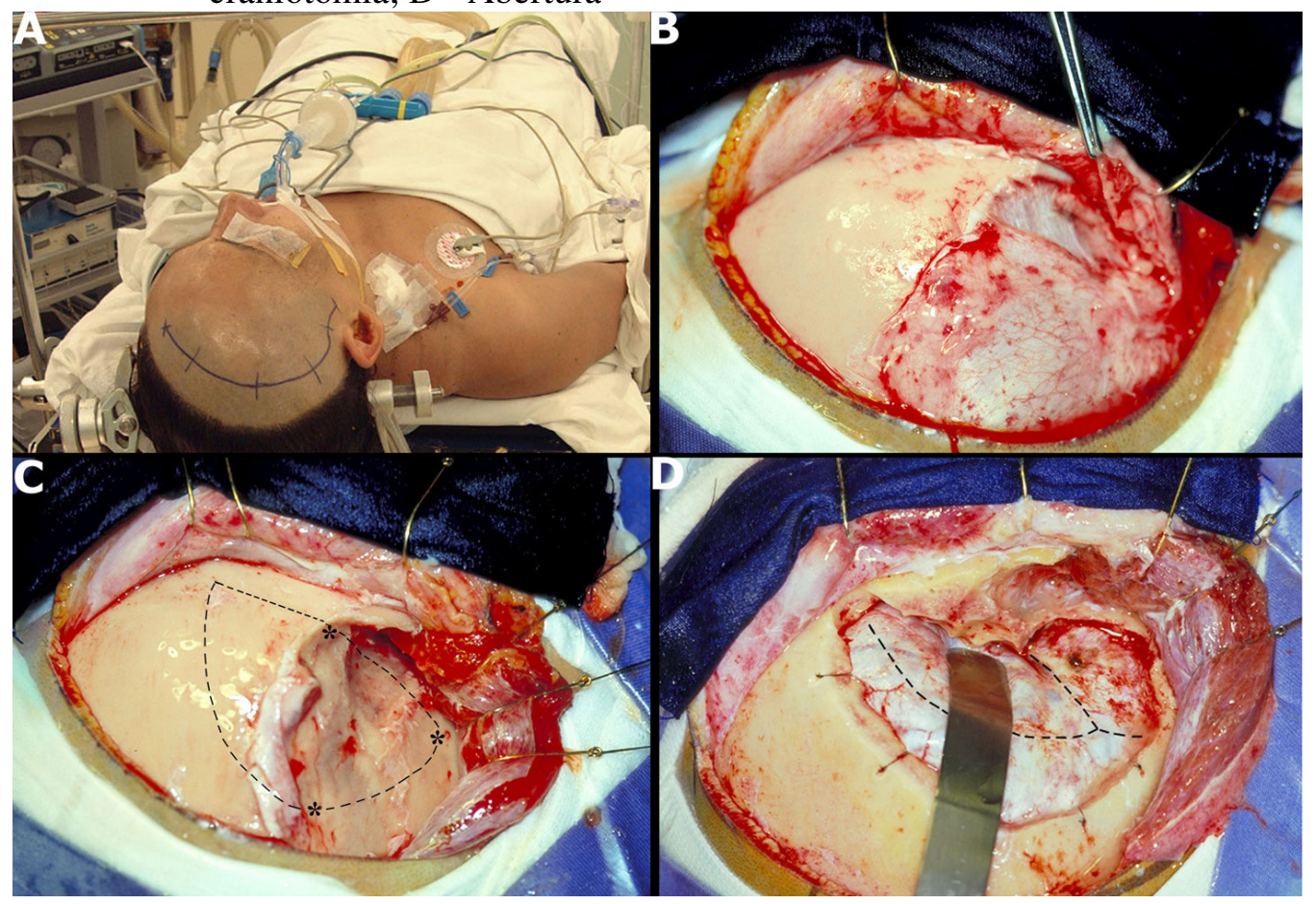

\footnotetext{
* O termo em inglês é “drill”. Não existe drilar em português, apesar dos neurocirurgiões usarem tal expressão nas descrições cirúrgicas. O termo equivalente em português é brocar.

** Figura gentilmente cedida pelo Dr. Wen Hung Tzu
} 
O procedimento prossegue com a abertura da fissura silviana e das cisternas basais, utilizando técnica microcirúrgica. As cisternas basais que podem ser alcançadas pelo acesso pterional são: cisterna olfatória (contém o tracto olfatório), carotídea (contém o segmento supraclinóideo da artéria carótida interna e seus ramos), compartimento esfenoidal da fissura silviana, cisterna quiasmática, cisterna da lâmina terminalis (contém os segmentos A1 e início de A2 da artéria cerebral anterior), cisterna ambiens, cisterna interpeduncular (1/3 distal da artéria basilar, artérias cerebral posterior e cerebelar superior) e cisterna crural ${ }^{59}$.

2.3.3 Acesso pré-temporal: é uma variante do acesso pterional. Usado para abordar lesões localizadas na região interpeduncular, na região petroclival alta, fossa média, região selar, parasselar, porção anterior da incisura tentorial. Oferece acesso ao assoalho da fossa média e ao seio cavernoso. A dissecação interfascial segue os mesmos princípios da abordagem pterional. O músculo temporal é desconectado de todo osso zigomático e refletido sobre a porção horizontal do arco zigomático. Posteriormente, o músculo temporal é retraído até que a raiz posterior do arco zigomático seja exposta. Após a craniotomia, as asas do esfenóide e o teto da órbita e a parte escamosa do osso temporal são aplanadas, expondo-se o pólo temporal.

Este procedimento cria três possibilidades de acesso: um corredor pterional, um corredor através da porção anterior do pólo temporal (corredor têmporo-polar) e outro pelo assoalho da fossa média, abaixo do lobo temporal (corredor subtemporal). O corredor escolhido depende da lesão em questão ${ }^{60}$.

2.3.4 Craniotomia (pré-temporal) fronto-órbito-zigomática: é outra variante da craniotomia pterional convencional. Promove a exposição extradural de elementos da fossa anterior e média. Permite a abordagem de lesões intradurais que 
se originam ou se dirigem para as fossas anterior e média, regiões selar e parasselar, interpeduncular, ápice petroso e terço superior do clivus. A exposição da base da fossa anterior e média permite também a abordagem de lesões extradurais destas regiões. Permite também o acesso aos seios esfenoidal, frontal e etmoidal, componentes da órbita, seio cavernoso, fossa infratemporal, ápice petroso, artéria carótida interna intrapetrosa e ao restante da fossa média. O procedimento é realizado com o paciente em posição supina. É feita uma incisão no couro cabeludo que se inicia 1 a $2 \mathrm{~cm}$ abaixo do arco zigomático. A incisão prossegue em curva, atrás da linha do cabelo, para o lado oposto, terminando ao final da linha temporal superior ou da linha pupilar média. O pericrânio geralmente é refletido anteriormente com o retalho do escalpe.

É feito um retalho interfascial. A camada externa da fáscia temporal é refletida anteriormente. $\mathrm{O}$ processo zigomático do osso temporal e o osso zigomático com seu processo temporal e frontal são expostos. O rebordo orbital superior e o forame supra-orbital com o nervo são identificados. O nervo supra-orbital é liberado na órbita com cuidado para não lesar a periórbita.

Após expor-se o processo zigomático do osso temporal (arco zigomático) e o osso zigomático com seu processo temporal e frontal, procede-se a osteotomia zigomática. $\mathrm{O}$ arco zigomático é cortado posteriormente de maneira oblíqua na sua raiz e em frente ao processo glenóide e então, anteriormente, até a junção do arco com o osso zigomático. O osso zigomático (eminência malar) é cortado de maneira oblíqua anteriormente, até o nível do forame zigomático-facial. Nesse ponto, o músculo temporal é dissecado na fossa temporal e refletido inferiormente com o arco zigomático, através da fossa infratemporal. 
A craniotomia pré-temporal é feita rente ao assoalho da fossa média. $\mathrm{Na}$ preparação para a osteotomia orbitária, o teto da órbita é afinado e a fissura orbital inferior identificada. $\mathrm{O}$ corte na eminência malar é então conectado à fissura orbitária inferior. Outro corte é feito no teto da órbita, do forame supra-orbital à fissura orbital superior e então, lateralmente, até conectar a fissura orbitária interior. O teto da órbita é então removido e a dura-máter aberta para o início da microcirurgia vascular 60.

2.3.5 Craniotomia subtemporal: para a realização desta craniotomia, a escama temporal é removida para a exposição da fossa temporal. Oferece uma visão lateral da fossa interpeduncular através da retração do lobo temporal superiormente

${ }^{60}$. Este acesso permite a abordagem de aneurismas grandes da porção terminal e média da artéria basilar, neurinomas trigeminais limitados à fossa média, tumores petrosos extradurais e meningiomas petroclivais ${ }^{58}$.

2.3.6 Craniotomia suboccipital lateral (acesso retrossigmóide): é usada para o tratamento de aneurismas da circulação posterior, abaixo da origem das artérias cerebelares superiores. A incisão na pele é feita 2 a $3 \mathrm{~cm}$ acima da linha nucal, estendendo-se inferiormente por mais ou menos $7 \mathrm{~cm}$. É feita uma incisão no periósteo e nos músculos splenius capitis, trapézio e esternocleidomastóideo. O princípio desta craniotomia é remover lateralmente o osso da região mastóidea, expondo-se a porção petrosa do temporal medialmente com mínima retração do cerebelo $^{57}$.

2.3.7 Craniotomia suboccipital mediana: este acesso é utilizado para a abordagem de aneurismas periféricos da artéria cerebelar póstero-inferior. Utiliza uma incisão mediana posterior, estendendo-se da proeminência occipital à apófise 
espinhosa de C2. É feita a dissecação da transição crânio-cervical e craniotomia ou craniectomia suboccipital com eventual abertura do forame magno ${ }^{57}$.

\subsection{Cefaléia pós-neurocirúrgica}

\subsubsection{Dor nos primeiros dias de pós-operatório}

As neurocirurgias foram consideradas, até pouco tempo, como cirurgias não dolorosas. A ausência de mobilização do sítio cirúrgico, ao contrário das cirurgias ortopédicas e viscerais, era a explicação usada para justificar esta tese ${ }^{61}$.

Essa impressão inicial foi reforçada por Dunbar et al. que concluíram que após craniotomias, os pacientes referiam menos dor e recebiam menos opióides comparativamente àqueles submetidos a cirurgias extracranianas e laminectomias descompressivas da região lombar. No entanto, esses autores só incluíram na sua investigação pacientes admitidos em unidade de assistência pós-anestésica. Isso determinou um viés de seleção, já que os pacientes com cirurgia intracraniana, quando evoluíam mal neurologicamente, não iam para essa unidade ${ }^{62}$. Esses achados divergem de trabalho posterior que não encontrou diferença entre craniotomias infratentoriais, supratentoriais e cirurgias de coluna quanto aos escores de dor, náuseas ou quantidade de analgésicos utilizados ${ }^{63}$.

Ensaios clínicos realizados com drogas e procedimentos anestésicos em neurocirurgias supratentoriais nos dão uma medida indireta da incidência de dor no pós-operatório imediato na medida em que avaliam a necessidade de utilização de analgésicos pelos pacientes. A necessidade de analgésicos nesses estudos varia de 50 a $90 \%{ }^{64-67}$. Deve-se salientar que esses estudos não foram desenhados com o 
objetivo de estudar a dor pós-operatória, devendo-se assim avaliar esses dados com cuidado.

Com esta finalidade, De Benedittis et al. acompanharam, por no mínimo 48 horas, pacientes que haviam se submetido à neurocirurgia. Encontraram incidência de dor pós-operatória em 59,5\%. A maior incidência de dor ocorreu 12 horas após a cirurgia e a duração média da dor foi de 43 horas e 15 minutos. Não houve relação entre o estado ou traços de ansiedade no pré-operatório e a dor no pós-operatório, ou entre a incidência e magnitude da dor e o acesso cirúrgico adotado, anestésico usado, status neurológico pós-cirúrgico, ou complicações ${ }^{68}$. Houve congruência parcial/absoluta entre a dor e o sítio cirúrgico em 86,4\%, não havendo relação entre a cefaléia pré e a pós-cirúrgica na maioria dos pacientes $(90,9 \%)$. A dor foi descrita mais freqüentemente como pulsátil, ou em pancada (36,4\%), tipo tensão $(31,8 \%)$, ou contínua e constante $(31,8 \%)$, tendo um padrão superficial em $72,7 \%$, profundo em $13,6 \%$, ou combinação de ambos em 13,6\%. Com isso os autores sugerem que a dor tem maior origem somática (músculos do pericrânio e tecidos moles) do que visceral 68.

\subsubsection{Cefaléia após neurocirurgia de fossa posterior}

\subsubsection{Incidência e evolução}

As cefaléias que ocorrem após neurocirurgias de fossa posterior têm sido o modelo mais frequientemente estudado. Entre elas as cirurgias para tratamento do neurinoma do nervo acústico são as mais estudadas. As investigações realizadas são, na sua maioria, estudos do tipo transversal ou coorte retrospectivo, e utilizam prontuários médicos e entrevistas com pacientes como fonte de dados. 
O tratamento cirúrgico é o tratamento de escolha para neurinomas do nervo acústico. Esse é realizado basicamente por 3 possíveis acessos: suboccipital (retrossigmóideo), translabiríntico (anterossigmóideo) e fossa média ${ }^{69}$. Dentre os 3 acessos, o suboccipital é responsável pela maior incidência de cefaléias póscirúrgicas. Essas, variam amplamente (de 0 a 100\%) ${ }^{2-11,69-77}$ em decorrência do desenho do estudo, forma de coleta de dados, da definição de cefaléia pós-cirúrgica e da técnica cirúrgica utilizada. A maioria dos estudos encontrou incidências superiores a $40 \%^{2-10}$.

No acesso translabiríntico, a craniotomia é realizada retirando-se a porção lateral do osso temporal, incluindo-se as células mastóideas e os canais semicirculares. Nesse tipo de abordagem cirúrgica, a incidência de cefaléia pósneurocirúrgica varia de 0 a $53 \%$ 4, 6, 7, 9, 69, 78-80.

O acesso de fossa média é obtido por uma pequena craniotomia temporal um pouco anterior ao canal auditivo externo. É um procedimento extradural indicado para tumores que estão restritos ao canal auditivo interno, já que a exposição da fossa posterior é muito restrita. A incidência de cefaléia pós-neurocirúrgica nesse tipo de acesso varia de 0 a $10 \%{ }^{69,73,81}$.

Levo et al. encontraram como fatores de risco para o desenvolvimento de cefaléia pós-cirúrgica em pacientes com neurinomas do nervo acústico, o acesso retrossigmóide, presença de cefaléia pré-cirúrgica, tumores pequenos e alterações de marcha pós-operatória ${ }^{9}$. No entanto, em outros estudos não se encontrou correlação entre a localização, o tamanho do tumor ${ }^{70}$, gênero ${ }^{9,70}$ ou idade e a incidência de cefaléia pós-operatória ${ }^{70,71}$. 
A cefaléia pós-neurocirúrgica de fossa posterior apresenta diminuição da prevalência $5,10,71,77,82-84$ e intensidade ${ }^{6,82}$ à medida que nos afastamos temporalmente da realização da cirurgia. Não houve relação entre a melhora da cefaléia pós-neurocirúrgica para neurinoma do nervo acústico e o tempo de duração da cirurgia, preservação dos nervos coclear ou facial, correção de fístula liquórica ou retirada total do tumor ${ }^{70}$.

Deve ser salientada a limitação desses estudos quanto à relação temporal dos eventos e às informações quanto às cefaléias prévias à cirurgia. Isto decorre dos desenhos dos mesmos, pois nos estudos transversais, os dados são colhidos em um momento temporal único, e nos estudos de coortes retrospectivos, a exposição e o desfecho já ocorreram quando da execução do estudo.

\subsubsection{Características da cefaléia}

Schessel et al. verificaram que a cefaléia apresentada após acesso suboccipital geralmente se localizava na incisão cirúrgica, estendendo-se até a região occipital e freqüentemente até a região parietal. A dor foi descrita pela maioria como "em esmagamento" ou “em compressão", e de forte intensidade ${ }^{4}$.

Harner et al., através de revisão de prontuários, verificaram que a cefaléia pós-craniectomia retrossigmóidea localizava-se predominantemente na região do vértex ou na região cervical. Essa dor tinha intensidade leve em $34,2 \%$ e frequiência quase diária em $25,3 \%$ dos pacientes, levando $38 \%$ dos que dela sofriam a necessitar de medicamentos diários e $2,5 \%$ a se sentirem incapacitados 5 .

Pedrosa et al., através de entrevistas, constataram que a cefaléia teve início no pós-operatório imediato em $70 \%$ e após um mês em $18 \%$ dos pacientes. Essa cefaléia localizava-se predominantemente nas regiões occipital e cervical, sendo descrita 
como "em aperto" (38\%), "em facada" (21\%) ou "pulsátil" (15\%), tendo freqüência diária em $60 \%$ dos pacientes e sendo de forte intensidade em $33 \%$ destes. Como fatores de piora foram citados a movimentação da cabeça, fadiga e exercícios ${ }^{6}$.

Inquérito feito por Vijayan mostrou que a maioria dos que referiram ter tido cefaléia apresentava um padrão do tipo tensional, com dor no local da cirurgia ou, menos freqüentemente, difusa com intensidade maior no local da cirurgia. $\mathrm{O}$ segundo padrão mais freqüente foi descrito como "fina" ou "tiro", perto do sítio cirúrgico. O terceiro mais freqüente foi o "pulsátil". A maioria teve uma combinação dos 3 padrões. Comparando-se a cefaléia pré-cirúrgica com a apresentada posteriormente à cirurgia, a segunda era mais posterior e mais intensa, freqüentemente perto do sítio cirúrgico $^{82}$.

Soumekh et al. enviaram questionário baseado no questionário de dor McGill, a pacientes com cefaléia após cirurgia para diversas indicações, pela via suboccipital. Constataram que a cefaléia localizava-se no local da incisão com irradiação para áreas circunjacentes. A dor era descrita como "fina", "chata", "cansativa" e “amedrontada". Os fatores de piora foram a movimentação da cabeça e pescoço ${ }^{75}$.

A maioria dos pacientes entrevistados por Mosek et al. com cefaléia póscirúrgica descreveram-na como "dor surda" ou "em pressão" (68\%), sendo também referido um padrão "pulsátil" ou "em pontada" (25\% dos casos). A dor, em geral, ocorreu no local da incisão ou em áreas adjacentes (82\%), sem irradiação, sendo diária e constante (75\%), não acompanhada de náuseas, vômitos, foto ou fonofobia. "Dolorimento" no local da incisão foi relatado por $46 \%$ dos pacientes, sendo a duração média deste de 12 meses e não estando relacionada com a presença ou 
duração de dor pós-operatória. O fenômeno da alodínea foi observado em $82 \%$ e considerado um problema para $19 \%$ dos entrevistados ${ }^{71}$.

Levo et al., utilizando o questionário de dor McGill, constataram que as palavras que melhor descreviam a dor nos pacientes que tinham cefaléia prévia e apresentaram cefaléia pós-cirúrgica foram: unilateral, intermitente, calor, dilacerante, dolorida, incômoda, forte, insuportável; e nos que não tinham cefaléia prévia e apresentaram dor pós-operatória foram: intermitente, unilateral, dilacerante, dolorida. A dor apresentada após a cirurgia localizava-se, em sua maioria, nas regiões occipital e cervical, do mesmo lado da cirurgia, tanto nos que tinham quanto nos que não tinham cefaléia pré-cirúrgica. Estresse emocional e físico, abaixar-se e permanecer acordado foram os principais fatores desencadeantes nos 2 grupos ${ }^{9}$.

Schaller e Baumann constataram que a cefaléia ocorrida após acesso retrossigmóide teve início no pós-operatório imediato em 90\% e após o primeiro mês em $10 \%$ dos pacientes. Na maioria deles, a cefaléia iniciava-se na cicatriz cirúrgica com irradiação para o centro da região occipital (79\%), era holocraniana em $11 \%$ e frontal em $10 \%$ dos casos. Na maioria dos casos, localizava-se do lado da cirurgia (73\%) e tinha caráter em pressão (90\%). Como fatores de piora, foram relatados a movimentação da cabeça (83\%), fadiga (58\%) e exercícios (40\%). A cefaléia não interferia com as atividades normais ${ }^{70}$.

Todos os trabalhos citados nessa seção foram realizados em pacientes com tratamento cirúrgico para neurinomas do nervo acústico, com exceção do estudo realizado por Soumekh et al. 


\subsubsection{Fisiopatologia}

Uma das causas propostas para justificar as cefaléias pós-cirúrgicas é o próprio trauma cirúrgico.

Sataloff et al., analisando as possíveis causas da dor que se segue à cirurgia de base de crânio, propõem que a dor incisional poderia estar associada à alergia ao material de sutura, infecção local, tensão muscular na área da incisão, irritação das terminações nervosas livres superficiais, ou a formação de neuromas. A dor muscular que se segue à cirurgia resultaria do trauma direto às fibras musculares ou aos nervos que as inervam ${ }^{85}$.

Driscoll e Beatty, em artigo de revisão, dividem a dor que ocorre após a cirurgia para neurinoma do nervo acústico em dor pós-operatória inicial, dor incisional persistente e cefaléia persistente. A dor pós-operatória inicial seria causada pela incisão cirúrgica, por hipotensão liquórica, por espasmos da musculatura do pescoço associado ao trauma e ao posicionamento do paciente durante a cirurgia. A dor incisional persistente seria causada por neuroma traumático do nervo occipital maior ou por compressão deste. Essa dor seria "em queimação" ou "fina”, localizada geralmente na região occipital operada ou na região frontal ou temporal e estaria freqüentemente associada a ponto gatilho na incisão ${ }^{86}$.

Vijayan, analisando os padrões de dor apresentado após cirurgia para neurinoma do nervo acústico, sugeriu que o trauma aos músculos cervicais e couro cabeludo seria a principal causa da mesma ${ }^{82}$.

Cohen defende que a incisão suboccipital é a causa mais comum de dor nucal e de cefaléia pós-operatória. Esse autor, após a diminuição do tamanho da incisão, não documentou mais nenhum caso de cefaléia pós-cirúrgica ${ }^{87}$. No entanto, Schessel et 
al. não encontraram diferença na incidência de cefaléia, quando compararam a técnica padrão com outra que utilizava uma menor dissecação ${ }^{3}$.

Hendler et al. relatam caso de paciente com cefaléia de difícil tratamento pósneurocirurgia. Após o uso de vários medicamentos, o paciente ficou sem dor após o uso de divalproato. Os autores, baseando-se no mecanismo de ação da droga, propuseram que a instabilidade da membrana celular dos vasos ou dos nervos que os inervam seriam causa da cefaléia ${ }^{88}$.

Outra causa proposta para justificar a ocorrência de dor após cirurgia de fossa posterior é a aderência da musculatura cervical à dura-máter. Uma das evidências a esse favor é a melhora da cefaléia pós-craniectomia após a realização de cranioplastia $^{75,89,90}$.

Em 1992, Schessel et al. apresentaram caso de paciente que tinha dor persistente e apresentava aderência entre a dura-máter e a musculatura cervical, constatada através de estudo histopatológico ${ }^{4}$. Posteriormente, estudos comparando pacientes submetidos a craniectomia e craniotomia suboccipitais verificaram que os últimos têm incidência de cefaléia significativamente menor ${ }^{3,8}$. Incidências menores de dor pós-cirúrgica também foram encontradas entre pacientes que realizaram cranioplastia quando comparados aos que fizeram craniectomia ${ }^{8,74,75}$. No entanto, essas diferenças de incidência não foram encontradas em todos os estudos ${ }^{6,76,84}$. Wazen et al. verificaram também uma diferença na intensidade da cefaléia apresentada por aqueles pacientes submetidos a cranioplastia, em relação àqueles submetidos apenas a craniectomia, sendo que nesses últimos, ela foi mais intensa ${ }^{2}$.

Outro fator de importância para a ocorrência de cefaléia, destacado por alguns autores, é a presença de debris causados pela brocagem óssea. Esses debris ósseos 
causariam uma meningite asséptica que seria a responsável pela dor. A maior incidência de cefaléia no acesso suboccipital, comparada com o translabiríntico 4, 7,9, 69, 72, ou por fossa média ${ }^{69,73}$, para cirurgia de neurinoma do nervo acústico, corrobora esta hipótese. No acesso suboccipital, é feita brocagem óssea para se ter acesso ao canal auditivo interno após a dura-máter ter sido aberta. No acesso translabiríntico, a brocagem é feita antes da abertura da dura-máter e no acesso por fossa média o procedimento é todo extradural. No entanto, essa diferença entre incidências não foi encontrada por outros autores ${ }^{6}$ e, apesar da incidência ter sido inicialmente maior no acesso suboccipital um ano após a cirurgia, a prevalência de cefaléia iguala-se àquela observada após acesso translabiríntico ${ }^{72}$. Nas cirurgias para neurectomia vestibular, também houve maior incidência de cefaléia nas técnicas cirúrgicas em que é necessária brocagem óssea, em relação àquelas em que esta não é necessário ${ }^{91-93}$. Outro fator a favor da importância dos debris ósseos é que os pacientes com os maiores neurinomas do nervo acústico tenderam a ter menos dor no pós-operatório ${ }^{9,11}$. Isso seria justificado pela menor circulação desses debris nestes pacientes, em comparação com os que tinham tumores menores.

Contudo, esta diferença não foi observada por outros autores ${ }^{70}$.

Catalano et al., após compararem pacientes que utilizaram ou não técnica desenvolvida com a finalidade de impedir a livre circulação intradural de debris ósseos gerados pela brocagem do canal auditivo interno, encontrou menor incidência de cefaléia entre os que utilizaram a técnica ${ }^{76}$.

Levo et al. realizaram estudos caso-controle incluindo como casos, pacientes operados por neurinoma do nervo acústico com cefaléia persistente após a cirurgia. Após a realização de testes vestibulares e avaliação da instabilidade postural 
(posturografia), concluíram ser improvável que as causas da cefaléia fossem relacionadas à disfunção vestibular ${ }^{94,95}$. Um terço dos pacientes melhorou da cefaléia após o uso de sumatriptano. Baseado nisso, os autores propuseram a hipótese da cefaléia ser de etiologia vascular ${ }^{94}$, decorrente de uma neuropatia trigeminal da fossa posterior causada por debris ósseos, manipulação da dura-máter, ou periósteo, com conseqüente ativação do sistema trigêmino-vascular ${ }^{95}$.

Com o objetivo de investigar a importância dos debris ósseos na gênese da cefaléia pós-cirúrgica, Jackson et al., compararam pacientes operados por neurinoma do nervo acústico com os operados para secção do nervo vestibular. A diferença entre os procedimentos é que na cirurgia para neurinoma é necessário realizar-se brocagem óssea intradural a fim de se ter acesso ao canal auditivo interno. A incidência de cefaléia foi muito menor nos pacientes submetidos à secção do nervo vestibular, fato esse que se manteve quando foram comparados os pacientes submetidos a cranioplastia nos dois grupos. Os autores concluíram que a brocagem intradural provavelmente foi a causa da cefaléia ${ }^{10}$.

Schaller e Baumann compararam pacientes submetidos à cirurgia para tratamento de neurinoma do nervo acústico, através do acesso retrossigmóide, quanto à presença ou ausência de cefaléia. Foram considerados como tendo cefaléia, os pacientes em que a mesma levava à necessidade de medicação analgésica diária ou a se sentirem incapacitados. Os pacientes nos quais a tábua óssea foi recolocada tiveram menor incidência de cefaléia pós-operatória. Nenhum dos pacientes submetidos a duraplastia teve cefaléia. A presença de meningite asséptica, constatada por febre e alterações liquóricas, teve forte associação com a cefaléia. A presença de espículas ósseas ao longo da ponte foi observada em $75 \%$ dos casos de meningite 
asséptica. Os autores concluem que a cefaléia pós-neurocirúrgica é multifatorial, tendo como possíveis causas: 1- a aderência da dura-máter aos músculos cervicais; 2meningite asséptica causada por debris ósseos; 3- tensão da dura-máter após fechamento da mesma ${ }^{70}$.

\subsubsection{Repercussão da cefaléia pós-neurocirúrgica na vida do paciente}

A cefaléia que ocorre após neurocirurgia pode interferir em diversos aspectos da vida dos que dela sofrem.

Dos 37 pacientes entrevistados por Schessel et al. que apresentaram cefaléia após cirurgia para neurinoma do nervo acústico por acesso suboccipital, 38\% referiram que a cefaléia pós-cirúrgica interferia no trabalho e $22 \%$ que a dor era incapacitante ${ }^{4}$.

Dos 89 pacientes que realizaram cirurgia para neurinoma do nervo acústico e que ainda tinham cefaléia no período em que foi realizada entrevista por Pedrosa et al., $60 \%$ referiram que a cefaléia interferia em suas atividades diárias, tais como atividades esportivas (25\%), trabalho (19\%) e atividades sociais (8\%), e que a mesma tinha impacto negativo sobre o humor $(15 \%)^{6}$.

Kane et al., após entrevistarem 56 pacientes operados por neurinoma do nervo acústico por via suboccipital, constataram que $28,6 \%$ referiram cefaléia intensa o suficiente para interferir de modo intermitente nas suas atividades diárias ${ }^{11}$.

Rigby et al. constataram que, em relação aos sintomas considerados como "problemáticos ou incapacitantes", em pacientes que realizaram cirurgia para neurinoma do nervo acústico, a cefaléia foi referida por 9,9\%, de 130 pacientes. Este foi o sexto sintoma mais citado e, para 3,4\%, o sintoma mais "incapacitante" a longo $\operatorname{prazo}^{12}$. 
van Leeuwen et al., procurando investigar a saúde física, uso de serviços médicos e qualidade de vida, enviaram questionário de qualidade de vida a pacientes operados por neurinoma do nervo acústico através de acessos suboccipital e translabiríntico. As dores do grupo translabiríntico foram menos intensas ${ }^{96}$.

Martin et al, utilizando o questionário de qualidade de vida SF-36 que foi enviado a pacientes submetidos a cirurgia para neurinoma do nervo acústico por acesso translabiríntico, constatou que as mulheres apresentaram menores escores de capacidade funcional, vitalidade e dor ${ }^{79}$.

Betchen et al., utilizando o mesmo SF-36 em pacientes submetidos à cirurgia para neurinoma do nervo acústico, observou que os escores deste foram significativamente menores nas dimensões "aspectos físicos" e "dor" nos pacientes que tinham cefaléia pós-cirúrgica, quando comparados com os que não a apresentavam $^{13}$.

\subsubsection{Cefaléia após neurocirurgia supratentorial}

Kaur et al., através da revisão de prontuários, de informações fornecidas pelo neurologista do paciente e pelo próprio paciente, procuraram estudar a cefaléia ocorrida após lobectomia temporal anterior para tratamento de epilepsia. Foram excluídos os pacientes que apresentaram crises epilépticas nos 12 meses posteriores à cirurgia, neoplasia com crescimento progressivo, anormalidade vascular persistente, infecção pós-cirúrgica, ou outra complicação maior. Todos os pacientes fizeram Ressonância Nuclear Magnética três meses após a cirurgia. As cefaléias prévias não foram consideradas como novas e as que não estavam presentes antes da cirurgia, ou eram relacionadas ao sítio cirúrgico, foram consideradas cefaléias relacionadas a craniotomia. Dos 126 pacientes estudados, 17,5\% tiveram cefaléia que perdurou por 
mais de dois meses e, dentre eles, $42 \%$ tinham cefaléias prévias de outras naturezas. Cefaléia que perdurou de 2 meses a 1 ano após a cirurgia ocorreu em 5,6\% dos pacientes. Em 11,9\% dos casos, a cefaléia persistiu por mais de 1 ano, sendo que destes, $27 \%$ necessitaram de medicamentos para cefaléia prescritos por médico e $33 \%$ não conseguiram controle das dores com medicamentos ${ }^{14}$.

Gee at al., com a finalidade de investigar a incidência e as características clínicas da cefaléia pós-craniotomia, revisaram prontuários de pacientes operados por tumores cerebrais, epilepsia e hemorragia intracraniana. Dos 44 pacientes que apresentavam cefaléia pré-cirúrgica, 64\% tiveram cefaléia pós-cirúrgica. Dos 58 pacientes que não tinham cefaléia pré-cirúrgica, 19\% tiveram cefaléia pós-cirúrgica; destes, $82 \%$ tiveram melhora com o tempo, $91 \%$ necessitaram de medicação aguda para dor no pós-operatório e $82 \%$ não necessitaram de medicação crônica para cefaléia. A dor, geralmente, iniciava-se no local da incisão ou áreas adjacentes (55\%). Dos que tiveram cefaléia, essa foi de leve a moderada intensidade e não interferia nas atividades diária em $82 \%$ dos casos; $82 \%$ referiram completa resolução da cefaléia em 1 a 3 anos. O restante desenvolveu cefaléia diária, mal localizada, em pressão, de leve a moderada intensidade ${ }^{15}$.

\subsubsection{A cefaléia pós-craniotomia e a Classificação Internacional de}

\section{Cefaléias}

A primeira versão da classificação da Internacional Headache Society (IHS) foi feita em $1988^{97}$ e representou um marco para a realização de estudos epidemiológicos relativos a cefaléia. Até então não havia instrumento adequado para classificar as várias modalidades de cefaléia. No entanto, a cefaléia que ocorria após cirurgia craniana não foi contemplada nesta versão. 
A segunda edição da Classificação Internacional de Cefaléias foi publicada em 2004 pela IHS ${ }^{1}$. Nesta, as cefaléias são divididas em: primárias, secundárias, neuralgias cranianas, dor facial primária e outras cefaléias.

Para classificar-se uma cefaléia como secundária, seguem-se os seguintes princípios gerais: ela deve ser causada por um transtorno reconhecidamente capaz de causar cefaléia; ocorrer em estreita relação temporal com o transtorno e/ou outra evidência de uma relação causal; sofrer acentuada redução ou remitir num período de 3 meses após tratamento bem-sucedido, ou após remissão espontânea do transtorno determinante. A última condição nem sempre pode ser apurada e alguns supostos transtornos causadores não podem ser tratados, ou não remitem espontaneamente.

A cefaléia pós-craniotomia está classificada no grupo 5 das cefaléias secundárias que tem a seguinte denominação: "cefaléia atribuída a trauma cefálico elou cervical'. Descreveremos abaixo os critérios necessários à classificação:

\section{Grupo 5.7.1 Cefaléia pós-craniotomia aguda}

A - Cefaléia de intensidade variável, máxima na área da craniotomia, preenchendo os critérios C e D.

B - Craniotomia realizada por uma razão outra que não trauma cefálico

C- A cefaléia aparece dentro de sete dias após a craniotomia.

D- Uma dentre as duas situações seguintes:

1- A cefaléia desaparece em até três meses após a craniotomia.

2- A cefaléia persiste, porém não se passaram três meses da craniotomia. Grupo 5.7.2 Cefaléia pós-craniotomia crônica

A- Cefaléia de intensidade variável, máxima na área da craniotomia, preenchendo os critérios C e D. 
B- Craniotomia realizada por uma razão outra que não trauma cefálico

C- A cefaléia aparece dentro de sete dias após a craniotomia

D- A cefaléia persiste por mais de três meses após a craniotomia

\subsection{Disfunção temporomandibular}

A disfunção temporomandibular (DTM) é um termo geral utilizado para designar a dor musculoesquelética do sistema mastigatório com múltiplas etiologias

${ }^{98}$. É caracterizada por dor crônica do tipo recorrente, não progressiva e associada a um impacto leve ou moderado na atividade social do paciente ${ }^{99}$.

A falta de uma definição universalmente aceita dificulta a determinação da real prevalência desta afecção. A maioria dos estudos epidemiológicos determina a prevalência de sinais e sintomas relacionados a DTM, mas não define a real prevalência dessa condição. Estudo de metanálise sobre o tema demonstra que $75 \%$ das investigações não definem DTM, sendo que a prevalência de indivíduos que não referiam nenhum sintoma de DTM, ou clinicamente não tinham disfunção verificada por estudos com amostras aleatorizadas é de respectivamente 70 e $56 \%{ }^{100}$.

A tendência atual é considerar que a disfunção temporomandibular (DTM) englobe as condições dolorosas crônicas decorrentes de músculos mastigatórios, articulações temporomandibulares e estruturas associadas ${ }^{101}$.

A classificação da International Association for the Study of Pain considera as seguintes características necessárias para o diagnóstico da "síndrome da disfunção e dor temporomandibular": dor muscular; "click" na articulação temporomandibular; dificuldade de abrir a boca e, em algumas vezes, desvio da mandíbula à abertura; dor 
mal localizada ou episódios de dor intensa associada à abertura mandibular, ou os dois ${ }^{102}$.

Para classificar-se uma cefaléia ou dor facial como sendo secundária a "transtorno da articulação temporomandibular" de acordo com a International Headache Society, é necessário que haja pelo menos uma das seguintes características: dor desencadeada por movimentos mandibulares ou pela mastigação de alimentos duros ou resistentes; redução na amplitude ou abertura irregular da mandíbula; ruído na articulação temporomandibular (ATM) durante os movimentos desta; dolorimento na cápsula articular da ATM. Deve-se demonstrar alteração da ATM através de exame complementar. Esse diagnóstico só pode ser feito retrospectivamente, após a cefaléia desaparecer depois do tratamento do transtorno da $\operatorname{ATM}^{1}$.

Procedimentos neurocirurgicos na região craniofacial, como a microcompressão do gânglio trigeminal por balão ${ }^{103}$ e cirurgias de base de crânio ${ }^{85}$, ${ }^{104}$, podem traumatizar a musculatura mastigatória e causar dor pós-operatória e limitação da abertura mandibular podendo ser fatores de risco para DTM .

\subsection{Os instrumentos utilizados}

\subsubsection{Questionário de Dor McGill}

O Questionário de Dor McGill é um dos instrumentos mais difundidos para avaliação de dor clínica e experimental ${ }^{105}$.

Este instrumento foi elaborado a partir de termos descritivos de dores obtidos na literatura médica. Estes termos foram agrupados em 20 subgrupos menores, cada um dos quais contendo palavras de qualidade similar, mas de intensidades diferentes. 
Foi solicitado a pessoas de diferentes níveis educacionais (grupos de pacientes, médicos e estudantes) que atribuíssem um valor numérico a cada termo, de acordo com a intensidade. As intensidades atribuídas às palavras tiveram um alto índice de concordância, servindo de base para a elaboração do questionário que é composto por um total de 78 descritores, distribuídos em 20 subgrupos ${ }^{106}$.

Pede-se ao paciente que preencha apenas um item em cada subgrupo e que não marque nada se nenhum termo relacionar-se a sua dor. A análise do número total de palavras marcadas e do índice total de dor (baseado no valor de intensidade atribuído a cada palavra) nos fornece informações sobre a intensidade da dor ${ }^{106}$.

Esse questionário tem sido usado como instrumento de pesquisa em cefaléias, permitindo a comparação entre diferentes entidades ${ }^{107-111}$, avaliação do resultado de tratamento das mesmas ${ }^{112-116}$ e comparação com outros tipos de dor ${ }^{117,118}$.

\subsubsection{Escala de Sonolência Epworth}

A Escala de Sonolência Epworth foi desenvolvida com a finalidade de ser uma maneira fácil e barata de avaliar a sonolência diurna. Nesta escala são fornecidas oito situações corriqueiras e é solicitado ao paciente que quantifique a chance de dormir nessas situações $(0=$ nenhuma; $1=$ chance pequena; $2=$ chance moderada; $3=$ alta chance). Se o paciente não vivenciou alguma das situações propostas, é solicitado que o mesmo estime a chance de dormir ${ }^{119}$. Esta escala mostrou-se um instrumento consistente e confiável para avaliar sonolência diurna em adultos ${ }^{120}$.

\subsubsection{The Hospital Anxiety and Depression Scale (HAD)}

Esta escala foi desenvolvida para o diagnóstico de ansiedade e depressão em pacientes ambulatoriais, bem como para medir a intensidade dos sintomas, 
permitindo avaliar também a piora ou melhora destes ${ }^{121}$. É um instrumento válido e confiável não só em pacientes ambulatoriais, mas também na população geral ${ }^{122-125}$, tendo sido utilizado em estudos sobre cefaléias ${ }^{126-132}$.

Para que os sintomas físicos das doenças sistêmicas não interferissem na avaliação destas doenças psiquiátricas, não foram incluídas questões referentes a sintomas somáticos que pudessem ser provenientes de ambas condições ${ }^{121}$. Sintomas decorrentes de doenças psiquiátricas graves, como tentativas de suicídio, também foram excluídos pois, apesar de serem comuns em clínicas psiquiátricas, são incomuns em pacientes de ambulatórios gerais ${ }^{121}$.

A escala é composta por sete perguntas referentes à depressão e sete referentes à ansiedade. Os escores sugeridos pelos autores da escala são: menores que sete, para não-casos, de 7 a 10 para casos duvidosos, e iguais e maiores que 11 para casos definidos ${ }^{121}$. No entanto, o ponto de corte que mostrou um ótimo balanço entre sensibilidade e especificidade na definição de casos foi $\geq 8^{124}$.

\subsubsection{The Medical Outcomes Study 36-item Short-Form Health Survey} (SF-36)

Um dos avanços ocorrido nas últimas décadas é o reconhecimento da importância do ponto de vista do paciente em relação a sua doença e tratamento. Nesse contexto, tornou-se importante avaliar a qualidade de vida do paciente.

Spilker", citado por Becker ${ }^{133}$, define qualidade de vida como "a percepção das pessoas quanto a sua posição na vida, no contexto de sua cultura e sistema de valores, e em relação a seus objetivos pessoais, expectativas, critérios e interesses".

\footnotetext{
† Spilker, B. Quality of life and pharmacoeconomics in clinical trials. 2nd ed. New York: Raven Press; 1995.
} 
Qualidade de vida relacionada à saúde pode ser definida como "o efeito global que uma doença e seu tratamento têm na percepção do paciente em relação a sua capacidade de viver uma vida útil e plena"134.

Diversos instrumentos têm sido propostos para avaliar a qualidade de vida em pacientes com doenças. Esses instrumentos podem ser divididos em dois grupos: específicos e genéricos.

Os instrumentos específicos foram desenvolvidos para acessar limitações únicas ou restrições à saúde específicas de determinadas doenças. São mais sensíveis em detectar o efeito do tratamento de longo prazo, em comparar vários tratamentos para uma mesma doença ou as variações na percepção da qualidade de vida durante o curso de uma doença. No entanto, estes instrumentos não permitem comparação entre doenças ${ }^{135}$.

Os instrumentos específicos de qualidade de vida para avaliação de cefaléias foram desenvolvidos, na sua maioria, para utilização em pacientes com migrânea, dentre eles: Migraine-Specific Quality of Life Instrument (MSQoLI), MigraineSpecific Quality of Life Questionnaire, 24-hr Migraine Quality of Life Questionnaire, Headache Disability Inventory e Cavallini Quality of Life Questionnaire ${ }^{133}$.

Os instrumentos genéricos foram desenhados para avaliar uma variedade ampla dos aspectos da qualidade de vida. Permitem comparar populações e diferentes doenças, qualidades importantes para o uso no planejamento em saúde ${ }^{135}$.

O SF-36 é um instrumento genérico de qualidade de vida amplamente utilizado. Tem sido usado extensivamente em pesquisas sobre cefaléias, conduzidas tanto em clínicas especializadas quanto em amostras derivadas da população geral. Este questionário já foi utilizado para determinar o impacto das cefaléias na 
qualidade de vida de quem delas sofria, comparando-as com pessoas "saudáveis" 136144 e com outras doenças ${ }^{142}$. Este instrumento também foi usado para avaliar o impacto dos diferentes diagnósticos de cefaléias ${ }^{137,140,141,144-150}$ e o resultado de tratamentos ${ }^{151-155}$.

Esse questionário foi desenvolvido para ser respondido diretamente pelo paciente, por entrevistas pessoais, ou por telefone. É constituído por oito componentes que medem diferentes conceitos de qualidade de vida relacionada à doença, referentes ao mês anterior à aplicação, e mais uma questão comparativa entre as condições de saúde atual com as do ano anterior ${ }^{156}$. Os escores destes componentes variam de zero a cem. Diferenças maiores que cinco nos escores são consideradas clinicamente significativas ${ }^{139,148-150}$. Quanto menor é o escore, pior a qualidade de vida.

As oito dimensões avaliadas por este questionário são: estado geral de saúde (5 itens); capacidade funcional (10 itens - limitação para atividades físicas); aspectos físicos (4 itens - problemas com o trabalho, ou outras atividades diárias devido à saúde física); dor (2 itens); vitalidade (4 itens - energia/fadiga); aspectos sociais (2 itens - interferência na atividade social normal devido a problemas físicos ou emocionais); aspectos emocionais (3 itens - problemas com o trabalho, ou outras atividades diárias devido a problemas emocionais) e saúde mental (5 itens - bemestar psicológico) ${ }^{156}$. 


\section{3 - OBJETIVOS}

\section{1 - Objetivo Geral:}

Estudar o comportamento e as características da cefaléia nos primeiros seis meses após a craniotomia para tratamento de aneurismas intracranianos.

\section{2 - Objetivos específicos:}

1- Verificar a relação entre presença de disfunção temporomandibular, diagnósticos dos tipos, lado e local de cefaléias primárias prévias à cirurgia e o comportamento doloroso pós-craniotomia.

2- Verificar a relação temporal entre a cirurgia e o início da cefaléia pósoperatória.

3- Verificar o comportamento da freqüência da cefaléia pós-craniotomia e sua associação com sintomas depressivos, ansiosos, sonolência diurna excessiva e presença de hemorragia subaracnóidea.

4- Identificar os pacientes que apresentaram cefaléia pós-craniotomia de maior intensidade.

5- Verificar o impacto da cefaléia pós-craniotomia na qualidade da vida dos pacientes e que fatores estão associados a um maior impacto dessa cefaléia.

6- Determinar a incidência de cefaléia pós-craniotomia na amostra estudada, segundo os critérios da classificação de cefaléias da IHS. 


\section{4 - MÉTODO}

\subsection{Casuística}

\section{A- Critérios de inclusão:}

Pacientes submetidos a craniotomia para clipagem de aneurisma de artérias cerebrais, com estado de consciência avaliado pela Escala de Coma de Glasgow igual a 15 durante os momentos de avaliação no pré e pós-operatórios, acompanhados no Hospital das Clínicas da Faculdade de Medicina da Universidade de São Paulo.

\section{B- Critérios de exclusão:}

Pacientes com nível de consciência inferior a 15 segundo a Escala de Coma de Glasgow nos momentos de avaliação durante os períodos pré e pós-operatórios, ou com infecção diagnosticada do SNC.

\subsection{Desenho do estudo}

A- Estudo tipo coorte prospectivo, em que foram incluídos pacientes submetidos a craniotomia realizada para tratamento de aneurismas cerebrais, independentemente de ter havido hemorragia subaracnóidea ou não. Os pacientes foram avaliados inicialmente entre 17/10/2002 e 02/10/2003, enquanto aguardavam procedimento cirúrgico durante sua internação no Hospital das Clínicas da Faculdade de Medicina da Universidade de São Paulo.

B- Na avaliação pré-operatória foram avaliados aspectos relacionados à presença ou não de cefaléias primárias prévias à cirurgia e suas características, dando-se ênfase a sua frequiência nos três meses que antecederam a avaliação pré- 
operatória e ao diagnóstico, aplicando-se os critérios da International Headache Society (IHS) para a classificação das cefaléias. Além disso, foram avaliadas se houve ou não hemorragia subaracnóidea (HSA) e a presença e características da cefaléia causada pela mesma. Foram aplicadas a escala Hospital Anxiety and Depression Scale (HAD) e a escala de sonolência Epworth (EPW).

C- Foram registrados os dados referentes ao procedimento cirúrgico.

D- Os pacientes, após alta hospitalar, eram encaminhados para o Ambulatório de Neurocirurgia Vascular do Hospital das Clínicas da FMUSP. Na primeira avaliação, em geral por ocasião da retirada dos pontos, foi fornecido um diário de cefaléia, com orientação para seu preenchimento e registro da presença e época de início da cefaléia pós-cirúrgica. Essa avaliação foi denominada "retirada de pontos" $(\mathrm{RP})$.

E- Os pacientes retornavam para reavaliação após um período médio de, respectivamente, 60, 120 e 180 dias após a cirurgia $\left(1^{\mathrm{a}}, 2^{\mathrm{a}}, 3^{\mathrm{a}}\right.$ consultas respectivamente). Nessas avaliações, verificou-se a presença ou não de cefaléia no período, obtendo-se dados que permitissem a caracterização da mesma. Foram aplicadas as escalas The Hospital Anxiety and Depression Scale (HAD) e Epworth. Após cada avaliação era fornecido um diário de cefaléia.

F- Na $2^{\mathrm{a}}$ consulta foi aplicado o questionário genérico de qualidade de vida Medical Outcomes Study 36-Item Short-Form Health Survey (SF-36) e o Questionário de Dor McGill.

G- Não foram prescritos medicamentos com caráter profilático durante o período do estudo, mas foram usadas medicamentos analgésicos para o tratamento agudo das crises de cefaléia (dipirona, paracetamol ou naproxeno sódico). 
H- Os pacientes foram avaliados pela Equipe de Dor Orofacial/ATM da Divisão de Odontologia do Hospital das Clínicas da FMUSP, através de protocolo diagnóstico padronizado ${ }^{157}$. Os cirurgiões-dentistas responsáveis por essa avaliação desconheciam os dados do acompanhamento médico sobre a cefaléia póscraniotomia. O diagnóstico de dor e disfunção temporomandibular (DTM) foi feito de acordo com os critérios da International Association for the Study of Pain ${ }^{102}$.

\subsection{Aspectos éticos}

O estudo obteve aprovação prévia da Comissão de Ética para Análise de Projetos de Pesquisa do Hospital das Clínicas da Faculdade de Medicina da Universidade de São Paulo, conforme processo número 880/2002.

Foi apresentado a cada paciente um termo de consentimento pós-informado. A coleta dos dados foi realizada após anuência do paciente e assinatura em local apropriado (Anexo).

\subsection{Definição de variáveis}

- Diagnóstico da cefaléia:

migranosa - preenche critérios diagnósticos para migrânea;

não migranosa - outra cefaléia que não migrânea;

sem cefaléia .

- Lado da cefaléia:

bilateral ;

mesmo lado da cirurgia;

lado diferente da cirurgia; 
sem cefaléia.

- Local da cefaléia (relativo ao local em que foi realizada a cirurgia):

igual;

diferente;

sem cefaléia.

- Tempo de início da cefaléia pós-craniotomia (em dias).

- Freqüência de cefaléia (em dias).

- Intensidade de depressão (valor de 0 a 24 da escala HAD).

- Intensidade de ansiedade (valor entre 0 e 24 da escala HAD).

- Intensidade de sonolência excessiva diurna (valor entre 0 e 27 da escala Epworth).

- Qualidade de vida (SF-36): 8 domínios, cada um com valores entre 0 e 100 (capacidade funcional, aspectos físicos, dor, estado geral de saúde, vitalidade, aspectos sociais, aspectos emocionais, saúde mental).

- Questionário de dor McGill: número total de itens marcados; índice de dor (baseado nos escores atribuídos a cada marcador).

- Número de pontos dolorosos à palpação do músculo temporal: 0 a 4.

- Presença de disfunção temporomandibular (DTM): sim ou não.

- Presença de cefaléia pós-cirúrgica no segundo trimestre de acompanhamento (dados do diário): sim ou não.

- $\quad$ Idade (em anos)

- Sexo: feminino ou masculino.

- Número de cirurgias: uma ou duas.

- Tipo de cirurgia: Frontal, Pterional ou Fronto-órbito-zigomática (FOZ). 
- Presença de HSA: sim ou não.

- Presença de cefaléia causada pela HSA (no momento da avaliação préoperatória): sim ou não.

- Presença de vasoespasmo após HSA: sim ou não.

- Presença de seqüelas: sim ou não.

- Presença de cefaléia pré-operatória primária: sim ou não.

- Preenche critérios para cefaléia pós-craniotomia pela IHS: sim ou não.

\subsection{Análise estatística}

A análise estatística foi realizada com o auxílio dos programas Microsoft Excel for Windows, versão 2000, Minitab for Windows, versão 13.0, SAS for Windows, versão 8.0, SPSS for Windows, versão 10 e S-Plus 2000. As técnicas estatísticas utilizadas foram: análise descritiva unidimensional, análise descritiva multidimensional, análise de dados categorizados, análise de sobrevivência, análise de associação e dependência de dados quantitativos.

Para a análise da freqüência da cefaléia nos seis meses após a cirurgia, consideramos três grupos: G0 (pacientes sem HSA), G1 (pacientes que tiveram HSA, mas que estavam sem cefaléia causada pela mesma no momento da avaliação préoperatória) e G2 (pacientes que tiveram HSA, mas que estavam com cefaléia causada pela mesma no momento da avaliação pré-operatória). As frequiências diárias de cefaléia após a cirurgia, obtidas através do diário de cefaléia, foram somadas para efeito da análise estatística (mês 1 ao 3 e mês 4 ao 6). Para a comparação entre os três grupos, utilizou-se o teste não paramétrico de Kruskal-Wallis (KW) ${ }^{158}$. 
Para avaliar a existência da relação entre a freqüência de cefaléia e, respectivamente, as intensidades de depressão, ansiedade e sonolência diurna, calculou-se as correlações de Pearson e os testes de significância para essas correlações.

Para o estudo multivariado da associação do domínio dor do SF-36 e o conjunto de variáveis foi utilizado o modelo de regressão linear multivariado com processo de seleção "stepwise" ${ }^{159}$. O mesmo método foi utilizado para o estudo da associação entre os escores do questionário McGill e o conjunto de variáveis. As variáveis inicialmente selecionadas para o modelo nesses casos foram:

- idade;

- sexo;

- presença de seqüelas;

- tipo de cirurgia;

- número de cirurgias;

- DTM;

- presença de dor e preencher os critérios de cefaléia pós-craniotomia pela IHS;

- diagnóstico da cefaléia prévia (migranosa x não migranosa);

- depressão e ansiedade (escores relativos à segunda consulta);

- HSA;

- com história de cefaléia primária e sem dor nos últimos 3 meses prévios à cirurgia X com história de cefaléia primária e com dor nos 3 meses prévios à cirurgia $\mathrm{X}$ sem história de cefaléia primária prévia. 
Para a seleção das variáveis foi utilizado o processo de seleção de variáveis “stepwise". O nível de significância utilizado para a entrada e saída do modelo foi de $5 \%$.

O modelo de regressão linear multivariado, com processo de seleção "stepwise", também foi utilizado para verificar a associação entre os domínios do SF-36 com a freqüência de cefaléia, no mês anterior à aplicação do mesmo (obtida através de diário), com os escores de depressão e ansiedade do questionário HAD, obtidos na $2^{\mathrm{a}}$ consulta.

Para o estudo multivariado da presença dos critérios para cefaléia póscraniotomia segundo a IHS, entre os pacientes que tiveram cefaléia após a cirurgia, foi utilizado o modelo de regressão logístico multivariado com processo de seleção "stepwise" ${ }^{159}$. As variáveis selecionadas inicialmente para o modelo nesses casos foram:

- idade;

- sexo;

- tipo de cirurgia;

- DTM;

- diagnóstico da cefaléia prévia (migranosa x não migranosa);

- HSA;

- com história de cefaléia primária e sem dor nos últimos 3 meses prévios à cirurgia X com história de cefaléia primária e com dor nos 3 meses prévios à cirurgia $\mathrm{X}$ sem história de cefaléia primária prévia;

- vasoespasmo. 
Para a seleção de variáveis foi utilizado o processo de seleção de variáveis “stepwise”. O nível de significância utilizado para a entrada e saída do modelo foi de $5 \%$. 


\section{5 - RESULTADOS}

\subsection{Caracterização da amostra e dados sobre o seguimento}

Durante o período do estudo, foram incluídos 86 indivíduos. Sete pacientes foram a óbito após a cirurgia, no período pós-operatório imediato. Setenta e nove pacientes constituíram o grupo de estudo. A Tabela 1 mostra as características gerais dos pacientes estudados.

Tabela 1 - Características gerais dos pacientes que participaram do estudo

\begin{tabular}{|c|c|}
\hline Número total de pacientes & 79 \\
\hline Sexo & $\begin{array}{l}\text { Masculino:28 }(35,4 \%) \\
\text { Feminino: } 51(64,6 \%)\end{array}$ \\
\hline Idade & $\begin{array}{l}\text { Média }=45,3 \text { anos }(\mathrm{DP}=10,1) \\
\quad \text { Mediana }=45 \text { anos }(23-71)\end{array}$ \\
\hline Cefaléia primária prévia & $\mathrm{Sem}=11(13,9 \%) ; \mathrm{Com}=68(86,1 \%)$ \\
\hline Tipos de cefaléia & $\begin{array}{l}\text { Cefaléia tipo tensional= } 28(36,8 \%) \\
\text { Migrânea }=46(60,5 \%) \\
\text { Cefaléia primária em facadas= } 1(1,3 \%) \\
\text { Cefaléia primária associada à atividade } \\
\text { sexual= } 1(1,3 \%)\end{array}$ \\
\hline $\begin{array}{c}\text { Mais de um diagnóstico de cefaléia } \\
\text { primária }\end{array}$ & $8(10,1 \%)$ \\
\hline HSA & $\operatorname{Sim}=69(87,3 \%) ;$ Não= $10(12,7 \%)$ \\
\hline Vasoespasmo & $\operatorname{Sim}=9(11,4 \%) ;$ Não= $70(88,6 \%)$ \\
\hline Seqüelas neurológicas & $\operatorname{Sim}=10(12,7 \%) ;$ Não= $69(87,3 \%)$ \\
\hline
\end{tabular}

Os motivos da descoberta dos aneurismas nos 10 pacientes que não apresentaram HSA foram: investigação por cefaléia (5 pacientes), por AVC (3 
pacientes), por epilepsia (1 paciente), achado incidental (1 paciente). Dentre os pacientes que estavam em investigação por cefaléia, quatro já a apresentavam por um longo período, não tendo havido mudança de padrão desta. Um paciente tinha cefaléia de início recente, sendo constatado hidrocefalia por efeito de massa do aneurisma. Este paciente evolui sem cefaléia após colocação de derivação ventrículoperitoneal e no momento da primeira avaliação permanecia sem cefaléia.

Dos 69 pacientes com HSA, 68 apresentaram cefaléia causada pela mesma. Um paciente não se lembra de ter tido cefaléia. Este paciente apresentou alteração do nível de consciência após o sangramento. Dos pacientes que apresentaram cefaléia, 45,6\% apresentaram cefaléias holocranianas e 92,6\%, cefaléias bilaterais.

Oito pacientes realizaram duas cirurgias, todas craniotomias pterionais. O intervalo médio entre a primeira e a segunda cirurgia foi de 38 dias $(\mathrm{DP}=24$ dias $)$. A Tabela 2 mostra os tipos de craniotomias realizadas nos pacientes que permaneceram em acompanhamento. A craniotomia pterional correspondeu a $89,7 \%$ das craniotomias realizadas.

Tabela 2 - Tipos de craniotomias realizadas nos 79 pacientes em seguimento

\begin{tabular}{cc}
\hline TIPO DE CRANIOTOMIA & TOTAL \\
\hline Pterional & $78(89,7 \%)$ \\
Fronto-órbito-zigomática & $5(5,8 \%)$ \\
Frontal & $4(4,6 \%)$ \\
TOTAL & $87(100 \%)$ \\
\hline
\end{tabular}

Oito pacientes não completaram o seguimento: um não retornou após a retirada de pontos, dois, após a primeira consulta e cinco, após a segunda consulta. 
Setenta e um pacientes realizaram a avaliação odontológica.

A Tabela 3 apresenta os intervalos de tempo entre as avaliações dos pacientes e a primeira cirurgia.

Tabela 3 - Intervalos de tempo entre a primeira cirurgia e os momentos de avaliação dos pacientes

\begin{tabular}{cccccc}
\hline TEMPO & MÉDIA & $\begin{array}{c}\text { DESVIO } \\
\text { PADRÃO }\end{array}$ & MÍNIMO & MEDIANA & MÁXIMO \\
\hline $\begin{array}{c}\text { Avaliação } \\
\text { pré-operatória } \\
\text { Retirada de } \\
\text { pontos }\end{array}$ & 6 & 6 & 1 & 4 & 26 \\
$1^{\text {a consulta }}$ & 56 & 5 & 6 & 13 & 45 \\
$2^{\text {a consulta }}$ & 14 & 24 & 21 & 50 & 171 \\
$3^{\text {a consulta }}$ & 206 & 20 & 50 & 126 & 181 \\
$\begin{array}{c}\text { Avaliação } \\
\text { odontológica }\end{array}$ & 162 & 55 & 176 & 202 & 276 \\
\hline
\end{tabular}

\subsection{Freqüência da cefaléia}

\subsubsection{Análise descritiva}

A Figura 2 mostra o comportamento geral da freqüência nos 6 meses posteriores à cirurgia. No período entre o primeiro e o sexto mês após a retirada de pontos, observamos uma tendência de aumento inicial da freqüência da cefaléia com posterior tendência decrescente na freqüência média de cefaléia para:

$\checkmark$ pacientes de ambos os sexos (Figura 3).

$\checkmark$ pacientes com cefaléia primária pré-operatória e com cefaléia 3 meses antes da avaliação pré-operatória (Figura 4).

$\checkmark$ pacientes sem cefaléia pré-operatória (Figura 4).

$\checkmark$ pacientes que foram submetidos a uma cirurgia (Figura 5). 
$\checkmark$ pacientes que foram submetidos aos três tipos de craniotomia (Figura 6).

Figura 2 - Perfis médios da freqüência da cefaléia no seguimento após a cirurgia

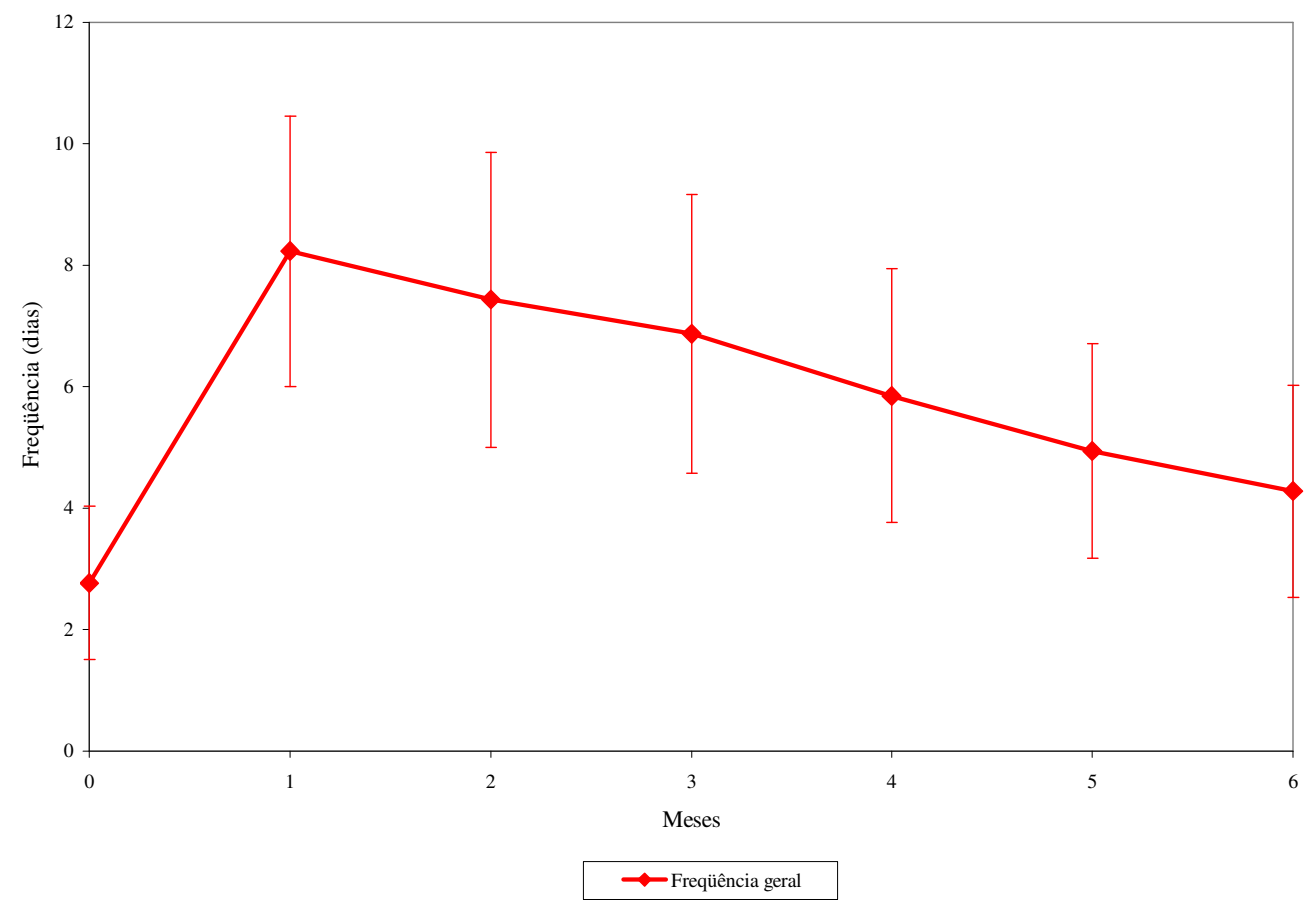

Figura 3 - Perfis médios da frequiência de cefaléia no seguimento após a cirurgia, segundo o sexo

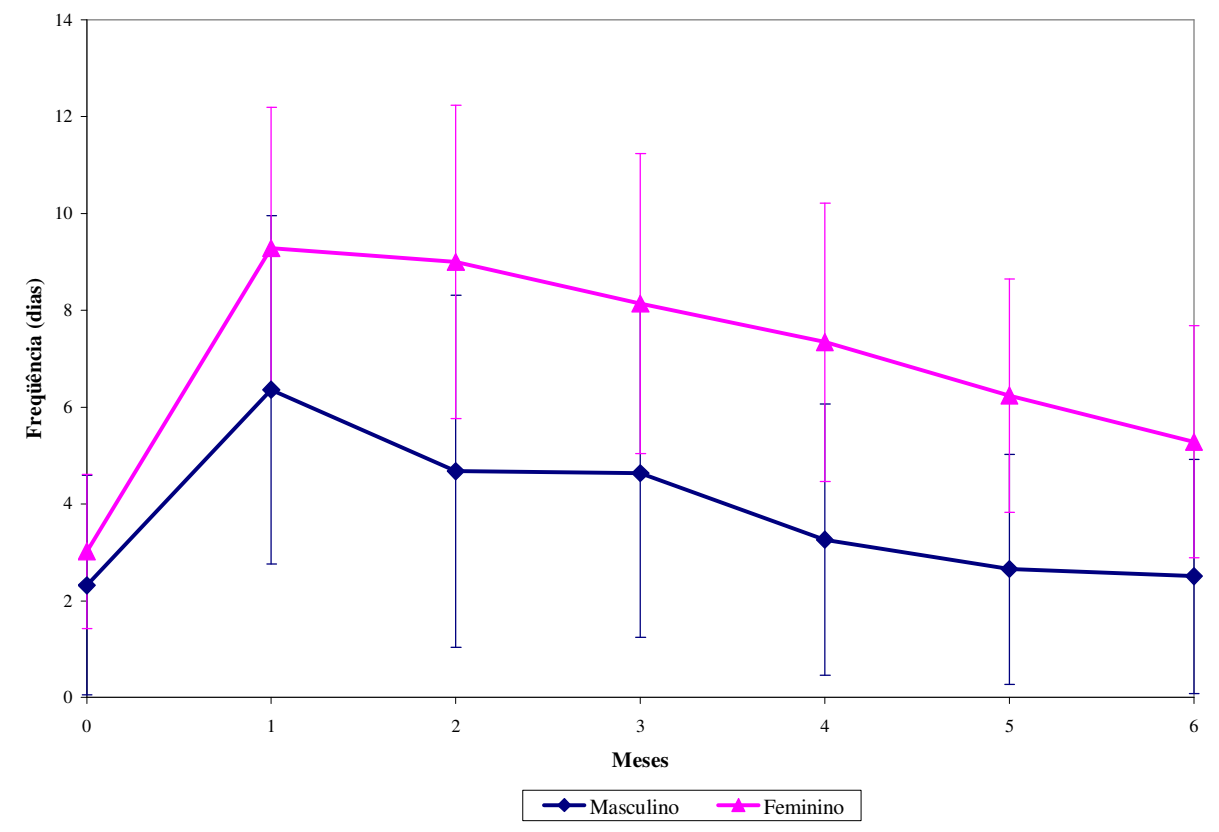


Figura 4 - Perfis médios da freqüência de cefaléia no seguimento após a cirurgia, segundo o diagnóstico de cefaléia primária pré-operatória e presença de crises de cefaléia, nos três meses que precederam a avaliação préoperatória

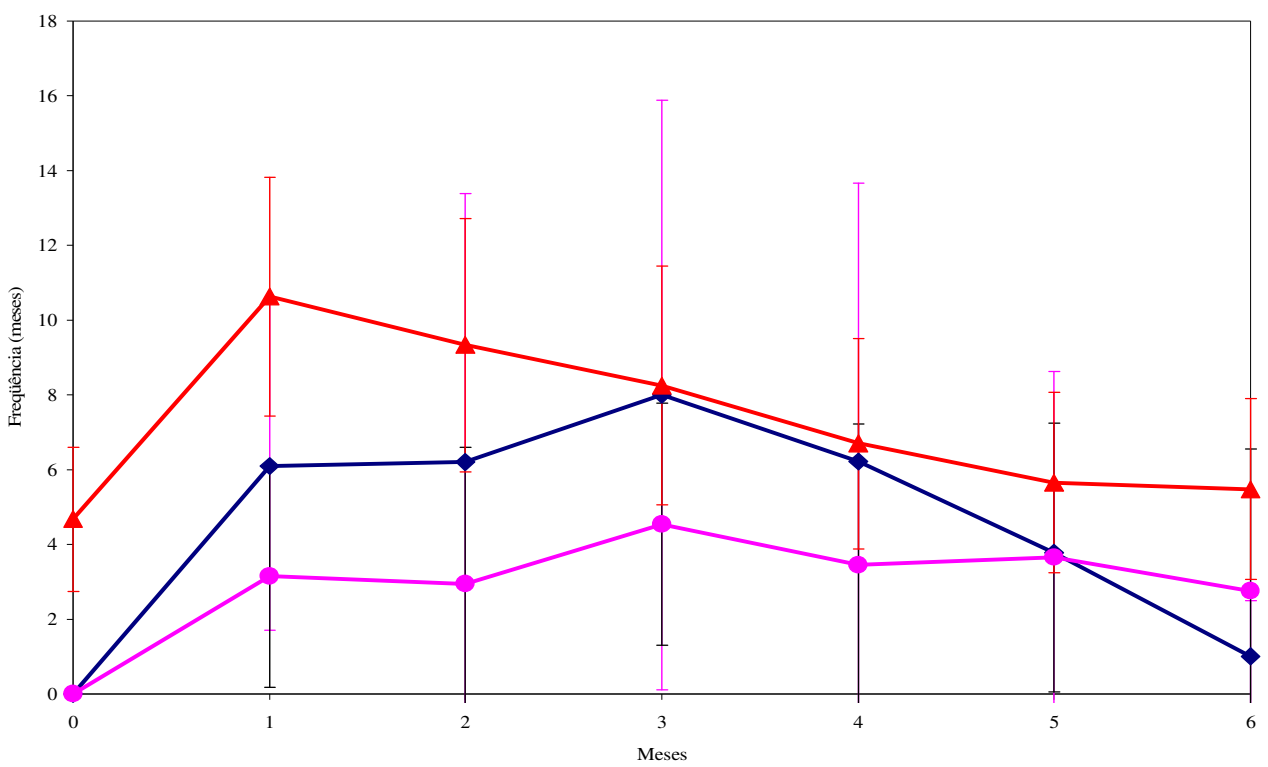

$\neg$ Sem cefaléia prévia $\quad \rightarrow$ Com cefaléia prévia sem dor $\quad$ †Com cefaléia prévia com dor

Figura 5 - Perfis médios da freqüência de cefaléia, no seguimento após a cirurgia, segundo o número de cirurgias

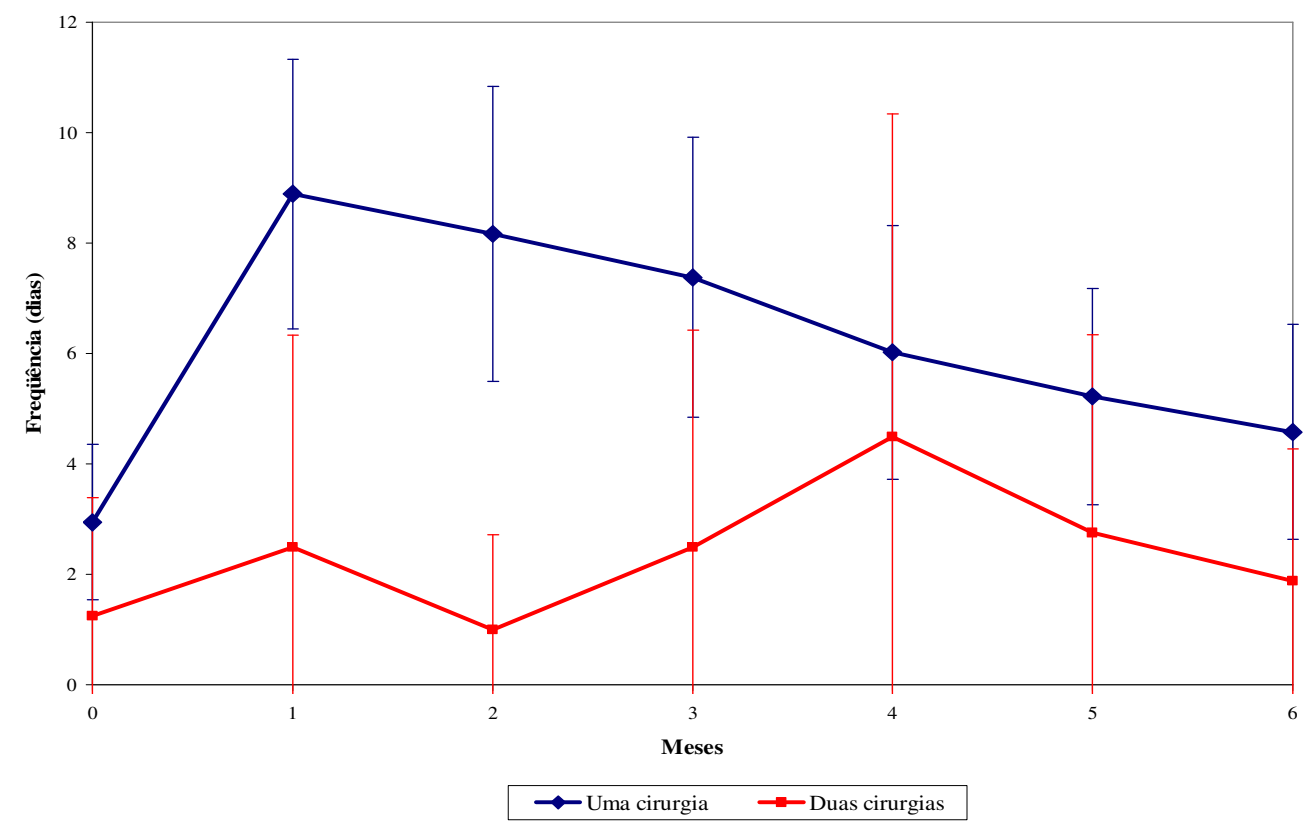


Figura 6 - Perfis médios da frequiência de cefaléia em dias, no seguimento após a cirurgia, segundo o tipo de craniotomia

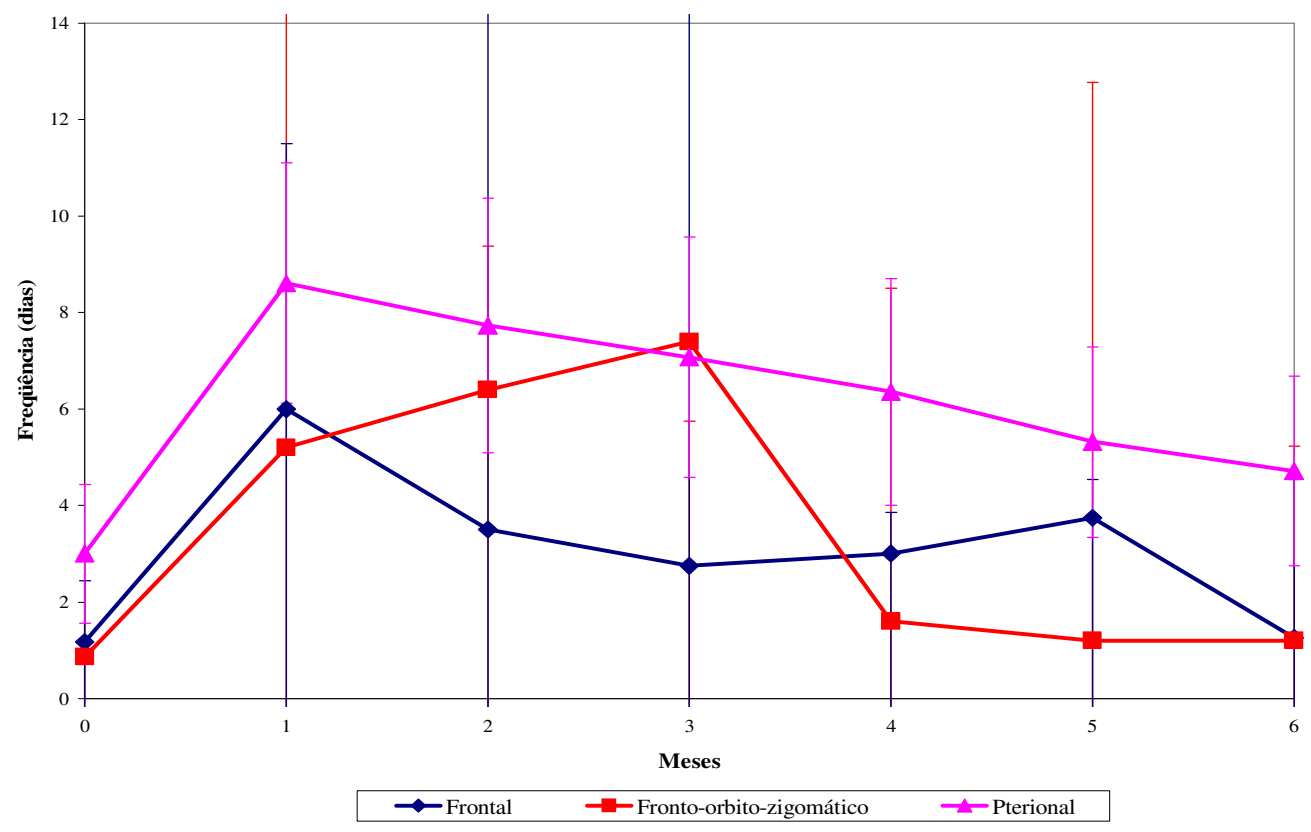

A tabela 4 nos mostra que houve um aumento médio da frequiência de cefaléia de 14 dias nos primeiros três meses após a cirurgia, em relação ao trimestre anterior à cirurgia. Observamos também um aumento médio da frequiência de cefaléia de 6,9 dias de dor nos últimos 3 meses de acompanhamento, em relação ao trimestre anterior à cirurgia e uma diminuição média de 7,9 dias de dor nos últimos 3 meses de acompanhamento em relação ao primeiro trimestre após a cirurgia. 
Tabela 4 - Diferenças das freqüências de cefaléia entre o trimestre pré-operatório, primeiros três meses de pós-operatório e últimos três meses de pósoperatório, em dias

\begin{tabular}{cccccc}
\hline $\begin{array}{c}\text { TEMPO } \\
\text { trimestre) }\end{array}$ & MÉDIA & $\begin{array}{c}\text { DESVIO } \\
\text { PADRÃO }\end{array}$ & $\begin{array}{c}1^{\text {o }} \\
\text { QUARTIL }\end{array}$ & MEDIANA & $\begin{array}{c}3^{\circ} \\
\text { QUARTIL }\end{array}$ \\
\hline $\begin{array}{c}\text { Primeiro } \\
\text { Trimestre pós- } \\
\text { operatório - } \\
\text { pré-operatório }\end{array}$ & 14,0 & 30,6 & 1,5 & 1 & 27 \\
$\begin{array}{c}\text { Segundo } \\
\text { Trimestre pós- } \\
\text { operatório - } \\
\text { pré-operatório }\end{array}$ & 6,9 & 28,3 & -1 & 0 & 15 \\
$\begin{array}{c}\text { Primeiro } \\
\text { Trimestre pós- } \\
\text { operatório - } \\
\text { Segundo }\end{array}$ & 7,9 & 16,6 & 0 & & \\
Trimestre pós- \\
operatório
\end{tabular}

\subsubsection{Análise da freqüência prévia de cefaléia}

A Figura 7 mostra a comparação dos percentis entre os grupos G0, G1 e G2, ilustrando a homogeneidade da medida da freqüência prévia de cefaléia entre os grupos. A análise estatística mostrou que os três grupos mostraram-se homogêneos quanto à frequiência prévia de cefaléia (teste de $\mathrm{KW} ; \mathrm{p}=0,36$ ). 
Figura 7 - Comparação dos percentis da freqüência da cefaléia primária prévia nos três meses que precederam a cirurgia nos pacientes sem HSA (G0), com HSA e sem cefaléia causada pela HSA (G1) ou com HSA e com cefaléia causada pela HSA (G2) no momento da avaliação pré-operatória

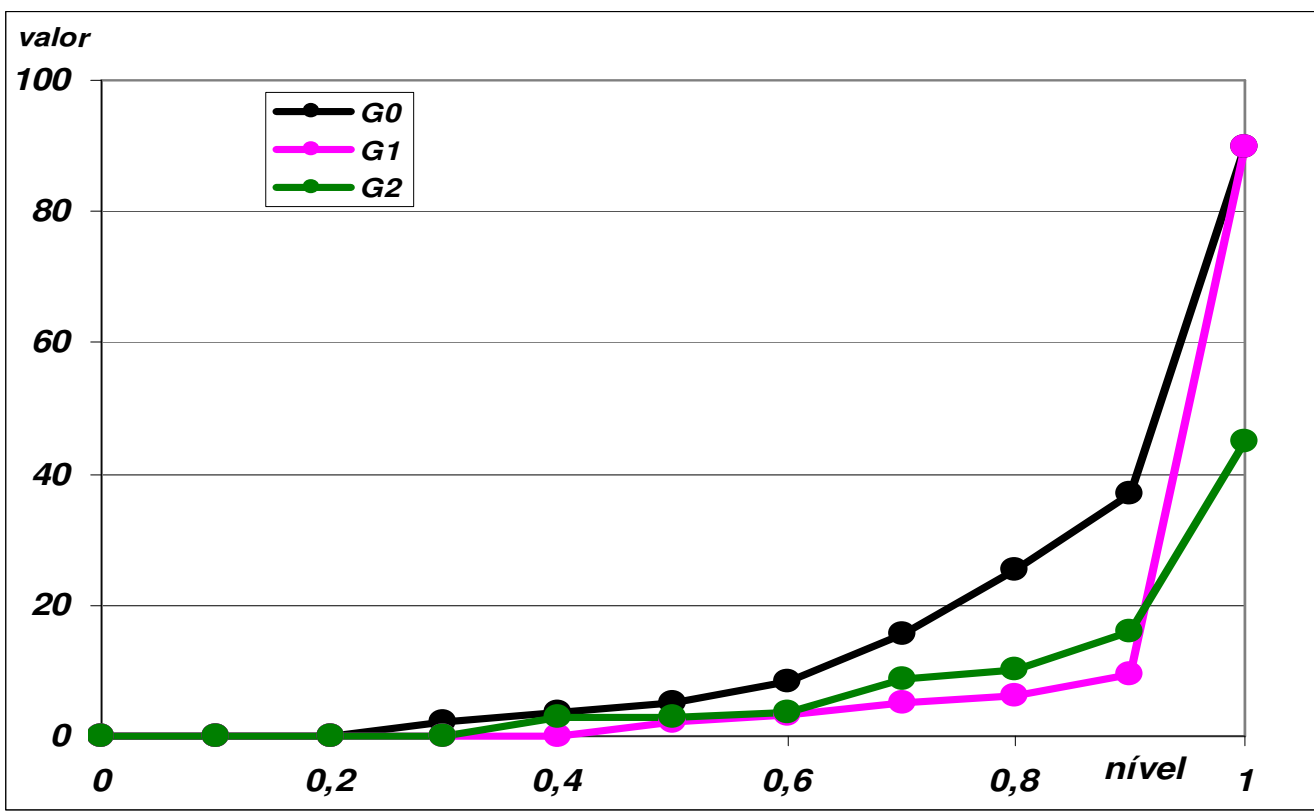

\subsubsection{Evolução da freqüência de cefaléia nos primeiros 3 meses após a}

cirurgia

A Figura 8 mostra a dispersão entre os valores pré-operatórios e os valores dos três primeiros meses após a cirurgia. Nota-se um acúmulo de pontos acima da diagonal, o que sugere um aumento da freqüência de cefaléia após a cirurgia. Esse aumento de frequiência é mostrado também na Figura 9, nos três grupos estudados. Não houve diferença estatisticamente significativa em relação ao aumento da freqüência de cefaléia entre os 3 grupos estudados (teste de KW; $\mathrm{p}=0,29$ ). 
Figura 8 - Dispersão entre a freqüência da cefaléia primária prévia e a freqüência nos primeiros 3 meses após a cirurgia nos pacientes sem HSA (G0), com HSA e sem cefaléia causada pela HSA (G1), e com HSA e com cefaléia causada pela HSA (G2) no momento da avaliação pré-operatória

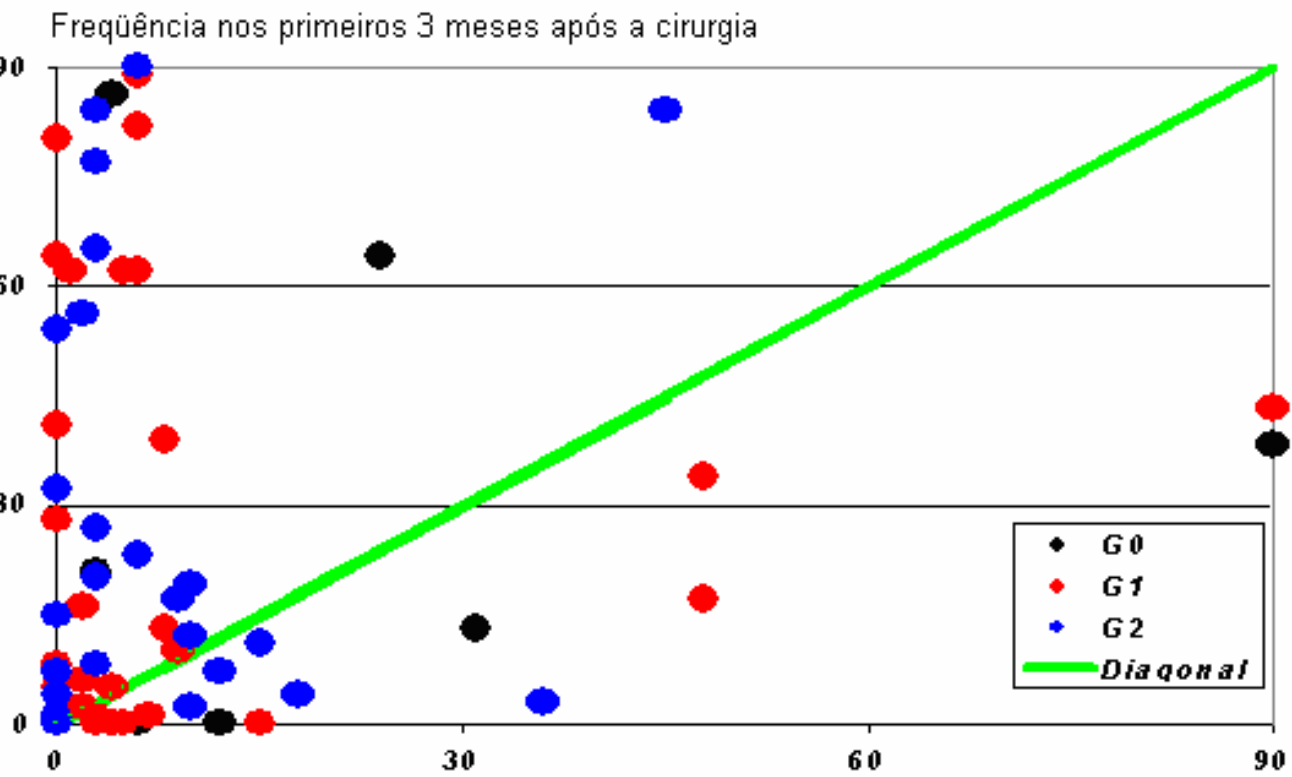

Freqüência nos 3 meses anteriores à cirurgia

Figura 9 - Comparação de percentis entre a diferença da frequiência de cefaléia primária prévia e a freqüência nos primeiros 3 meses após a cirurgia nos pacientes sem HSA (G0), com HSA e sem cefaléia causada pela HSA (G1), e com HSA e com cefaléia causada pela HSA (G2) no momento da avaliação pré-operatória

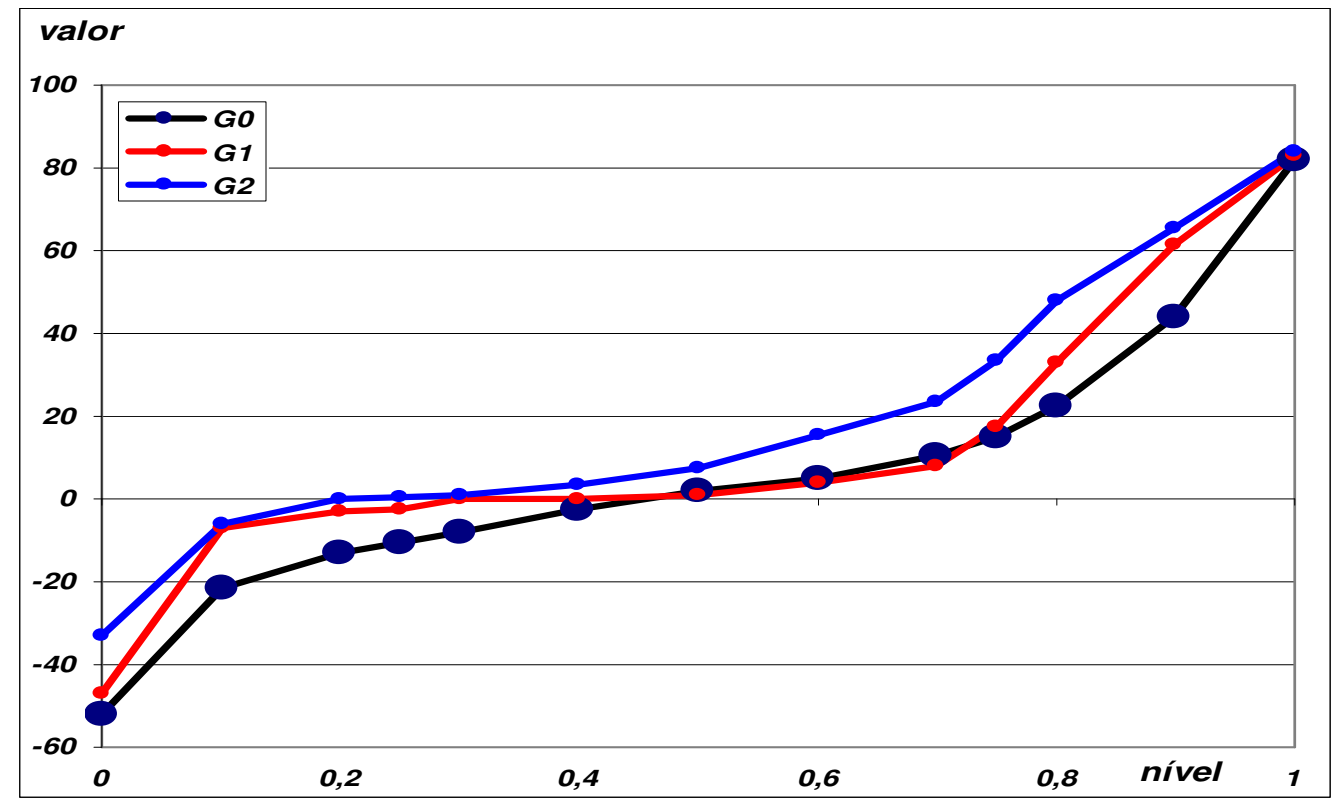


5.2.4 Evolução da freqüência de cefaléia nos últimos 3 meses em relação à freqüência prévia de cefaléia.

A Figura 10 mostra um acúmulo de pontos acima da diagonal, sugerindo um aumento da freqüência de cefaléia em relação à freqüência prévia. A Figura 11 mostra que a curva de percentis do G2 é superior à dos outros grupos. A análise estatística não revelou diferença estatisticamente significativa em relação ao aumento da freqüência da cefaléia entre os grupos (teste de KW; $\mathrm{p}=0,054$ ).

Figura 10 - Dispersão entre a frequiência da cefaléia primária prévia e a freqüência nos 3 últimos meses após a cirurgia nos pacientes sem HSA (G0), com HSA e sem cefaléia causada pela HSA (G1), e com HSA e com cefaléia causada pela HSA (G2) no momento da avaliação pré-operatória

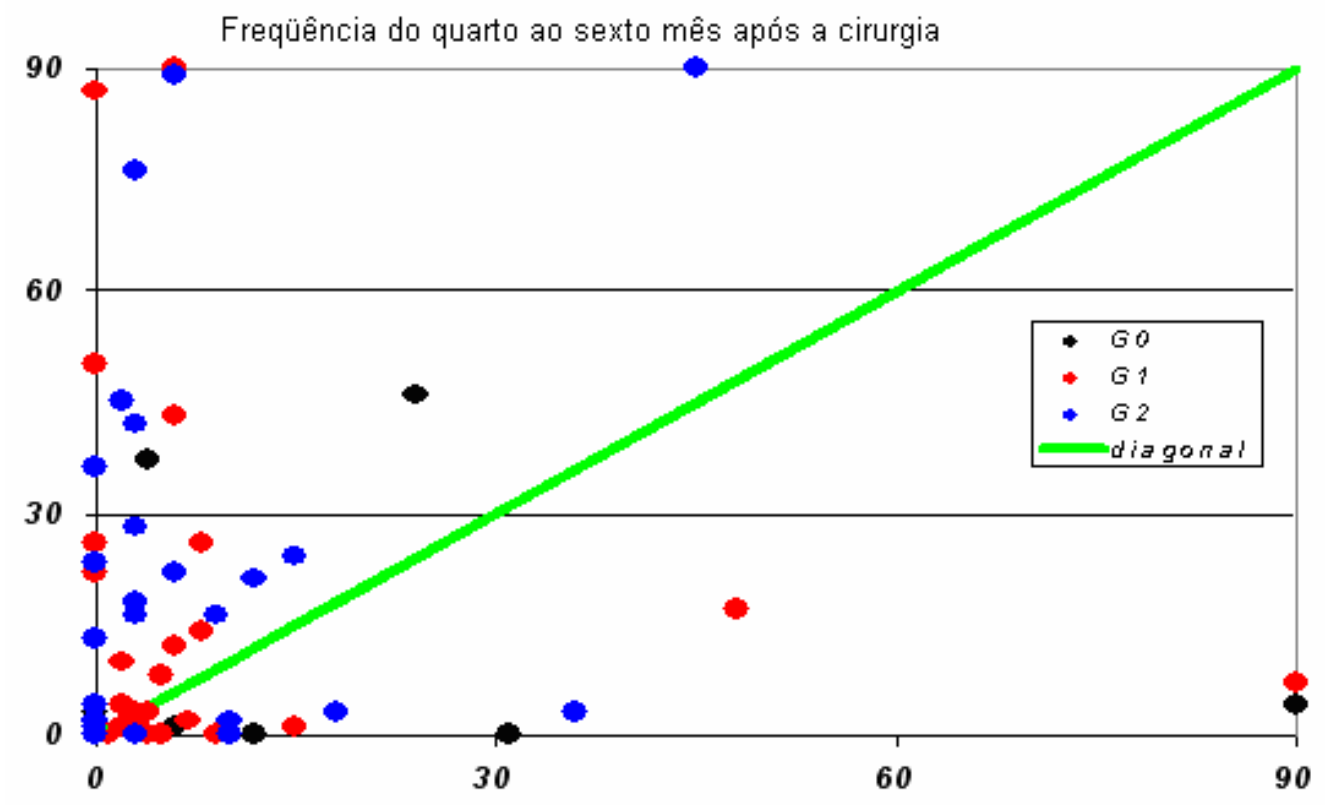

Freqüência nos 3 meses anteriores à cirurgia 
Figura 11 - Comparação de percentis entre a diferença da freqüência da cefaléia primária prévia e a freqüência nos 3 últimos meses após a cirurgia nos pacientes sem HSA (G0), com HSA e sem cefaléia causada pela HSA (G1), e com HSA e com cefaléia causada pela HSA (G2) no momento da avaliação pré-operatória

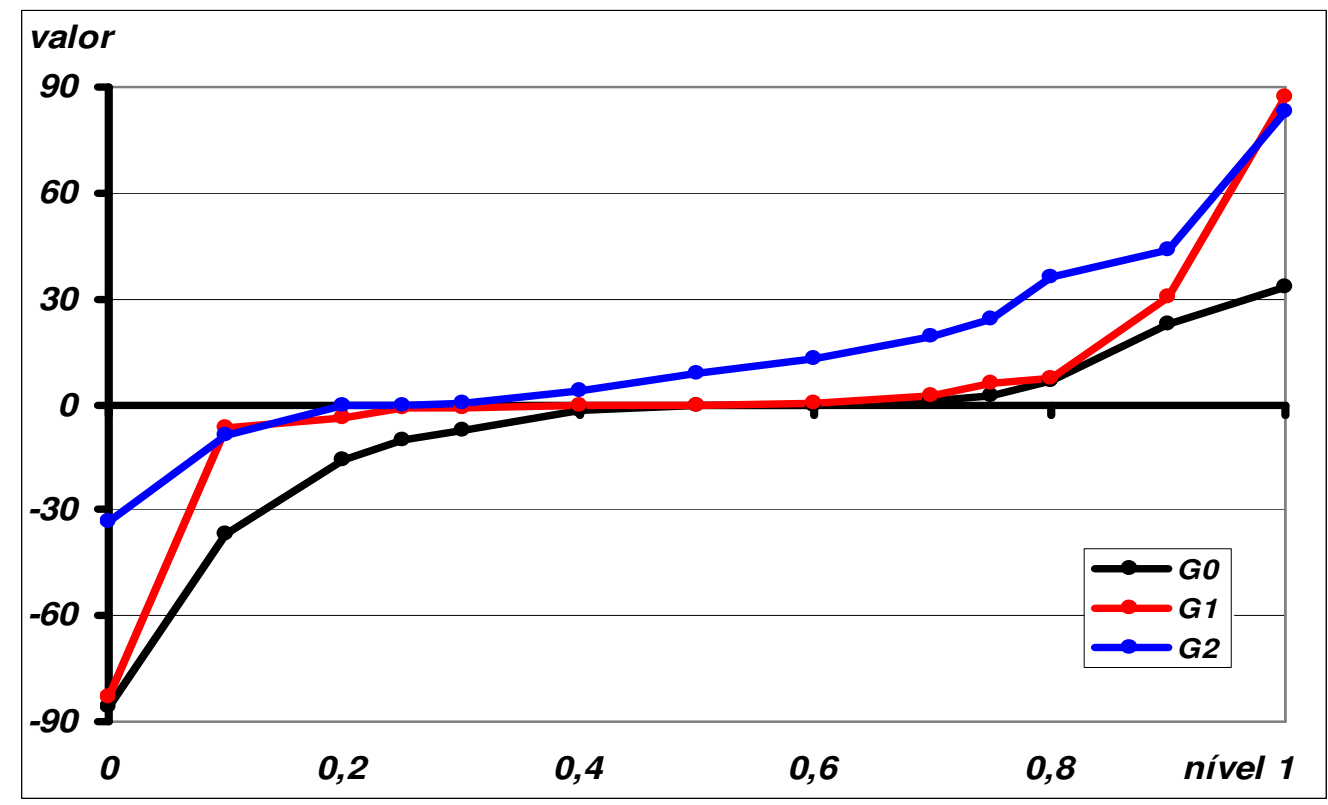

\subsubsection{Comparação da freqüência de cefaléia dos 3 primeiros meses com} os últimos 3 meses.

A Figura 12 mostra a dispersão entre os 3 primeiros meses e os últimos 3 meses. O acúmulo de pontos abaixo da diagonal, já que estamos avaliando a diferença entre os primeiros 3 meses e os últimos 3 meses, sugere uma tendência à diminuição da freqüência de dor. Não observamos diferença estatisticamente significativa entre os grupos no que diz respeito à diminuição da dor (teste de $\mathrm{KW}$; $\mathrm{p}$ $=0,33)$.

A Figura 13 mostra a comparação dos percentis de diminuição da frequiência de cefaléia dos grupos estudados. Pode-se observar que as curvas dos grupos G1 e G2 são muito semelhantes, enquanto a do grupo G0 ficou acima dos outros dois. Isto 
sugere uma diminuição mais acentuada da freqüência da cefaléia no grupo que não apresentou HSA, em relação aos que a apresentaram. $\mathrm{O}$ fato de não termos encontrado diferença estatisticamente significativa pode dever-se ao pequeno número de indivíduos no grupo G0.

Figura 12 - Dispersão entre a freqüência da cefaléia dos 3 primeiros meses e os 3 últimos meses de pós-operatório nos pacientes sem HSA (G0), com HSA e sem cefaléia causada pela HSA (G1), e com HSA e com cefaléia causada pela HSA (G2) no momento da avaliação pré-operatória

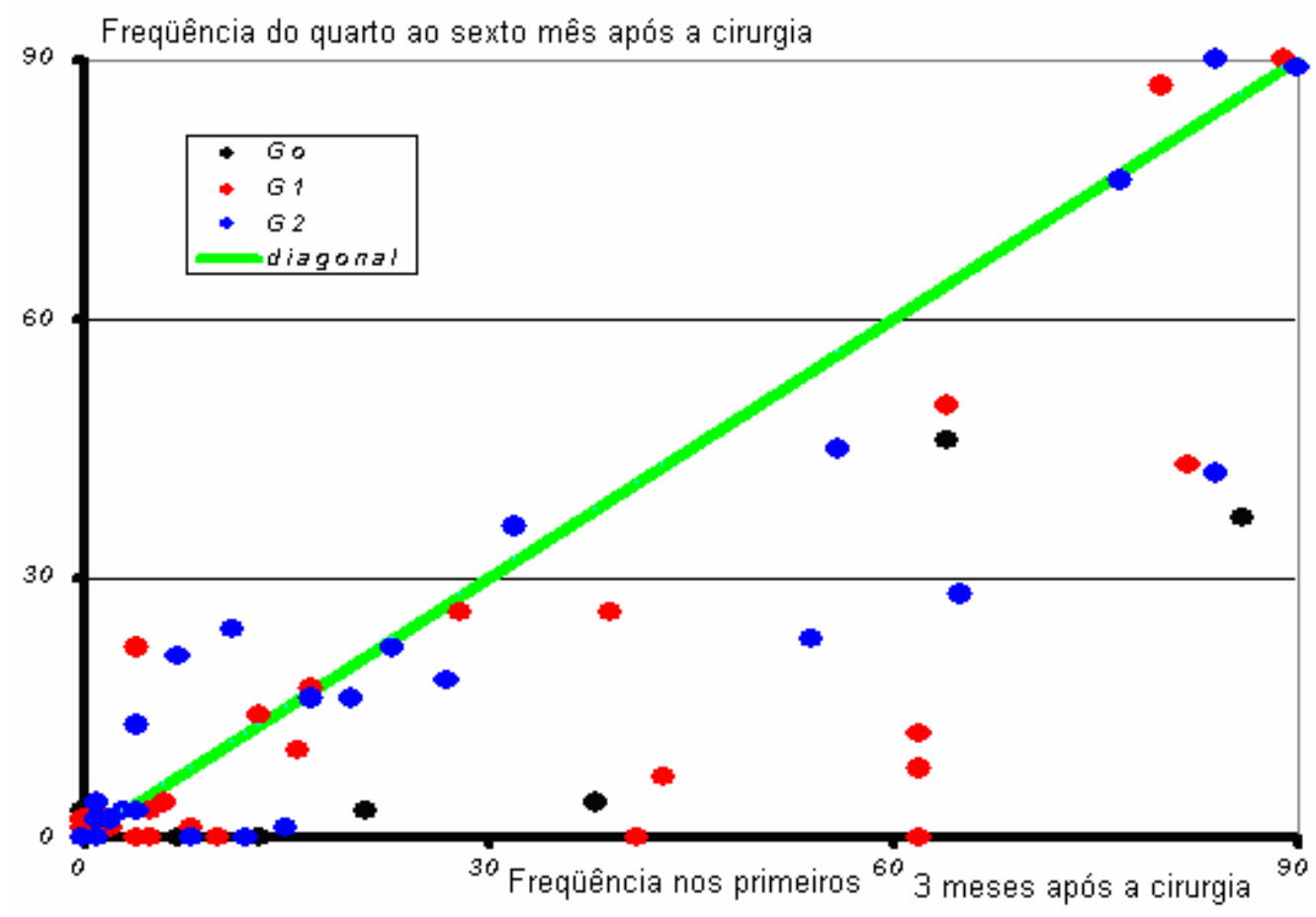


Figura 13 - Comparação dos percentis entre a freqüência da cefaléia dos 3 primeiros meses e os 3 últimos meses de pós-operatório nos pacientes sem HSA (G0), com HSA e sem cefaléia causada pela HSA (G1), e com HSA e com cefaléia causada pela HSA $(\mathrm{G} 2)$ no momento da avaliação préoperatória

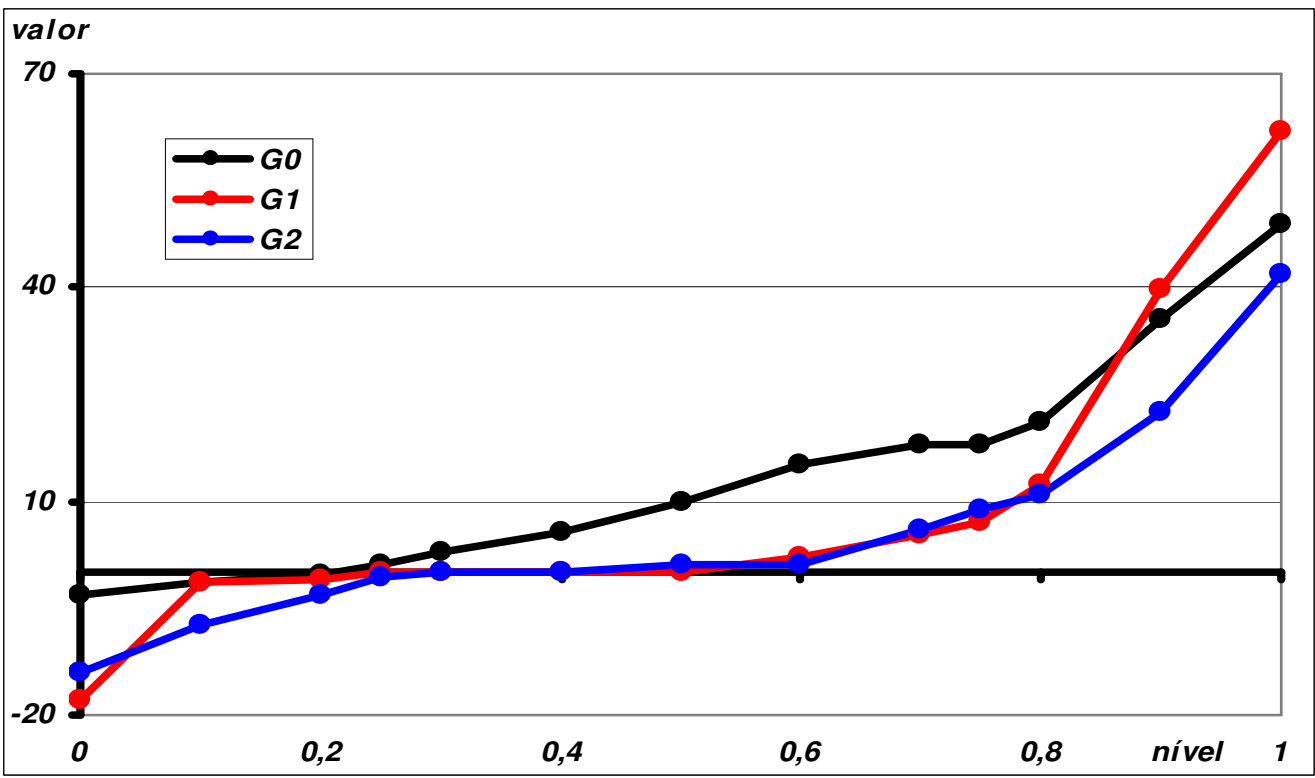

5.3 Relação entre freqüência de cefaléia e os sintomas depressivos, ansiosos e sonolência diurna

A Tabela 5 mostra os escores referentes à intensidade dos sintomas ansiosos, depressivos e da sonolência diurna nas diversas avaliações.

As Tabelas 6, 7 e 8 mostram as correlações de Pearson e os testes de significância para essas correlações para, respectivamente, a intensidade de depressão, ansiedade e sonolência excessiva diurna nas quatro avaliações (préoperatória, $1^{\mathrm{a}}, 2^{\mathrm{a}}$ e $3^{\mathrm{a}}$ consultas) com a freqüência de cefaléia nos períodos correspondentes a cada uma das avaliações. Os resultados mostram que a correlação entre frequiência de cefaléia e: 
$\checkmark$ a intensidade de depressão foi estatisticamente significativa e positiva nas três consultas;

$\checkmark$ a intensidade de ansiedade foi estatisticamente significativa e positiva em todos os períodos;

$\checkmark$ a intensidade de sonolência excessiva diurna foi estatisticamente significativa e positiva apenas na $1^{\mathrm{a}}$ consulta;

Estas análises foram repetidas retirando-se os pacientes com seqüelas sem que houvesse modificação dos resultados.

Tabela 5 - Intensidade da ansiedade (HAD), depressão (HAD) e sonolência diurna (EPW) de acordo com os momentos de avaliação

\begin{tabular}{|c|c|c|c|c|c|}
\hline $\begin{array}{c}\text { MOMENTO } \\
\text { DA } \\
\text { AVALIACCÃO }\end{array}$ & MÉDIA & $\begin{array}{c}\text { DESVIO } \\
\text { PADRÃO }\end{array}$ & MEDIANA & MÍNIMO & MÁXIMO \\
\hline $\begin{array}{l}\text { Pré-operatório } \\
\text { (Ansiedade) }\end{array}$ & 7,8 & 5,1 & 7,0 & 0,0 & 19,0 \\
\hline $\begin{array}{l}\text { Pré-operatório } \\
\text { (Depressão) }\end{array}$ & 4,9 & 3,8 & 4,0 & 0,0 & 16,0 \\
\hline $\begin{array}{c}\text { Pré-operatório } \\
\text { (EPW) }\end{array}$ & 8,4 & 6,2 & 6,0 & 0,0 & 24,0 \\
\hline $\begin{array}{l}1^{\mathrm{a}} \text { consulta } \\
(\text { Ansiedade })\end{array}$ & 7,0 & 5,1 & 5,0 & 0,0 & 21,0 \\
\hline $\begin{array}{l}1^{\mathrm{a}} \text { consulta } \\
\text { (Depressão) }\end{array}$ & 5,3 & 4,2 & 5,0 & 0,0 & 16,0 \\
\hline $\begin{array}{c}1^{\mathrm{a}} \text { consulta } \\
(\mathrm{EPW})\end{array}$ & 7,3 & 5,5 & 6,0 & 0,0 & 21,0 \\
\hline $\begin{array}{c}2^{\mathrm{a}} \text { consulta } \\
\text { (Ansiedade) }\end{array}$ & 7,5 & 5,3 & 6,0 & 0,0 & 20,0 \\
\hline $\begin{array}{l}2^{\mathrm{a}} \text { consulta } \\
\text { (Depressão) }\end{array}$ & 6,2 & 5,2 & 5,0 & 0,0 & 19,0 \\
\hline $\begin{array}{c}2^{\mathrm{a}} \text { consulta } \\
(\mathrm{EPW})\end{array}$ & 7,7 & 6,0 & 6,0 & 0,0 & 24,0 \\
\hline $\begin{array}{c}3^{\mathrm{a}} \text { consulta } \\
\text { (Ansiedade) }\end{array}$ & 7,0 & 5,2 & 6,0 & 0,0 & 20,0 \\
\hline $\begin{array}{l}3^{\mathrm{a}} \text { consulta } \\
\text { (Depressão) }\end{array}$ & 6,3 & 5,2 & 6,0 & 0,0 & 20,0 \\
\hline $\begin{array}{c}3^{\mathrm{a}} \text { consulta } \\
(\mathrm{EPW})\end{array}$ & 8,1 & 6,0 & 6,0 & 0,0 & 22,0 \\
\hline
\end{tabular}


Tabela 6 - Correlações amostrais e níveis descritivos do teste de significância da correlação da intensidade de depressão (HAD), nas quatro avaliações, com a frequiência de cefaléia nos períodos correspondentes a cada avaliação

\begin{tabular}{|c|c|c|c|}
\hline $\begin{array}{l}\text { INTENSIDADE } \\
\text { DA } \\
\text { DEPRESSÃO } \\
\text { (MOMENTO } \\
\text { DA } \\
\text { AVALIAÇÃO) }\end{array}$ & $\begin{array}{l}\text { FREQÜÊNCIA } \\
\text { DE CEFALÉIA }\end{array}$ & $\begin{array}{c}\text { CORRELAÇÃO ENTRE } \\
\text { A INTENSIDADE DA } \\
\text { DEPRESSÃO E A } \\
\text { FREQÜÊNCIA DA } \\
\text { CEFALÉIA }\end{array}$ & $\begin{array}{c}\text { NÍVEL } \\
\text { DESCRITIVO } \\
(\mathrm{p})\end{array}$ \\
\hline $\begin{array}{c}\text { avaliação pré- } \\
\text { operatória }\end{array}$ & $\begin{array}{c}\text { avaliação pré- } \\
\text { operatória }\end{array}$ & 0,14 & 0,01 \\
\hline $1^{\text {a }}$ Consulta & $\begin{array}{l}1 \text { mês após a } \\
\text { retirada de } \\
\text { pontos }\end{array}$ & 0,33 & $<0,01$ \\
\hline $1^{\mathrm{a}}$ Consulta & $\begin{array}{l}2 \text { meses após a } \\
\text { retirada de } \\
\text { pontos }\end{array}$ & 0,31 & $<0,01$ \\
\hline $2^{\mathrm{a}}$ Consulta & $\begin{array}{l}3 \text { meses após a } \\
\text { retirada de } \\
\text { pontos }\end{array}$ & 0,27 & $<0,01$ \\
\hline $2^{\mathrm{a}}$ Consulta & $\begin{array}{l}4 \text { meses após a } \\
\text { retirada de } \\
\text { pontos }\end{array}$ & 0,32 & $<0,01$ \\
\hline $3^{\mathrm{a}}$ Consulta & $\begin{array}{l}5 \text { meses após a } \\
\text { retirada de } \\
\text { pontos }\end{array}$ & 0.28 & 0,02 \\
\hline $3^{a}$ Consulta & $\begin{array}{l}6 \text { meses após a } \\
\text { retirada de } \\
\text { pontos }\end{array}$ & 0,40 & $<0,01$ \\
\hline
\end{tabular}


Tabela 7 - Correlações amostrais e níveis descritivos do teste de significância da correlação da intensidade de ansiedade, nas quatro avaliações, com a freqüência de cefaléia nos períodos correspondentes a cada avaliação

\begin{tabular}{|c|c|c|c|}
\hline $\begin{array}{c}\text { INTENSIDADE } \\
\text { DA } \\
\text { ANSIEDADE }\end{array}$ & $\begin{array}{l}\text { FREQÜÊNCIA } \\
\text { DE CEFALÉIA }\end{array}$ & $\begin{array}{c}\text { CORRELAÇÃO } \\
\text { ENTRE A } \\
\text { INTENSIDADE DA } \\
\text { ANSIEDADE E A } \\
\text { FREQÜÊNCIA DA } \\
\text { CEFALÉIA }\end{array}$ & $\begin{array}{c}\text { NÍVEL } \\
\text { DESCRITIVO } \\
(\mathrm{p})\end{array}$ \\
\hline $\begin{array}{l}\text { avaliação pré- } \\
\text { operatória }\end{array}$ & $\begin{array}{l}\text { avaliação pré- } \\
\text { operatória }\end{array}$ & 0,29 & 0,01 \\
\hline $1^{a}$ Consulta & $\begin{array}{l}1 \text { mês após a } \\
\text { retirada de pontos }\end{array}$ & 0,39 & $<0,01$ \\
\hline $1^{a}$ Consulta & $\begin{array}{l}2 \text { meses após a } \\
\text { retirada de pontos }\end{array}$ & 0,36 & $<0,01$ \\
\hline $2^{a}$ Consulta & $\begin{array}{l}3 \text { meses após a } \\
\text { retirada de pontos }\end{array}$ & 0,46 & $<0,01$ \\
\hline $2^{a}$ Consulta & $\begin{array}{l}4 \text { meses após a } \\
\text { retirada de pontos }\end{array}$ & 0,43 & $<0,01$ \\
\hline $3^{a}$ Consulta & $\begin{array}{l}5 \text { meses após a } \\
\text { retirada de pontos }\end{array}$ & 0.40 & $<0,01$ \\
\hline $3^{a}$ Consulta & $\begin{array}{l}6 \text { meses após a } \\
\text { retirada de pontos }\end{array}$ & 0,50 & $<0,01$ \\
\hline
\end{tabular}


Tabela 8 - Correlações amostrais e níveis descritivos do teste de significância da correlação da intensidade de sonolência excessiva diurna, nas quatro avaliações, com a freqüência de cefaléia nos períodos correspondentes a cada avaliação

\begin{tabular}{|c|c|c|c|}
\hline $\begin{array}{l}\text { INTENSIDADE } \\
\text { DA } \\
\text { SONOLENCIA }\end{array}$ & $\begin{array}{l}\text { FREQÜÊENCIA } \\
\text { DE CEFALÉIA }\end{array}$ & $\begin{array}{c}\text { CORRELAÇÃO } \\
\text { ENTRE A } \\
\text { INTENSIDADE DA } \\
\text { SONOLÊNCIA E A } \\
\text { FREQÜÊNCIA DA } \\
\text { CEFALÉIA }\end{array}$ & $\begin{array}{c}\text { NÍVEL } \\
\text { DESCRITIVO } \\
\text { (p) }\end{array}$ \\
\hline $\begin{array}{c}\text { avaliação pré- } \\
\text { operatória }\end{array}$ & $\begin{array}{c}\text { avaliação pré- } \\
\text { operatória }\end{array}$ & $-0,02$ & 0,87 \\
\hline $1^{\text {a }}$ Consulta & $\begin{array}{l}1 \text { mês após a } \\
\text { retirada de pontos }\end{array}$ & 0,19 & 0,10 \\
\hline $1^{\text {a Consulta }}$ & $\begin{array}{l}2 \text { meses após a } \\
\text { retirada de pontos }\end{array}$ & 0,24 & 0,05 \\
\hline $2^{\mathrm{a}}$ Consulta & $\begin{array}{l}3 \text { meses após a } \\
\text { retirada de pontos }\end{array}$ & 0,17 & 0,15 \\
\hline $2^{\mathrm{a}}$ Consulta & $\begin{array}{l}4 \text { meses após a } \\
\text { retirada de pontos }\end{array}$ & 0,20 & 0,11 \\
\hline $3^{\text {a Consulta }}$ & $\begin{array}{l}5 \text { meses após a } \\
\text { retirada de pontos }\end{array}$ & 0.14 & 0,23 \\
\hline $3^{a}$ Consulta & $\begin{array}{l}6 \text { meses após a } \\
\text { retirada de pontos }\end{array}$ & 0,19 & 0,12 \\
\hline
\end{tabular}

\subsection{Características da cefaléia}

\subsubsection{Intervalo de tempo para o início da cefaléia após a craniotomia}

A Tabela 9 apresenta as medidas correspondentes ao intervalo de tempo para o início da cefaléia após a craniotomia nos pacientes G0, G1 e G2. Os resultados sugerem que o início da cefaléia pós-craniotomia ocorre num menor intervalo de tempo naqueles pacientes que apresentavam cefaléia causada pela HSA no momento da avaliação pré-operatória. 
Tabela 9 - Período de tempo de início da cefaléia pós-craniotomia (em dias): sem HSA (G0), com HSA e sem cefaléia causada pela HSA no momento da avaliação pré-operatória (G1), com HSA e com cefaléia causada pela HSA no momento da avaliação pré-operatória $(\mathrm{G} 2)$

\begin{tabular}{ccccccc}
\hline & N & MÉDIA & $\begin{array}{c}\text { DESVIO } \\
\text { PADRÃO }\end{array}$ & $\begin{array}{c}1^{\text {o }} \\
\text { QUARTIL }\end{array}$ & MEDIANA & $\begin{array}{c}3^{\text {o }} \\
\text { QUARTIL }\end{array}$ \\
\hline G0 & 9 & $27(1-182)$ & 58 & 4 & 5 & 19 \\
G1 & 36 & $20(1-182)$ & 37 & 3 & 5 & 19 \\
G2 & 27 & $5(1-27)$ & 7 & 1 & 2 & 5 \\
TOTAL & 72 & $16(1-182)$ & 34 & 2 & 4 & 14 \\
\hline
\end{tabular}

A Figura 14 mostra as curvas de latência para o início da cefaléia póscraniotomia para os pacientes com HSA e com cefaléia causada pela HSA, para os pacientes com HSA e sem cefaléia causada pela HSA e para os pacientes sem HSA, calculadas pela técnica de Kaplan-Meier. Elas foram construídas para verificar a existência de associação entre o tempo de início da cefaléia e a presença de HSA e de cefaléia causada pela HSA. Essas curvas foram comparadas através de testes tipo "log-rank" cujos níveis descritivos são apresentados na Tabela 10. Os resultados sugerem que os pacientes dos grupos G0 e G1 apresentam tempo de início da cefaléia equivalentes, enquanto que os pacientes do grupo G2 tendem a apresentar cefaléia mais precocemente no seguimento. 
Tabela 10 - Níveis descritivos (valores de p) do teste Log-Rank para a comparação da evolução da proporção de pacientes sem dor, no período pósoperatório, segundo presença de HSA e presença de cefaléia causada pela HSA

\begin{tabular}{cc}
\hline TESTE DE LOG-RANK & NÍVEL \\
& $\begin{array}{c}\text { DESCRITIVO } \\
(\mathrm{p})\end{array}$ \\
\hline Entre os pacientes das três grupos & 0,02 \\
Entre os pacientes com HSA e sem dor causada pela HSA (G1) e & 0,96 \\
os pacientes sem HSA (GO)
\end{tabular}

Figura 14 - Estimativas de Kaplan-Meier para as proporções de pacientes sem cefaléia, no período pós-operatório, segundo presença de HSA e presença de cefaléia causada pela HSA

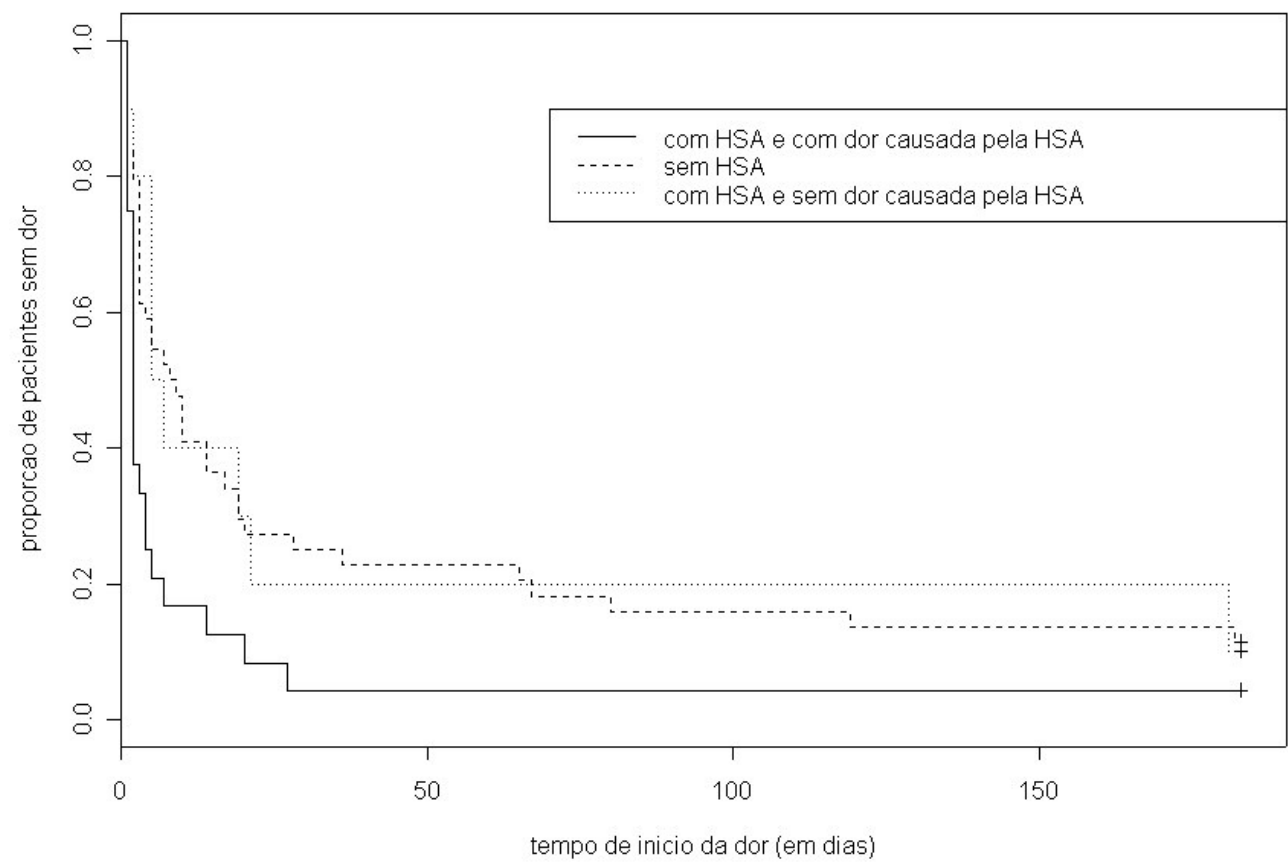




\subsubsection{Diagnósticos}

Nenhum paciente apresentou cefaléia associada à manobra de Valsalva ou relacionada à posição ortostática.

A Tabela 11 mostra a distribuição segundo o diagnóstico de cefaléia nos períodos pré e pós-operatórios $\left(1^{\mathrm{a}}, 2^{\mathrm{a}}\right.$ e $3^{\mathrm{a}}$ consultas $)$. Nessa tabela não foram considerados os pacientes que apresentaram dois tipos de cefaléia primária no período pré-operatório e o paciente que perdeu o acompanhamento após a retirada de pontos. Os dados mostram que este grupo de pacientes teve uma diminuição das características migranosas das cefaléias após a cirurgia e que, em cada período, a proporção de pacientes sem cefaléia aumentou.

Tabela 11 - Distribuição de padrões diagnósticos da cefaléia nos períodos préoperatório e pós-operatório ( $1^{\mathrm{a}}, 2^{\mathrm{a}}$ e $3^{\mathrm{a}}$ consultas)

\begin{tabular}{ccccc}
\hline PERÍODO & MIGRANOSA & $\begin{array}{c}\text { NÃO } \\
\text { MIGRANOSA }\end{array}$ & $\begin{array}{c}\text { SEM } \\
\text { CEFALÉIA }\end{array}$ & TOTAL \\
\hline Pré-operatório & $38(54 \%)$ & $21(30 \%)$ & $11(16 \%)^{*}$ & 70 \\
Primeira Consulta & $28(40 \%)$ & $21(30 \%)$ & $21(30 \%)$ & 70 \\
Segunda Consulta & $19(27 \%)$ & $24(35 \%)$ & $26(38 \%)$ & 69 \\
Terceira Consulta & $20(30 \%)$ & $20(30 \%)$ & $26(39 \%)$ & 66 \\
\hline
\end{tabular}

* Sem diagnóstico de cefaléia primária prévia à cirurgia

As estimativas e intervalos de confiança (95\%) para o coeficiente Kappa, apresentados na Tabela 12, indicam pouca evidência de concordância entre os diagnósticos das cefaléias pré-operatórias e o diagnósticos das cefaléias em cada uma das três consultas, sugerindo diagnósticos pré-operatórios diferentes dos pósoperatórios. 
Tabela 12 - Estimativa e intervalo de confiança com 95\% de confiança para o coeficiente Kappa de concordância entre o diagnóstico da cefaléia préoperatória e o diagnóstico da cefaléia em cada uma das três consultas

\begin{tabular}{lcc}
\hline & $\begin{array}{c}\text { COEFICIENTE } \\
\text { KAPPA }\end{array}$ & IC (95\%) DO COEFICIENTE KAPPA \\
\hline $1^{\text {a } \text { Consulta }}$ & $-0,02$ & {$[-0,33 ; 0,30]$} \\
$2^{\text {a Consulta }}$ & 0,10 & {$[-0,18 ; 0,38]$} \\
$3^{\text {a Consulta }}$ & 0,09 & {$[-0,20 ; 0,38]$} \\
\hline
\end{tabular}

Os testes apresentados nas Tabela 13 não incluem os pacientes que não completaram o período total de acompanhamento. Nesta tabela apresentamos os níveis descritivos (valores de p) dos testes de homogeneidade marginal entre as distribuições do diagnóstico da cefaléia pré-operatória e as distribuições do diagnóstico da cefaléia nas três consultas, além da homogeneidade entre as distribuições do diagnóstico da cefaléia em consultas sucessivas e da homogeneidade das distribuições do diagnóstico da cefaléia entre todas as avaliações. Os resultados mostram que a distribuição de pacientes por diagnóstico da cefaléia pré-operatória é equivalente à distribuição de pacientes por diagnóstico da cefaléia na $1^{\mathrm{a}}$ consulta. $\mathrm{Na}$ $2^{\mathrm{a}}$ e na $3^{\mathrm{a}}$ consultas não há evidência de homogeneidade entre a distribuição de pacientes por diagnóstico da cefaléia pré-operatória e a distribuição de pacientes por diagnóstico da cefaléia nessas consultas. Isto ocorreu, provavelmente, pela diminuição das características migranosas do grupo (Tabela 11).

A distribuição de pacientes por diagnóstico da cefaléia na $1^{\mathrm{a}}$ consulta não é equivalente à distribuição de pacientes por diagnóstico da cefaléia na $2^{\mathrm{a}}$ consulta. Pode-se observar, como mostrado na Tabela 11, que houve um percentual menor de pacientes na $2^{\mathrm{a}}$ consulta com cefaléia migranosa quando comparados com a $1^{\mathrm{a}}$ consulta. A hipótese de que a distribuição de pacientes por diagnóstico da cefaléia na 
$2^{\mathrm{a}}$ consulta é equivalente à distribuição de pacientes por diagnóstico da cefaléia na $3^{\mathrm{a}}$ consulta não é rejeitada na análise estatística.

Tabela 13 - Testes de homogeneidade marginal para a distribuição dos padrões diagnósticos entre os diversos momentos de avaliação

\begin{tabular}{|c|c|}
\hline TESTE DE HOMOGENEIDADE MARGINAL ENTRE & $\begin{array}{l}\text { NÍVEL DESCRITIVO } \\
\text { (valores de } \mathrm{p} \text { ) }\end{array}$ \\
\hline Diagnóstico da cefaléia em todas as avaliações & $<0,01$ \\
\hline Diagnóstico da cefaléia no Pré-operatório e o & 0,10 \\
\hline \multicolumn{2}{|l|}{ Diagnóstico da cefaléia na $1^{\mathrm{a}}$ consulta } \\
\hline Diagnóstico da cefaléia no Pré-operatório e o & $<0,01$ \\
\hline \multicolumn{2}{|l|}{ Diagnóstico da cefaléia na $2^{\mathrm{a}}$ consulta } \\
\hline Diagnóstico da cefaléia no Pré-operatório e o & $<0,01$ \\
\hline \multicolumn{2}{|l|}{ Diagnóstico da cefaléia na $3^{\mathrm{a}}$ consulta } \\
\hline Diagnóstico da cefaléia na $1^{\mathrm{a}}$ consulta e o & 0,06 \\
\hline \multicolumn{2}{|l|}{ Diagnóstico da cefaléia na $2^{\mathrm{a}}$ consulta } \\
\hline Diagnóstico da cefaléia na $2^{\mathrm{a}}$ consulta e o & 0,53 \\
\hline Diagnóstico da cefaléia na $3^{\mathrm{a}}$ consulta & \\
\hline
\end{tabular}

\subsubsection{Lado da cefaléia}

A Tabela 14 mostra a distribuição segundo o lado da cefaléia nos períodos pré e pós-operatório (retirada de pontos, $1^{\mathrm{a}}, 2^{\mathrm{a}}$ e $3^{\mathrm{a}}$ consultas). Não foram considerados os pacientes submetidos a duas cirurgias. Esta tabela mostra que, na avaliação préoperatória, apenas $7 \%$ dos pacientes apresentavam cefaléia do mesmo lado em que seriam operados, enquanto que, de 33 a $46 \%$ dos pacientes apresentaram cefaléia do mesmo lado da cirurgia após a mesma. Essa mudança de lado da cefaléia, observada no período pós-operatório em relação ao período pré-operatório, sugere uma influência da cirurgia na evolução de lado da cefaléia. 
Tabela 14 - Distribuição do lado da cefaléia nos períodos pré-operatório e pósoperatório $\left(1^{\mathrm{a}}, 2^{\mathrm{a}}\right.$ e $3^{\mathrm{a}}$ consultas $)$

\begin{tabular}{cccccc}
\hline PERÍODO & BILATERAL & $\begin{array}{c}\text { MESMO } \\
\text { LADO }\end{array}$ & $\begin{array}{c}\text { LADO } \\
\text { DIFERENTE }\end{array}$ & $\begin{array}{c}\text { SEM } \\
\text { CEFALÉIA }\end{array}$ & TOTAL \\
\hline $\begin{array}{c}\text { Pré- } \\
\text { operatório }\end{array}$ & $51(72 \%)$ & $5(7 \%)$ & $7(10 \%)$ & $8(11 \%)^{*}$ & 71 \\
$\begin{array}{c}\text { Retirada de } \\
\text { pontos }\end{array}$ & $26(37 \%)$ & $24(34 \%)$ & $0(0 \%)$ & $21(30 \%)$ & 71 \\
$\begin{array}{c}\text { Primeira } \\
\text { Consulta }\end{array}$ & $17(24 \%)$ & $32(46 \%)$ & $4(6 \%)$ & $17(24 \%)$ & 70 \\
$\begin{array}{c}\text { Segunda } \\
\text { Consulta }\end{array}$ & $14(21 \%)$ & $31(46 \%)$ & $2(3 \%)$ & $21(31 \%)$ & 68 \\
$\begin{array}{c}\text { Terceira } \\
\text { Consulta }\end{array}$ & $17(27 \%)$ & $21(33 \%)$ & $3(5 \%)$ & $22(35 \%)$ & 63 \\
\hline
\end{tabular}

* Sem diagnóstico de cefaléia primária prévia à cirurgia

As estimativas e intervalos de confiança (95\%) para o coeficiente Kappa, apresentados na Tabela 15, indicam pouca evidência de concordância entre o lado da cefaléia pré-operatória e o lado da cefaléia em cada uma das quatro avaliações, sugerindo lateralidade da cefaléia no período pré-operatório diferente do período pós-operatório. 
Tabela 15 - Estimativa e intervalo de confiança com 95\% de confiança para o coeficiente Kappa de concordância entre o lado da cefaléia pré-operatória e o lado da cefaléia nas três consultas

\begin{tabular}{lcc}
\hline & $\begin{array}{c}\text { COEFICIENTE } \\
\text { KAPPA }\end{array}$ & IC (95\%) DO COEFICIENTE \\
& 0,01 & KAPPA \\
\hline Retirada de pontos & 0,02 & {$[-0,31 ; 0,32]$} \\
$1^{\text {a }}$ Consulta & 0,05 & {$[-0,25 ; 0,30]$} \\
$2^{\text {a Consulta }}$ & 0,12 & {$[-0,23 ; 0,32]$} \\
$3^{\text {a }}$ Consulta & {$[-0,14 ; 0,39]$} \\
\hline
\end{tabular}

Na Tabela 16 apresentamos os níveis descritivos (valores de p) dos testes de homogeneidade marginal entre as distribuições do lado da cefaléia pré-operatória e as distribuições do lado da cefaléia nas três consultas e na retirada de pontos, além da homogeneidade entre as distribuições do lado da cefaléia em consultas sucessivas. Os testes apresentados não incluem os pacientes que não completaram o período total de acompanhamento. Os resultados indicam que não há evidência de homogeneidade entre a distribuição de pacientes por lado da cefaléia pré-operatória e a distribuição de pacientes por lado da cefaléia pós-operatória. Isto se deve possivelmente à diminuição das cefaléias bilaterais e ao aumento das cefaléias do mesmo lado que a cirurgia (Tabela 14). A distribuição de pacientes por lado da cefaléia foi equivalente entre consultas pós-operatórias sucessivas, como podemos observar na Tabela 14. Os testes que compararam a distribuição de pacientes por lado da cefaléia na retirada de pontos com a distribuição de pacientes por lado da cefaléia em outras avaliações e que comparam a distribuição de pacientes por lado da cefaléia entre todas as avaliações, não puderam ser realizados, pois, na retirada de pontos, não houve pacientes na categoria "lado diferente". 
Tabela 16 - Testes de homogeneidade marginal para a distribuição do lado da cefaléia entre os diversos momentos de avaliação

TESTE DE HOMOGENEIDADE MARGINAL ENTRE

NÍVEL DESCRITIVO

(p)

Lado da cefaléia no Pré-operatório e o

(p)

Lado da cefaléia na Retirada de pontos

Lado da cefaléia no Pré-operatório e o $<0,01$

Lado da cefaléia na $1^{\mathrm{a}}$ consulta

Lado da cefaléia no Pré-operatório e o $<0,01$

Lado da cefaléia na $2^{\mathrm{a}}$ consulta

Lado da cefaléia no Pré-operatório e o $<0,01$

Lado da cefaléia na $3^{\text {a }}$ consulta

Lado da cefaléia na Retirada de pontos e o Lado da * *

cefaléia na $1^{\mathrm{a}}$ consulta

Lado da cefaléia na $1^{\mathrm{a}}$ consulta e o $\quad 0,56$

Lado da cefaléia na $2^{\mathrm{a}}$ consulta

Lado da cefaléia na $2^{\mathrm{a}}$ consulta e o $\quad 0,54$

Lado da cefaléia na $3^{\mathrm{a}}$ consulta

\subsubsection{Local da cefaléia}

A Tabela 17 mostra a distribuição segundo o local da cefaléia nos períodos pré-operatório e pós-operatório (retirada de pontos, $1^{\mathrm{a}}, 2^{\mathrm{a}}$ e $3^{\mathrm{a}}$ consultas). Observamos que, na avaliação pré-operatória, $4 \%$ dos pacientes apresentavam dor no mesmo local em que seria feita a cirurgia, enquanto que nas avaliações pósoperatórias, de 27 a $32 \%$ dos pacientes apresentaram dor no local da cirurgia. Isto sugere possível influência da cirurgia na evolução do local da cefaléia. 
Tabela 17 - Distribuição do local da cefaléia nos períodos pré-operatório e pósoperatório $\left(1^{\mathrm{a}}, 2^{\mathrm{a}}\right.$ e $3^{\mathrm{a}}$ consultas $)$

\begin{tabular}{ccccc}
\hline PERÍODO & DIFERENTE & IGUAL & $\begin{array}{c}\text { SEM } \\
\text { CEFALÉIA }\end{array}$ & TOTAL \\
\hline Pré-operatório & $65(82 \%)$ & $3(4 \%)$ & $11(14 \%)^{*}$ & 79 \\
Retirada de pontos & $34(43 \%)$ & $21(27 \%)$ & $24(30 \%)$ & 79 \\
Primeira Consulta & $32(41 \%)$ & $25(32 \%)$ & $21(27 \%)$ & 78 \\
Segunda Consulta & $28(37 \%)$ & $21(28 \%)$ & $27(36 \%)$ & 76 \\
Terceira Consulta & $26(37 \%)$ & $19(27 \%)$ & $26(37 \%)$ & 71 \\
\hline
\end{tabular}

* Sem diagnóstico de cefaléia primária prévia à cirurgia

As estimativas e intervalos de confiança (95\%) para o coeficiente Kappa, apresentados na Tabela 18, indicam pouca evidência de concordância entre os locais das cefaléias pré-operatórias e os locais das cefaléias em cada uma das quatro avaliações feitas após a cirurgia, sugerindo localização das cefaléias diferentes no pós-operatório em relação ao pré-operatório.

Tabela 18 - Estimativa e intervalo de confiança com 95\% de confiança para o coeficiente Kappa para a concordância entre o local da cefaléia préoperatória e o local da cefaléia na retirada de pontos e nas três consultas

\begin{tabular}{lcc}
\hline & $\begin{array}{c}\text { COEFICIENTE } \\
\text { KAPPA }\end{array}$ & $\begin{array}{c}\text { IC (95\%) DO COEFICIENTE } \\
\text { KAPPA }\end{array}$ \\
\hline Retirada de pontos & 0,00 & {$[-0,40 ; 0,40]$} \\
$1^{\text {a Consulta }}$ & $-0,02$ & {$[-0,41 ; 0,37]$} \\
$2^{\text {a Consulta }}$ & 0,10 & {$[-0,26 ; 0,45]$} \\
$3^{\text {a Consulta }}$ & 0,20 & {$[-0,12 ; 0,52]$} \\
\hline
\end{tabular}

A Tabela 19 mostra os níveis descritivos (valores de p) do teste de homogeneidade marginal entre o local da cefaléia pré-operatória e o local da cefaléia nas 3 consultas e na retirada de pontos, além da homogeneidade entre as distribuições do local da cefaléia em consultas sucessivas e da homogeneidade das 
distribuições do local da cefaléia entre todas as avaliações. Os testes apresentados não incluem os pacientes que não completaram o período total de acompanhamento do estudo. Os resultados da análise estatística mostram que não houve evidência de homogeneidade entre a distribuição de pacientes por local da cefaléia pré-operatória e a distribuição de pacientes por local da cefaléia no período pós-operatório, porém a distribuição de pacientes por local da cefaléia é equivalente entre avaliações pósoperatórias sucessivas. Estes resultados podem ser explicados pelo fato de que pacientes que no pré-operatório tiveram cefaléia em local diferente da cirurgia, apresentaram cefaléia no mesmo local da cirurgia no pós-operatório (Tabela 17).

Tabela 19 - Testes de homogeneidade marginal para a distribuição do local da cefaléia entre os diversos momentos de avaliação

TESTE DE HOMOGENEIDADE MARGINAL ENTRE

NÍVEL DESCRITIVO

\begin{tabular}{lc}
\hline Local da cefaléia em todas as avaliações & $(\mathrm{p})$ \\
\hline $\begin{array}{l}\text { Local da cefaléia no Pré-operatório e o } \\
\text { Local da cefaléia na Retirada de pontos }\end{array}$ & $<0,01$ \\
Local da cefaléia no Pré-operatório e o & $<0,01$ \\
Local da cefaléia na $1^{\mathrm{a}}$ consulta & $<0,01$ \\
Local da cefaléia no Pré-operatório e o & \\
Local da cefaléia na $2^{\mathrm{a}}$ consulta & $<0,01$ \\
Local da cefaléia no Pré-operatório e o & \\
Local da cefaléia na $3^{\mathrm{a}}$ consulta & 0,83 \\
Local da cefaléia na Retirada de pontos e o Local da \\
cefaléia na $1^{\mathrm{a}}$ consulta
\end{tabular}




\subsubsection{Intensidade da dor: análise do questionário McGill}

A análise multivariada do número total de descritores marcados no questionário de dor McGill mostrou que a intensidade da dor foi maior nos pacientes do sexo feminino.

A análise multivariada do índice total de dor do questionário de dor McGill mostrou uma correlação positiva entre a intensidade da dor e a intensidade dos sintomas ansiosos e que a intensidade da dor é maior nos pacientes com cirurgia por acesso frontal ou fronto-órbito-zigomático.

\subsection{Disfunção temporomandibular e presença de cefaléia após a}

\section{craniotomia}

Setenta e um pacientes foram avaliados pela odontologia, dos quais $26,8 \%$ referiram ruídos na articulação temporomandibular (ATM) e 9,9\% referiram ranger dos dentes.

Em relação às queixas de dor e suas localizações relatadas durante a avaliação odontológica, $28,2 \%$ relataram dor craniana, $14,1 \%$ relataram dor facial e 5,6\%, dor craniofacial. Vinte pacientes $(28,2 \%)$ relataram que a dor era desencadeada por atividades mandibulares rotineiras: $21,1 \%$ ao mastigar, $7,0 \%$ ao bocejar, $7,0 \%$ ao falar e $7,0 \%$ ao sorrir. Quinze pacientes $(21,1 \%)$ pacientes relataram que sua dor piorava por atividades mandibulares rotineiras. Ao exame físico, verificou-se crepitação na ATM em 9,9\% dos pacientes, estalos na ATM em 16,9\% e 54,9\% apresentaram dor desencadeada pelo exame da motilidade mandibular.

Dos 71 pacientes submetidos à avaliação odontológica, 42 pacientes $(59,2 \%)$ apresentaram síndrome da disfunção e dor temporomandibular (DTM). Não houve 
relação entre o tipo (teste de $\chi^{2}-\mathrm{p}=0,06$ ) ou número de cirurgias (teste exato de Fisher $-\mathrm{p}=0,61)$ com a presença de DTM.

A Tabela 20 mostrou que aqueles que se submeteram a craniotomia do lado direito ou dos dois lados apresentaram número significativamente maior de pontos dolorosos no músculo temporal direito do que os que realizaram cirurgia do lado esquerdo (teste Dunn $-\mathrm{p}<0,05$ ).

A Tabela 21 mostra a relação entre a presença de cefaléia do quarto ao sexto mês após a cirurgia e o diagnóstico de DTM. Houve uma associação estatisticamente significativa entre a presença de cefaléia no segundo trimestre após a cirurgia e a presença de DTM (teste de $\left.\chi^{2}-\mathrm{p}<0,02\right)$.

Tabela 20 - Relação do lado da cirurgia com o número de pontos dolorosos no músculo temporal

\begin{tabular}{|c|c|c|c|c|}
\hline MÚSCULO & \multicolumn{3}{|c|}{ NÚMERO DE PONTOS DOLOROSOS } & KW \\
\hline \multirow[t]{3}{*}{ TEMPORAL } & \multicolumn{3}{|c|}{ POR LADO DA CIRURGIA } & (Valor de p) \\
\hline & Dos dois lados & Direito & Esquerdo & \\
\hline & $(n=7)$ & $(\mathrm{n}=35)$ & $(n=29)$ & \\
\hline Esquerdo & $1,86 \pm 1,67$ & $1,26 \pm 1,31$ & $2,0 \pm 1,43$ & $<0,12$ \\
\hline Direito* & $1,86 \pm 1,35$ & $2,03 \pm 1,65$ & $0,83 \pm 1,28$ & $<0,01$ \\
\hline
\end{tabular}

* Teste Dunn, $\mathrm{p}<0,05$ 
Tabela 21 - Correlações entre presença de cefaléia do quarto ao sexto mês após a cirurgia e a presença de síndrome da disfunção e dor temporomandibular

\begin{tabular}{|c|c|c|c|c|}
\hline & & SÍNDR & IE DA & TOTAL \\
\hline & & DISFUNC & O E DOR & \\
\hline & & TEMPORO & DIBULAR & \\
\hline & & Sim & Não & \\
\hline Droconcodo & $\operatorname{Sim}$ & $32(69,6 \%)$ & $14(30,4 \%)$ & 46 \\
\hline Cefaléia & & $9(39,1 \%)$ & $14(60,9 \%)$ & 23 \\
\hline TO & & 41 & 28 & 69 \\
\hline
\end{tabular}

\subsection{Qualidade de vida}

A Tabela 22 mostra que os escores do SF-36 encontrados neste estudo são significativamente menores em todos os domínios, quando comparados com os valores encontrados na população geral, em estudo realizado na cidade de Montes Claros-SP ${ }^{160}$.

A Tabela 23 mostra que não foi encontrada diferença estatisticamente significativa nos escores de dor do SF-36 quando comparamos nossos pacientes com estudo realizado com pacientes operados por neurinoma do nervo acústico ${ }^{13}$. 
Tabela 22 - Comparação entre os escores do SF-36 de população urbana brasileira ${ }^{160}$ e os encontrados neste estudo

\begin{tabular}{lcc}
\hline \multicolumn{1}{c}{ DOMÍNIOS DO SF-36 } & POPULAÇÃO GERAL & ESTE ESTUDO \\
\hline & média & média \\
Capacidade Funcional & $83^{*}$ & 66,4 \\
Aspectos Físicos & $87^{*}$ & 47,0 \\
Dor & $73^{*}$ & 64,9 \\
Estado Geral de Saúde & $75^{*}$ & 66,0 \\
Vitalidade & $70^{*}$ & 59,1 \\
Aspectos Sociais & $84^{*}$ & 69,4 \\
Aspectos Emocionais & $86^{*}$ & 53,1 \\
Saúde Mental & $73^{*}$ & 60,2 \\
\hline
\end{tabular}

* p<0,05 (teste t de uma média com desvio-padrão populacional desconhecido)

Tabela 23 - Comparação entre os escores do SF-36 neste estudo com cirurgia de fossa posterior para tratamento de neurinoma do acústico ${ }^{13}$

\begin{tabular}{lcc}
\hline \multicolumn{1}{c}{ DOMÍNIOS DO } & PACIENTES OPERADOS & PACIENTES OPERADOS \\
SF-36 & POR ANEURISMAS & POR NEURINOMA DO \\
& CEREBRAIS & NERVO ACÚSTICO \\
\hline Capacidade Funcional & 66,4 & média \\
Aspectos Físicos & 47,0 & $82,5^{*}$ \\
Dor & 64,9 & $71,7^{*}$ \\
Estado Geral de Saúde & 66,0 & 60,5 \\
Vitalidade & 59,1 & $71,3^{*}$ \\
Aspectos Sociais & 69,4 & 63,8 \\
Aspectos Emocionais & 53,1 & $79,8^{*}$ \\
Saúde Mental & 60,2 & $73,9^{*}$ \\
\hline
\end{tabular}

$* \mathrm{p}<0,05$ (teste t de uma média com desvio-padrão populacional desconhecido) 
A análise multivariada da associação do domínio dor do SF-36 e um conjunto de variáveis mostrou que os sintomas ansiosos e tipo de cirurgia foram importantes para explicar os escores deste domínio. Quanto maiores os escores de ansiedade da escala HAD na $2^{\mathrm{a}}$ consulta, menor o domínio dor. Os pacientes que se submeteram à cirurgia por acesso frontal também tiveram menores escores neste domínio.

A análise multivariada da associação dos escores dos domínios do SF-36 em relação à frequiência de cefaléia, ansiedade e depressão mostrou que a capacidade funcional, vitalidade e saúde mental correlacionaram-se negativamente com os escores de depressão e ansiedade. Os domínios aspectos físicos, estado geral de saúde e aspectos emocionais correlacionam-se negativamente com os escores de depressão. Os domínios dor e aspectos sociais correlacionam-se negativamente com a frequiência de cefaléia no mês anterior à aplicação do questionário e com os escores de depressão.

\subsection{Cefaléia pós-craniotomia segundo a classificação da IHS}

Dos 79 pacientes estudados, 91,1\% apresentaram cefaléia em algum momento após a cirurgia. Apesar de termos perdido oito pacientes neste estudo, para esta análise consideramos sete perdas, já que um paciente nos enviou posteriormente seu diário de cefaléia pelo correio e pôde ser incluído. Estas perdas ocorreram nos seguintes momentos: uma, 15 dias após a cirurgia, uma, após 1 mês, três, após 3 meses e duas, após 4 meses. Para efeito da classificação global, três dessas perdas não foram importantes, pois dois desses pacientes já haviam preenchido critério para cefaléia pós-craniotomia (CPC) e um teve cefaléia com mais de sete dias após a cirurgia. Desse modo, consideramos 75 pacientes para análise. Encontramos 
incidência de 40\% CPC. Quarenta e quatro pacientes apresentaram dor no local da craniotomia em algum momento do seguimento. Se aumentarmos o critério de tempo de início da cefaléia para 14 dias, encontraremos incidência de CPC de 46,7\% (35/75). Se tivéssemos utilizado 30 dias como critério, a incidência de CPC subiria para $54,7 \%(41 / 75)$ e $93,2 \%(41 / 44)$ daqueles que apresentaram cefaléia apenas no local da craniotomia seriam incluídos.

Para a análise da classificação da forma aguda e crônica, foram incluídos 73 pacientes, já que um paciente teve cefaléia com mais de sete dias após a cirurgia e foi incluído na análise. Encontramos uma incidência de 11,0\% da forma aguda e 30,2\% da forma crônica.

Nenhuma das variáveis utilizadas no modelo de regressão logística mostrouse importante para explicar o preenchimento dos critérios diagnósticos para cefaléia pós-craniotomia pela IHS. 


\section{6 - DISCUSSÃO}

\subsection{Limitações do estudo}

Esse estudo foi do tipo coorte prospectivo em que a inclusão dos pacientes foi baseada na exposição (craniotomia) e o desfecho (cefaléia pós-craniotomia) ainda não havia ocorrido na época do início do estudo.

Nesse tipo de estudo, a principal fonte de viés é a perda de pacientes durante o seguimento. O viés ocorre quando a causa da perda relaciona-se com a exposição ou com o desfecho ${ }^{161}$. Por exemplo, se os pacientes não comparecerem às avaliações por terem melhorado da cefaléia. Por esse motivo é importante tentar conhecer a razão das perdas.

Em nosso estudo, perdemos oito pacientes $(10,1 \%)$. Três desses pacientes não retornaram por haverem se mudado do Estado de São Paulo por motivos pessoais, que não estavam relacionados à cefaléia. Nos outros casos, não conseguimos identificar as causas da perda de acompanhamento. Consideramos que essas perdas não esclarecidas (em torno de 6\%) não comprometeram nossa investigação.

A aplicação dos questionários SF-36 e McGill, feita concomitantemente na segunda consulta, apresentou três perdas $(3,8 \%)$. A avaliação odontológica, feita em média 162 dias após a cirurgia, apresentou oito perdas (10,1\%), sendo dois pacientes por terem mudado de endereço. Consideramos que estas perdas não comprometeram a validade do estudo.

Optamos por aplicar os questionários SF-36 e McGill em um único momento para não tornar as avaliações muito demoradas e cansativas para o paciente, possibilitando assim uma maior adesão e confiabilidade à avaliação. Isto 
impossibilitou analisar se houve qualquer mudança temporal na qualidade de vida e na intensidade da dor com o transcorrer do tempo. Esses questionários foram aplicados na $2^{\mathrm{a}}$ consulta por imaginarmos que, nesse momento, essas medidas expressariam o efeito da cefaléia pós-craniotomia e não a cefaléia consequiente à hemorragia subaracnóidea.

Os pacientes foram avaliados dentro do período esperado, com exceção na última avaliação que ocorreu num tempo maior que o planejado.

A maioria das craniotomias realizadas foram pterionais. Consideramos a possibilidade de incluir apenas estas na análise. Isso não foi realizado considerandose que o objetivo do trabalho era avaliar a cefaléia pós-craniotomia globalmente e não os diferentes padrões evolutivos da cefaléia pós-craniotomia em relação às diferentes vias de acesso utilizadas. Portanto, resolvemos incluir todas as craniotomias realizadas, já que a classificação da IHS ${ }^{1}$, não considera importante a distinção entre os vários tipos de craniotomias. Além disso, o conhecimento cientifico sobre o tema encontra-se numa fase inicial de caracterização. Com a evolução do conhecimento, análises setoriais da avaliação da dor pós-operatória nas várias vias de acesso podem eventualmente auxiliar os neurocirurgiões quanto às melhores opções de acesso.

As craniotomias realizadas para o tratamento de aneurismas foram escolhidas por serem procedimentos utilizados para tratar patologias não progressivas, já que os aneurismas são considerados curados após tratamento cirúrgico bem sucedido. Tínhamos consciência de que esta escolha apresentava como fator de confusão o fato da HSA poder ser a causadora da cefaléia. 
A cefaléia causada pela HSA tem, por definição, uma duração limitada de 30 dias ${ }^{1}$. A mediana do intervalo de tempo entre a HSA e a avaliação pré-operatória foi de oito dias e entre esta e a cirurgia, foi de quatro dias. Este intervalo pode ter minimizado o efeito do sangramento sobre a cefaléia apresentada após a cirurgia. Tentamos controlar esse efeito do sangramento nas análises feitas. O efeito do sangramento, como esperado, ocorreu numa fase inicial, no tempo de início da cefaléia no pós-operatório.

\subsection{Freqüência da cefaléia}

Existem poucas referências sobre o comportamento da freqüência da cefaléia após neurocirurgias na literatura. Rigby et al. observaram aumento da frequiência de cefaléia depois da cirurgia. Os pacientes que participaram desse trabalho o fizeram em média 39 meses após a cirurgia ${ }^{12}$. Segundo Martin et al., a frequiência da cefaléia não varia significativamente com o tempo após a cirurgia. Entretanto, esse estudo não foi feito com o objetivo de investigar a cefaléia, e o tempo médio entre a cirurgia e a aplicação do questionário foi de 18 meses ${ }^{79}$. Nenhum dos dois estudos utilizou diários de cefaléia.

Até onde temos conhecimento, este é o primeiro estudo prospectivo que utilizou diários para avaliar o comportamento da frequiência da cefaléia após um procedimento neurocirúrgico. Procuramos controlar a freqüência da cefaléia primária prévia e a HSA na análise estatística realizada. Consideramos estas duas variáveis como os principais fatores de confusão. 
Não encontramos diferença estatisticamente significativa na freqüência de cefaléia entre os pacientes que apresentaram, comparados com os que não apresentaram HSA, em nenhum momento do acompanhamento.

A freqüência da cefaléia prévia foi estimada pelo paciente e não verificada através de diários. Não houve outra solução possível, já que a HSA é uma condição aguda, de maneira que os pacientes só puderam ser avaliados pouco tempo antes da cirurgia. Não nos parece que ter procedido desta maneira tenha levado a um viés de memória. Isto poderia ter ocorrido pelo fato de que alguns pacientes vinham em curso de uma doença séria (HSA) e outros não. Entretanto, a freqüência prévia foi homogênea entre os grupos.

A análise descritiva dos perfis médios da freqüência revelou que ocorre um aumento na frequiência da cefaléia após a cirurgia, com posterior diminuição com o transcorrer do tempo. Este foi o comportamento encontrado nos pacientes:

- de ambos os sexos;

- com cefaléia primária pré-operatória e com cefaléia nos três meses anteriores à avaliação pré-operatória;

- sem cefaléia pré-operatória;

- submetidos a uma cirurgia

- submetidos aos três tipos de craniotomia (pterionais, fronto-órbitozigomáticas, frontais).

O pequeno número de pacientes e o fato da segunda cirurgia ter sido realizada em diferentes intervalos de tempo após a primeira dificultaram a identificação de uma tendência no grupo com duas cirurgias. 
Quando a frequiência de cefaléia do trimestre anterior à cirurgia foi comparada com os primeiros três meses após a cirurgia, verificamos um aumento da freqüência (mediana=1; média=14 dias). Essa diferença entre média e mediana ocorreu porque alguns pacientes tiveram um aumento muito acentuado da freqüência, aumentando assim a média.

Acreditamos que se houve um viés, este ocorreu no sentido de subestimar o aumento encontrado no primeiro trimestre. Isto pode ter ocorrido porque o diário só foi entregue na retirada de pontos, em média 14 dias após a cirurgia. Se nos primeiros dias após a cirurgia a frequiência da cefaléia seguiu a tendência apresentada durante todo o seguimento, esta provavelmente, foi maior no período pós-operatório precoce.

Decidimos só entregar o diário na retirada de pontos com a finalidade de diminuir a influência da HSA na avaliação da freqüência da cefaléia. Consideramos que esta influência ocorreria apenas na fase aguda. Isto pode explicar o fato dos pacientes com cefaléia causada pela HSA na avaliação pré-operatória terem tido cefaléia pós-operatória de início mais precoce e não terem apresentado diferença no comportamento da freqüência.

Como a freqüência da cefaléia prévia foi estimada, outra possibilidade que pode ter levado a uma diminuição desta diferença entre as freqüências do trimestre anterior e do trimestre posterior à cirurgia é se os pacientes tivessem superestimado a freqüência prévia.

Existem poucos trabalhos que investigam a memória para dor. Em geral, esses estudos foram realizados com o objetivo de avaliar a intensidade e não a freqüência da dor. $\mathrm{Na}$ dor crônica, a intensidade dor passada tende a ser 
superestimada ${ }^{162}$. Se esse comportamento verificado na memória da intensidade também ocorrer no caso da memória para a freqüência da dor, levaria nossos pacientes a referirem freqüências prévias maiores que as reais. Isso nos levaria a ter encontrado um aumento da freqüência da cefaléia após a cirurgia menor que o real.

Quando comparamos a frequiência de cefaléia do trimestre anterior à cirurgia com o segundo trimestre após a mesma, verificamos que, em média, a freqüência da cefaléia foi 6,9 dias maior que a frequiência prévia. No entanto, em metade dos pacientes, essa diferença entre as freqüências foi menor ou igual a zero, ou seja, as freqüências foram iguais ou menores que a freqüência prévia. Nessa situação também pode ter ocorrido uma superestimação da frequiência de cefaléia préoperatória pelos pacientes pelas razões referentes à memória da dor já discutidas anteriormente. Isso pode ter levado a uma diminuição da magnitude dessa diferença. É importante salientar que alguns pacientes permaneceram com uma frequiência de magnitude suficiente para garantir um aumento da média do grupo.

A comparação entre o primeiro e segundo trimestre de pós-operatório forneceu uma informação mais objetiva em relação à frequiência, pois ela foi avaliada através de diários durante todo esse período.

Verificamos que a maioria dos pacientes apresentou uma diminuição da freqüência de cefaléia com o passar do tempo após a cirurgia. Consideramos esta, uma constatação de importância clínica e científica com implicações de natureza prática para a orientação dos pacientes e planejamento em saúde. O conhecimento do comportamento da freqüência de cefaléia pós-craniotomia deve ser levado em conta no desenho de futuros estudos, bem como, nas abordagens terapêuticas a serem utilizadas. 


\subsection{Características da cefaléia pós-craniotomia}

Poucos estudos avaliaram o intervalo de tempo de início da cefaléia que ocorre após uma neurocirurgia. De Benedittis et al. constataram que 59,5\% dos pacientes tiveram dor nos primeiros dias de pós-operatório de neurocirurgias para o tratamento de tumores e doenças vasculares. Como os pacientes só foram seguidos por alguns dias após a cirurgia, não foi possível avaliar se algum paciente tinha dor após este curto período de seguimento ${ }^{68}$.

Outros pesquisadores chamam atenção para o fato de que em 70 a $90 \%$ dos pacientes, a cefaléia inicia-se no pós-operatório imediato de uma neurocirurgia e que

em 10 a $18 \%$ dos casos, estas se iniciam mais de um mês após ${ }^{6}{ }^{70}$. Esta concepção de que, na maioria dos pacientes, a cefaléia inicia-se em estreita relação temporal com a cirurgia, mas que, em uma minoria, ela começa tardiamente, está de acordo com os nossos dados.

Tentamos controlar a influência da cefaléia causada pela HSA na análise estatística. A HSA exerceu influência, no tempo de início da cefaléia pós-cirúrgica, naqueles que apresentavam cefaléia causada pela HSA na avaliação pré-operatória. Nestes, a cefaléia pós-cirúrgica teve um início mais precoce. No entanto, mesmo quando esses pacientes não são levados em consideração, a metade teve início da cefaléia em período de até cinco dias após a cirurgia e em um quarto destes, a cefaléia teve um início mais tardio, em um tempo maior ou igual a 19 dias.

Existem poucas relatos na literatura sobre a intensidade da cefaléia após procedimento neurocirúrgico. Como a maior parte dos estudos são retrospectivos, a intensidade da cefaléia foi medida indiretamente, através da necessidade do uso de medicações para dor, ou da sua repercussão na vida dos pacientes $5,6,12,14,15,83$. 
O índice total de dor ${ }^{106,163}$ e o número total de palavras marcadas no questionário McGill estão relacionados à intensidade da dor ${ }^{106}$. Entretanto, geralmente o índice total de dor é mais sensível para detectar mudanças na intensidade ${ }^{106}$, já tendo sido registrada a relação entre o índice total de dor com a intensidade da cefaléia anotada em diário de cefaléia ${ }^{108}$.

A análise multivariada mostrou que nos pacientes do sexo feminino, considerando-se o número total de palavras marcadas, nos pacientes com mais sintomas ansiosos e nos com craniotomias frontal ou fronto-órbito-zigomática, considerando-se o índice total de dor, houve maior intensidade de dor.

Essa diferença entre a análise do número total de palavras marcadas e o índice total de dor provavelmente ocorreu, porque nos pacientes do sexo feminino, embora tenham registrado um número maior de palavras, estas tinham um valor de intensidade menor (menores escores) que os do sexo masculino, de modo que não houve diferença em relação à intensidade medida pelo índice total de dor. Observamos que as mulheres apresentaram dor mais intensa que os homens, fato este que está de acordo com a literatura ${ }^{164-168}$.

A relação entre ansiedade e intensidade da dor tem sido relatada, tanto em estudos clínicos, quanto experimentais. A ansiedade pode levar a um aumento da percepção da intensidade da dor ${ }^{169-175}$, conforme verificamos em nossos pacientes.

Estudo recente, utilizando a ressonância magnética funcional, demonstrou que a modulação da intensidade da dor produzida pela ansiedade está associada a mudanças na ativação do córtex entorrinal da formação hipocampal ${ }^{169}$.

Esperávamos que a extensão da dissecação tivesse uma relação direta com a intensidade da dor registrada pelos pacientes, sendo maior no acesso fronto-órbito- 
zigomático, seguido pelo pterional e frontal. Entretanto, essa relação entre a extensão da dissecação e a intensidade de dor referida pelos pacientes não foi observada.

Dunbar et al. verificaram que, dentre os pacientes com cirurgia intracraniana e bom nível de consciência, aqueles submetidos a craniotomias frontais apresentaram dor com maior intensidade ${ }^{62}$. Isso está em concordância com os nossos resultados, que mostram que os submetidos à craniotomias frontais e fronto-órbito-zigomáticas têm cefaléia mais intensa que os submetidos a craniotomias pterionais. Já De Benedittis et al. não encontraram associação entre a magnitude da dor e o acesso cirúrgico adotado ${ }^{68}$.

Não podemos afastar a possibilidade de nossos resultados em relação aos pacientes submetidos a craniotomias frontais e fronto-órbito-zigomáticas possam ser devidos a variáveis de confusão não controladas. Essas craniotomias tiveram representação pequena no total das craniotomias realizadas em nosso estudo. A análise do domínio dor do SF-36 revelou que os pacientes com craniotomias frontais têm maior repercussão da dor sobre sua qualidade de vida, o que fala a favor de que o achado em relação à intensidade de dor realmente tenha procedência.

Nosso estudo mostrou que, nem a presença de cefaléia primária previa, nem a presença de HSA, se correlacionou com a intensidade da dor pós-neurocirúrgica.

A comparação entre as características da cefaléia primária pré-existente e da cefaléia que ocorre após a cirurgia é de grande importância, pois a cefaléia póscraniotomia poderia ser apenas uma expressão da cefaléia prévia. A maioria dos estudos encontrados na literatura são retrospectivos, o que dificulta esta comparação. 
De Benedittis et al. observaram que havia semelhança parcial ou total entre a cefaléia prévia e a que ocorreu após a cirurgia em apenas $9,1 \%$ dos casos. No entanto, essa análise foi feita apenas em relação à dor que ocorreu nos primeiros dias de pós-operatório ${ }^{68}$.

Procuramos realizar os diagnósticos das cefaléias primárias apresentadas pelo paciente durante sua vida com dados obtidos antes da cirurgia. As cefaléias póscirúrgicas foram classificadas como se fossem cefaléias primárias, a fim de possibilitar a comparação com as cefaléias prévias. Os pacientes que apresentavam dois tipos de cefaléias pré-operatórias, migranosa e não migranosa, foram excluídos das análises estatísticas, pois nestes casos não haveria possibilidade de mudança no diagnóstico da cefaléia pós-neurocirúrgica. Os pacientes que não completaram todo o período de acompanhamento também foram excluídos da análise estatística para que o grupo permanecesse constante durante toda a análise.

Devemos esclarecer que o aumento dos casos classificados como "sem cefaléia" no pós-operatório, não significa que a cirurgia teve um "efeito positivo" sobre a dor, já que essa categoria no pré-operatório foi classificada como "sem cefaléia na vida" e no pós-operatório, como "sem cefaléia no período entre as avaliações".

Devemos ressaltar que a diminuição da prevalência de cefaléia que ocorreu durante o período de seguimento também foi verificada entre os pacientes que apresentavam cefaléia não migranosa.

Também não seria correto afirmar que os mesmos pacientes que tinham diagnóstico de cefaléia não migranosa permaneceram com esse tipo de cefaléia durante todo o seguimento. Durante as diversas avaliações, as cefaléias apresentadas 
pelos pacientes poderiam mudar de tipo. O importante foi analisar as características do grupo nos diversos momentos, ou seja, não foi realizada a análise longitudinal de um mesmo paciente no transcorrer do tempo e sim do grupo.

Os nossos dados mostraram que houve uma semelhança entre os padrões de cefaléia primária pré-operatória e a apresentada num momento inicial nos grupos estudados entre a cirurgia e a primeira consulta. Após este período houve uma mudança de padrão, provavelmente determinada pela perda das características migranosas.

Não podemos afastar a possibilidade de que as características da cefaléia na primeira consulta tenham sofrido influência da HSA e que as consultas posteriores refletiram melhor as características da cefaléia pós-craniotomia por não estarem mais sujeitas à influência da HSA. Entretanto, a tendência à diminuição das características migranosas já pode ser observada desde a primeira consulta. Isto poderia explicar o fato de outros estudos terem constatado que o padrão mais freqüente de cefaléias apresentadas por pacientes submetidos a craniotomias assemelha-se ao padrão observado na cefaléia tipo tensional ${ }^{6,15,70,71,82}$. Esses estudos foram realizados com dados obtidos depois de um longo período após a realização do procedimento cirúrgico, o que poderia fazer com que as características migranosas da cefaléia já tivessem sido perdidas.

Observamos que o número de pacientes sem dor aumenta com o transcorrer do tempo a partir da cirurgia. Esta constatação está de acordo com a literatura sobre o tema $5,6,9,10,14,15,71,77,82-84,91$. 
A cefaléia que ocorre após neurocirurgias é descrita como ocorrendo, na sua

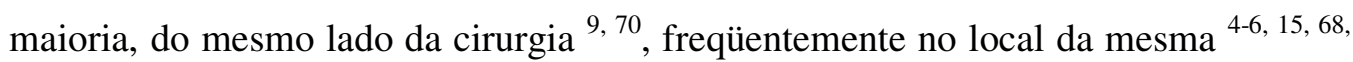
$70,75,82,176$. Isto está de acordo com os nossos resultados.

Um possível fator de confusão pode ter sido a cefaléia causada pela HSA. Esta, ao contrário do que encontramos na cefaléia pós-craniotomia, mais localizada, foi mais difusa, sendo holocraniana em 45,6\% dos casos e, em 92,6\% dos casos, bilateral. Em nenhum dos nossos casos, a cefaléia causada pela HSA ocorreu predominantemente no local da cirurgia. Todos os nossos pacientes conseguiram diferenciar claramente a cefaléia primária prévia da cefaléia causada pela HSA. Se houve influência da cefaléia causada pela HSA sobre os padrões pós-cirúrgicos observados, essa foi no sentido de diminuir as diferenças encontradas, isto é, de tornar a cefaléia que ocorreu após a cirurgia mais difusa.

Nossos dados mostram que houve uma mudança de diagnósticos, lado e local da dor em relação à cefaléia prévia. Houve um aumento dos pacientes que tinham dor do mesmo lado e local da cirurgia. Essas mudanças perduraram por todo o período pós-operatório e são sugestivas de um efeito da cirurgia. Esta comparação entre a cefaléia primária pré-cirúrgica e a cefaléia pós-cirúrgica em relação à lateralidade e local da dor, até onde sabemos, não havia sido previamente relatada em outros estudos.

\subsection{Relação entre freqüência de cefaléia e os sintomas depressivos,} ansiosos e sonolência diurna

Nossa hipótese inicial, quando decidimos incluir uma escala de sonolência neste estudo, era que a cefaléia pós-craniotomia pudesse levar a distúrbios do sono, a 
semelhança do que é observado na síndrome pós-concussional, que ocorre após traumatismos crânio-encefálicos ${ }^{177}$. O fato de 15 a $33 \%$ de pacientes após cirurgias para tratamento no nervo acústico terem referido distúrbios do sono reforçava esta hipótese $^{78,79,178}$.

Não observamos associação entre a frequiência de cefaléia no período póscirúrgico e a intensidade da sonolência diurna em nossos pacientes.

Depressão e ansiedade são doenças prevalentes em pessoas com problemas de saúde ${ }^{128,179}$, inclusive naquelas submetidas a neurocirurgias ${ }^{7,11,78,79,178 .}$

Os escores médios para ansiedade e depressão dos nossos pacientes foram menores que oito em todas as avaliações realizadas. Estes valores são inferiores ao ponto de corte na escala HAD para casos de depressão e ansiedade.

Apesar desses pacientes não serem em média ansiosos ou deprimidos, constatamos existir uma associação entre a freqüência da cefaléia e a intensidade dos sintomas ansiosos e depressivos. Não encontramos, na literatura, estudo que investigue essa associação em pacientes submetidos à neurocirurgia.

Os estudos que investigaram a associação entre freqüência de cefaléias primárias com ansiedade e depressão têm mostrado resultados contraditórios. A maioria dos estudos aponta para uma correlação positiva entre a freqüência de cefaléia e a presença de eventos estressantes ${ }^{180}$, a intensidade da ansiedade e da depressão ${ }^{131,181,182}$, enquanto outros não encontraram esta relação ${ }^{128}$.

Observamos uma a relação positiva entre sintomas depressivos e ansiosos e a frequiência da cefaléia pós-craniotomia, fato esse de grande importância no manejo clínico desses pacientes. O estudo revelou também que a intensidade dos sintomas ansiosos está diretamente relacionada com a intensidade da cefaléia pós-craniotomia 
e com a maior repercussão desta na qualidade de vida. Isto mostra a necessidade de que essas condições sejam devidamente pesquisadas e façam parte das estratégias terapêuticas na abordagem da cefaléia pós-craniotomia.

\section{5 - Qualidade de vida}

Para fins de comparação, utilizamos os resultados de estudo populacional realizado em Montes Claros, no Estado de São Paulo, no qual 3038 indivíduos foram avaliados ${ }^{160}$. Decidimos utilizá-los por considerarmos os valores do SF-36 de tal estudo mais adequado à população brasileira do que os estudos realizados em outros países.

Os nossos pacientes apresentaram pior qualidade de vida em todas as dimensões medidas pelo SF-36 quando comparados à "população geral". Esta diferença foi clínica e estatisticamente significativa. Entretanto, não podemos atribuir esta diferença somente à presença de cefaléia. Outros fatores, tais como a presença de seqüelas, presença de co-morbidades psiquiátricas, presença de doença neurológica séria (HSA), possivelmente também estão envolvidos.

Quando levamos em consideração somente a dimensão dor, que avalia a presença e repercussão da dor na vida do paciente, ela foi clínica e estatisticamente menor (pior) que a da população de referência. Isto mostra que realmente os pacientes do nosso estudo apresentaram uma maior repercussão da dor em relação a sua qualidade de vida.

A literatura referente à cefaléia pós-craniotomia sugere que aqueles pacientes submetidos a craniotomias para o tratamento de lesões infratentoriais apresentam 
maior incidência de cefaléia do que aqueles submetidos a craniotomias supratentorias.

Existem poucos estudos que levam em consideração a qualidade de vida em pacientes com cirurgias infratentoriais e nenhum, em cirurgias supratentoriais. Dois estudos utilizaram o SF-36 na avaliação de pacientes operados por neurinoma do nervo acústico. Martin et al. ${ }^{79}$ não encontraram diferença na dimensão dor entre os pacientes operados e a população geral. Entretanto, o questionário foi respondido num tempo superior ao nosso (média, 18 meses após a cirurgia) e, como observamos em nosso estudo, a prevalência da cefaléia pós-craniotomia tende a diminuir com o tempo. Não pudemos comparar os nossos resultados com os desses autores, pois os mesmos não forneceram as médias do SF-36. Betchen et al. ${ }^{13}$ encontraram escores menores na dimensão dor em relação à população geral, o que está de acordo com os nossos resultados. Quando comparamos os valores da dimensão dor encontrados por Betchen et al. com os nossos, não encontramos diferenças nem clínica, nem estatisticamente significativas. Os pacientes foram avaliados por aqueles autores pelo menos seis meses após a cirurgia, o que prejudica a comparação.

A análise multivariada revelou que os pacientes mais ansiosos e aqueles submetidos a cirurgias através do acesso frontal apresentaram maior repercussão da dor. Esperávamos que os outros tipos de craniotomia causassem mais dor por implicarem numa maior manipulação e dissecação da musculatura e que, portanto, tivessem maior repercussão na vida dos indivíduos. Devemos salientar que dos 79 pacientes acompanhados, apenas quatro realizaram craniotomias frontais, podendo esta diferença ser devida à outra variável não controlada. O fato desses pacientes com craniotomias frontais terem apresentado cefaléia mais intensa que os com 
craniotomias pterionais fala a favor de que esta diferença na qualidade de vida realmente corresponda à realidade.

A ansiedade pode diminuir os escores das oito dimensões do SF-36 ${ }^{183}$. A preocupação de alguns desses pacientes de que a cefaléia pós-cirúrgica pudesse representar um sinal de perigo para a ocorrência de um novo sangramento foi claramente perceptível durante o acompanhamento, apesar de não termos um registro sistemático do fato. Essa preocupação provavelmente não ocorreu de maneira homogênea entre os que apresentaram ruptura do aneurisma, já que a análise multivariada não demonstrou que a HSA fosse uma variável importante para influir na repercussão da dor. Devemos considerar a possibilidade que essa preocupação tenha gerado ansiedade em alguns, conseqüentemente, levado a uma maior repercussão da cefaléia.

Idade, sexo, as variáveis referentes à cefaléia primária prévia (diagnóstico e presença nos últimos três meses), a presença de HSA, número de cirurgias, a presença de seqüelas, DTM e depressão não foram importantes em relação à dimensão dor. Outros estudos com pacientes submetidos à craniotomia também não encontraram relação entre a dimensão dor e a idade dos pacientes ${ }^{13,79}$.

Embora estudos do SF-36 na população geral mostrem que as mulheres, em geral, têm piores escores de qualidade de vida do que os homens, inclusive na dimensão dor ${ }^{184,}{ }^{185}$, os estudos feitos após craniotomia mostram resultados conflitantes quanto ao sexo nesta dimensão ${ }^{13,79}$.

Com a finalidade de avaliar a repercussão da cefaléia nas outras dimensões da qualidade de vida, utilizamos a freqüência de cefaléia medida através de diários no mês anterior à aplicação do SF-36. Utilizamos o mês anterior porque as perguntas 
feitas para avaliar as oito dimensões de qualidade de vida também se referem a esse mês. Não temos conhecimento de estudos que tenham realizado este tipo de avaliação em pacientes submetidos a craniotomias.

A análise da freqüência de cefaléia dos nossos pacientes mostrou que a mesma está associada a sintomas depressivos e ansiosos. Depressão e ansiedade são doenças que repercutem na qualidade de vida do indivíduo ${ }^{143}{ }^{183}$, portanto, essas variáveis foram controladas na análise multivariada. Os resultados mostraram que a freqüência de cefaléia foi responsável por pior qualidade de vida nas dimensões dor e aspectos sociais. Pode-se depreender que, quanto maior a freqüência de cefaléias, maior foi a repercussão da dor na vida dos pacientes e maior a interferência nas suas atividades sociais cotidianas. Do mesmo modo que os nossos pacientes, aqueles com cefaléias primárias podem ter menores escores nas dimensões dor e aspectos sociais do SF-36 ${ }^{136,138-144,147}$.

Uma informação indireta sobre a repercussão da frequiência da cefaléia na qualidade de vida encontra-se na comparação entre as cefaléias primárias episódicas e crônicas diárias. Em investigações feitas em clínicas especializadas, constata-se que as cefaléias crônicas levam a uma pior qualidade de vida ${ }^{147}$ 148-150 . Esses estudos avaliam os casos mais graves e não controlaram as morbidades associadas psiquiátricas, dificultando uma generalização.

Não encontramos nenhum estudo na literatura compilada que faça referência à relação da freqüência da cefaléia e qualidade de vida de pessoas com cefaléia ocorrida após neurocirurgias. 


\section{6 - Disfunção temporomandibular e presença de cefaléia após a craniotomia}

O fato de não termos investigado a presença de DTM antes da cirurgia nos impede de afirmar que esta foi uma conseqüência do ato cirúrgico. A presença de ruídos articulares e o histórico de ranger de dentes nesses pacientes nos sugerem a possibilidade que alguns deles poderiam ter tido DTM previamente.

Estudo anterior realizado com pacientes submetidos à craniotomia pterional mostrou que a presença de dor mastigatória e limitação dos movimentos mandibulares podem ser causadas por esta craniotomia. Essas alterações diminuem com o transcorrer do tempo, porém persistindo em alguns após 180 dias ${ }^{104}$. Sabe-se que as lesões decorrentes do traumatismo cirúrgico podem causar cicatrizes, isquemia e hiperalgesia ${ }^{186}$. As lesões do músculo temporal, conseqüentes ao trauma cirúrgico, podem ter contribuído para as anormalidades funcionais da mandíbula no pós-operatório desses doentes. Nosso estudo mostra que aqueles que se submeteram à craniotomia do lado direito ou dos dois lados apresentaram significativamente maior número de pontos dolorosos à palpação do músculo temporal direito do que os que realizaram cirurgia do lado esquerdo. Isso sugere uma correlação entre a abordagem cirúrgica no desencadeamento de disfunção temporomandibular, já que este músculo precisa ser dissecado durante as craniotomias pterionais e fronto-órbitozigomáticas. Não encontramos os mesmos achados em relação ao músculo temporal esquerdo. Isso pode ter ocorrido pelo fato de que a avaliação foi realizada em média após 5 meses da cirurgia, já que essas alterações diminuem com o tempo.

A presença de dor associada a atividades da mandíbula sugere envolvimento dos músculos da mastigação, pelo menos em parte dos pacientes com cefaléia pós- 
craniotomia. Desta forma, é necessário que o neurologista considere também doenças funcionais do aparelho mastigatório no diagnóstico diferencial desses pacientes. A classificação da IHS reconhece as disfunções da articulação temporomandibular como causas de cefaléia e dor na face. No entanto, este diagnóstico só pode ser feito retrospectivamente, pois é necessário que esses distúrbios sejam tratados e que a cefaléia desapareça em até três meses após o tratamento ${ }^{1}$. Dessa maneira, esse diagnóstico não pôde ser feito neste estudo.

A avaliação odontológica era cega em relação aos resultados do acompanhamento relativo à cefaléia. Assim, tentamos evitar que ocorresse viés de classificação.

A associação que foi constatada entre a cefaléia e DTM no segundo trimestre, seja ela prévia ou causada pela cirurgia, sugere que o envolvimento dos músculos da mastigação possa agir como fator perpetuante da dor. Pela literatura consultada, provavelmente este é o primeiro estudo que avalia a associação entre cefaléia póscraniotomia e disfunções temporomandibulares, embora estudo anterior descrevesse o envolvimento da abordagem cirúrgica pterional com anormalidade funcional da mandíbula ${ }^{104}$. Consideramos ser essa associação de importância clínica e sugerimos que a associação entre a cefaléia e os movimentos mandibulares deva ser sempre questionada na anamnese desses pacientes e que a presença de DTM deva ser sempre pesquisada e tratada nos pacientes com cefaléia pós-craniotomia.

Estudos prospectivos com modelos adequados são necessários para avaliar melhor a incidência e evolução de DTM pós-craniotomia e a sua associação com a cefaléia pós-craniotomia. 


\subsection{Cefaléia pós-craniotomia segundo classificação da IHS}

Até onde sabemos, este é o primeiro trabalho que tenta estabelecer a incidência de cefaléia pós-craniotomia (CPC) tomando como base a classificação da IHS. No entanto, quando essa classificação foi publicada, nosso trabalho já estava em andamento. Por este motivo, em vez de utilizarmos como preconiza a classificação “intensidade máxima na área da craniotomia", utilizamos "dor apenas no local da craniotomia".

Encontramos incidência de CPC de $40 \%$. Esta incidência pode ter sido subestimada, já que em 60,8\%, a cefaléia ocorre dentro de sete dias após a craniotomia, preenchendo o critério temporal da classificação. Se retirarmos os pacientes em que a cefaléia não passa pelo local da craniotomia, a incidência cai para $58,2 \%$, ou seja, a maior incidência que poderíamos chegar, se todos estes pacientes tivessem referido intensidade máxima na área da craniotomia.

Se forem considerados apenas os pacientes que apresentaram congruência total entre o local da dor e o sítio cirúrgico, mesmo critério adotado neste trabalho, De Benedittis et al. teriam uma incidência de CPC de 40,5\%, valores próximos aos nossos. Se forem considerados os pacientes que apresentaram congruência total ou parcial entre a dor e o sítio cirúrgico, a incidência estaria em torno de 51\%. Contudo, estes autores acompanharam os pacientes por um período menor que sete dias após a cirurgia ${ }^{68}$. Nguyen et al., teriam encontrado uma incidência de 80 a $86 \%$. No entanto, estes pacientes foram seguidos por apenas 48 horas após a cirurgia ${ }^{176}$.

As análises multivariadas do McGill e SF-36 demonstraram que preencher ou não critérios para CPC não é importante para explicar variação dos escores dessas escalas, ou seja, não se encontrou diferença em relação à intensidade da dor ou à 
qualidade entre esses pacientes. Também não houve diferença entre os que preencheram ou não critérios para CPC em relação à idade, sexo, cefaléia prévia com ou sem crises nos três meses anteriores à cirurgia, diagnóstico da cefaléia prévia, presença de HSA, tipo de cirurgia, DTM, presença de vasoespasmo.

Isto pode significar que essa classificação produz uma divisão que clinicamente não é relevante. Entretanto, estes resultados podem ter ocorrido devido a um erro de classificação gerado por não termos usado a classificação da maneira como é preconizada, levando a uma possível homogeneização entre os grupos.

O ponto de corte de sete dias para o início da cefaléia está de acordo com a concepção adotada pela classificação de que uma cefaléia secundária deve ocorrer em estreita relação temporal com o transtorno que a causou. No entanto, este é um ponto de corte arbitrário que está baseado em poucas evidências científicas prévias. Em nosso estudo, o ponto de corte de sete dias engloba $68,2 \%$ dos nossos pacientes que apresentaram cefaléia apenas no local da craniotomia, enquanto que, se o ponto de corte fosse de 30 dias, 93,2\% destes seriam englobados.

Quanto à localização da cefaléia, outro pilar da classificação, apesar de as cefaléias que ocorrem após neurocirurgias serem mais frequientes no mesmo local da cirurgia, estas também podem ocorrer em outras localizações 5, 6, 9, 15, 68, 70, 71, 82, 176. Apesar de intuitivamente acharmos que o local de maior intensidade deva ser o local da craniotomia, faltam evidencias científicas que suportem tal afirmação.

A inclusão da CPC na segunda edição da Classificação Internacional de Cefaléias foi um avanço, já que a IHS reconhece a existência dessa entidade e cria critérios uniformes para a realização de estudos epidemiológicos. No entanto, a 
utilidade clínica dessa classificação precisa ser melhor avaliada em futuras investigações. 


\section{7 - CONCLUSÕES}

1- Após a cirurgia, houve mudanças na distribuição dos pacientes em relação ao diagnóstico, local e lado da cefaléia primária prévia à cirurgia com diminuição das cefaléias com características migranosas e aumento do número de pacientes que apresentavam dor do mesmo lado e local da cirurgia. Estas mudanças se mantiveram durante todo o período pós-operatório. Houve associação entre a persistência de cefaléia no segundo trimestre após a cirurgia e presença de disfunção temporomandibular.

2- A cefaléia pós-cirúrgica, na maioria dos casos, iniciou-se precocemente (em até cinco dias) após a craniotomia.

3- Houve aumento da frequiência da cefaléia após a cirurgia em relação à frequiência da cefaléia primária prévia. A frequiência da cefaléia pós-neurocirúrgica manteve-se em média mais alta que a da cefaléia primária prévia durante todo o período pós-operatório. Houve diminuição da frequiência da cefaléia pósneurocirúrgica com o transcorrer do tempo no período pós-operatório. O comportamento da freqüência da cefaléia no período pós-operatório foi semelhante nos pacientes com e sem HSA. Houve correlação positiva da freqüência de cefaléia com a intensidade da depressão e com a intensidade da ansiedade. Não houve associação entre a freqüência da cefaléia e a intensidade da sonolência diurna.

4- Maior intensidade da dor foi relacionada com maior intensidade dos sintomas ansiosos e com sexo feminino. Os pacientes submetidos a craniotomia 
através dos acessos frontal e fronto-órbito-zigomático apresentaram maior intensidade da dor do que os com acesso pterional.

5- Os pacientes do estudo apresentaram pior qualidade de vida na dimensão dor do SF-36 do que população geral urbana usada como referência. Maior intensidade de ansiedade e craniotomia frontal foram relacionados com menores escores (piores) no domínio dor do SF-36. Os pacientes com maior freqüência de cefaléia tiveram menores escores nos domínios dor e aspectos sociais do SF-36.

6- Encontrou-se incidência de $40 \%$ de cefaléia pós-craniotomia quando utilizada a classificação da IHS. A cefaléia persistiu por mais de três meses na maior parte destes pacientes, preenchendo os critérios de cefaléia pós-craniotomia crônica. 


\subsection{Consentimento livre e esclarecido}

\section{HOSPITAL DAS CLÍNICAS}

DA

FACULDADE DE MEDICINA DA UNIVERSIDADE DE SÃO PAULO

\section{TERMO DE CONSENTIMENTO LIVRE E ESCLARECIDO}

(Instruções para preenchimento no verso)

\section{I - DADOS DE IDENTIFICAÇÃO DO SUJEITO DA PESQUISA OU RESPONSÁVEL LEGAL}

1. NOME DO PACIENTE :

DOCUMENTO DE IDENTIDADE № : SEXO:.$M \square \quad F$

DATA NASCIMENTO:

ENDEREÇO

BAIRRO: №

APTO: $\ldots . .$.

CEP: TELEFONE: DDD (

..)

2. RESPONSÁVEL LEGAL

\begin{tabular}{|c|c|c|c|c|c|c|}
\hline NATUREZA & (grau & de & parentesco, & tutor, & curador & etc.) \\
\hline \multirow{2}{*}{\multicolumn{7}{|c|}{$\begin{array}{l}\text { DOCUMENTO DE IDENTIDADE :..............................SEXO: M } \square \mathrm{F} \square \\
\text { DATA NASCIMENTO: } \ldots \ldots . / \ldots \ldots / \ldots \ldots .\end{array}$}} \\
\hline ENDEREÇO:. & . & & & & & \\
\hline
\end{tabular}

\section{II - DADOS SOBRE A PESQUISA CIENTÍFICA}

1. TÍTULO DO PROTOCOLO DE PESQUISA: Cefaléia pós-craniotomia: Estudo prospectivo

PESQUISADOR: Pedro Augusto Sampaio Rocha Filho

CARGO/FUNÇÃO: Médico

INSCRIÇÃO CONSELHO REGIONAL № 95.911 UNIDADE DO HCFMUSP:

3. AVALIAÇÃO DO RISCO DA PESQUISA:

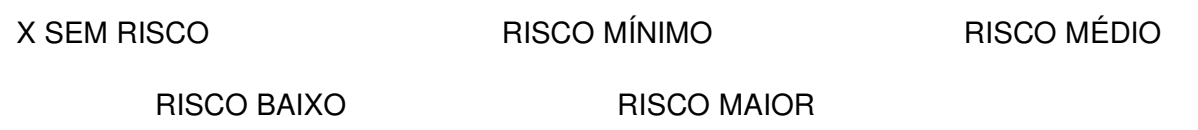

(probabilidade de que o indivíduo sofra algum dano como consequência imediata ou tardia do estudo)

4.DURAÇÃO DA PESQUISA : 2 anos 


\section{III - REGISTRO DAS EXPLICAÇÕES DO PESQUISADOR AO PACIENTE OU SEU REPRESENTANTE LEGAL SOBRE A PESQUISA CONSIGNANDO:}

1. justificativa e os objetivos da pesquisa; 2. procedimentos que serão utilizados e propósitos, incluindo a identificação dos procedimentos que são experimentais; $\mathbf{3}$. desconfortos e riscos esperados; 4 . benefícios que poderão ser obtidos; 5. procedimentos alternativos que possam ser vantajosos para o indivíduo

As dores de cabeça representam importante causa de sofrimento para um grande número de pessoas. Dentre as dores de cabeça, as que são conseqüentes à cirurgia com craniotomia são freqüentes, porém pouco estudadas. Sua intensidade e sintomas associados podem levar à forte impacto no aspecto pessoal, social, familiar e até profissional para as pessoas que são por elas acometidas. Entender melhor esse tipo de dor de cabeça é importante para que possamos no futuro preveni-la e melhor tratá-la.

Craniotomia é cirurgia em que é necessária a abertura do crânio, parte óssea que está em volta do cérebro, para o cirurgião poder operar o aneurisma com precisão.

A Clinica Neurológica do Hospital das Clinicas da Faculdade de Medicina da Universidade de São Paulo, no sentido de estudar o impacto que essas dores de cabeça tem nos pacientes, seu comportamento, seus fatores de risco e sua relação com as dores de cabeça pré-existentes, está avaliando os pacientes que serão submetidos a cirurgia de aneurisma de artérias cerebrais. Será feito acompanhamento posteriormente a cirurgia por seis meses. Durante este período serão avaliados e registrados fatores que podem influenciar neste tipo de dor de cabeça e aplicadas escalas com a finalidade de avaliar o impacto desta para o paciente. O paciente será acompanhado e tratado para dor de cabeça com medicamentos analgésicos quando for necessário.

Sua participação é voluntária e as respostas que você der e informações obtidas durante o seu acompanhamento serão mantidas sob sigilo, sendo apenas utilizadas de forma globalizada, junto com as informações de todas as outras pessoas acompanhadas, para permitir uma avaliação adequada e cientificamente testada sobre o assunto em questão.

Os entrevistadores são pessoas preparadas e o auxiliarão a responder adequadamente às questões e você será acompanhado por médicos com treinamento na área de dor de cabeça.

Os resultados obtidos deste estudo têm por finalidade auxiliar no estudo das dores de cabeça e principalmente auxiliar os estudiosos do assunto em planejar técnicas para prevenir e melhor tratar este problema de tamanha importância para pessoas que se submetem à cirurgia de craniotomia.

$\overline{\mathrm{IV}}$ - ESCLARECIMENTOS DADOS PELO PESQUISADOR SOBRE

\section{GARANTIAS DO SUJEITO DA PESQUISA CONSIGNANDO:}

1 acesso, a qualquer tempo, às informações sobre procedimentos, riscos e benefícios relacionados à pesquisa, inclusive para dirimir eventuais dúvidas; 2. liberdade de retirar seu consentimento a qualquer momento e 
de deixar de participar do estudo, sem que isto traga prejuízo à continuidade da assistência; 3. salvaguarda da confidencialidade, sigilo e privacidade; 4. disponibilidade de assistência no HCFMUSP, por eventuais danos à saúde, decorrentes da pesquisa; 5 . viabilidade de indenização por eventuais danos à saúde decorrentes da pesquisa.

O paciente participante da pesquisa poderá perguntar a qualquer momento sobre suas dúvidas sobre a pesquisa. Para isso basta ir ao ambulatório da Liga de Cefaléia que acorre nas quintas-feiras, das 17 às 19:30 horas no sexto andar do Prédio dos ambulatório do Hospital das Clínicas.

O paciente poderá retirar seu consentimento para participar desta pesquisa a qualquer momento e deixar de participar do estudo, sem que isto traga prejuízo à continuidade do acompanhamento.

As informações obtidas durante o seu acompanhamento serão mantidas sob sigilo, sendo apenas utilizadas de forma globalizada, junto com as informações de todas as outras pessoas acompanhadas para permitir uma avaliação adequada e cientificamente testada sobre o assunto em questão. Sua identidade não será revelada.

Em caso de eventuais danos causados pela pesquisa, o paciente continuará a ser acompanhado no HCFMUSP

Apesar dos baixos riscos, no caso de eventuais danos à saúde decorrentes da pesquisa, não há possibilidade de indenização por não haver recursos para tal.

V. INFORMAÇÕES DE NOMES, ENDEREÇOS E TELEFONES DOS RESPONSÁVEIS PELO ACOMPANHAMENTO DA PESQUISA, PARA CONTATO EM CASO DE INTERCORRÊNCIAS CLÍNICAS E REAÇÕES ADVERSAS.

Pedro Augusto Sampaio Rocha Filho Telefone: 5549-5016

\section{Getúlio Daré Rabello}

Ambulatório da liga de cefaléia

Prédio dos ambulatório do Hospital das Clínicas- sexto andar .

quintas-feiras, das 17 às 19:30 horas

\section{OBSERVAÇÕES COMPLEMENTARES:}

\section{VII - CONSENTIMENTO PÓS-ESCLARECIDO}

Declaro que, após convenientemente esclarecido pelo pesquisador e ter entendido o que me foi explicado, consinto em participar do presente Protocolo de Pesquisa São Paulo, de de 20 


\section{9 - REFERÊNCIAS BIBLIOGRÁFICAS}

1. Headache Classification Committee of the International Headache Society. The International Classification of Headache Disorders: 2nd edition. Cephalalgia. 2004; 24 Suppl 1: 9-160.

2. Wazen JJ, Sisti M, Lam SM. Cranioplasty in acoustic neuroma surgery. Laryngoscope. 2000; 110(8): 1294-7.

3. Schessel DA, Rowed DW, Nedzelski JM, Feghali JG. Postoperative pain following excision of acoustic neuroma by the suboccipital approach: observations on possible cause and potential amelioration. Am J Otol. 1993; 14(5): 491-4.

4. Schessel DA, Nedzelski JM, Rowed D, Feghali JG. Pain after surgery for acoustic neuroma. Otolaryngol Head Neck Surg. 1992; 107(3): 424-9.

5. Harner SG, Beatty CW, Ebersold MJ. Headache after acoustic neuroma excision. Am J Otol. 1993; 14(6): 552-5.

6. Pedrosa CA, Ahern DK, McKenna MJ, Ojemann RG, Acquadro MA. Determinants and impact of headache after acoustic neuroma surgery. Am J Otol. 1994; 15(6): 793-7.

7. Jorgensen BG, Pedersen CB. Acoustic neuroma. Follow-up of 78 patients. Clin Otolaryngol. 1994; 19(6): 478-84.

8. Koperer H, Deinsberger W, Jodicke A, Boker DK. Postoperative headache after the lateral suboccipital approach: craniotomy versus craniectomy. Minim Invasive Neurosurg. 1999; 42(4): 175-8.

9. Levo H, Pyykko I, Blomstedt G. Postoperative headache after surgery for vestibular schwannoma. Ann Otol Rhinol Laryngol. 2000; 109(9): 853-8. 
10. Jackson CG, McGrew BM, Forest JA, Hampf CR, Glasscock ME 3rd, Brandes JL, Hanson MB. Comparison of postoperative headache after retrosigmoid approach: vestibular nerve section versus vestibular schwannoma resection. Am J Otol. 2000; 21(3): 412-6.

11. Kane NM, Kazanas S, Maw AR, Coakham HB, Torrens MJ, Morgan MH, Stranjalis G, Butler SR. Functional outcome in patients after excision of extracanalicular acoustic neuromas using the suboccipital approach. Ann $R$ Coll Surg Engl. 1995; 77(3): 210-6.

12. Rigby PL, Shah SB, Jackler RK, Chung JH, Cooke DD. Acoustic neuroma surgery: outcome analysis of patient-perceived disability. Am J Otol. 1997; 18(4): 427-35.

13. Betchen SA, Walsh J, Post KD. Self-assessed quality of life after acoustic neuroma surgery. J Neurosurg. 2003; 99(5): 818-23.

14. Kaur A, Selwa L, Fromes G, Ross DA. Persistent headache after supratentorial craniotomy. Neurosurgery. 2000; 47(3): 633-6.

15. Gee JR, Ishaq Y, Vijayan N. Postcraniotomy headache. Headache. 2003; 43(3): $276-8$.

16. Bonica JJ. Definitions and taxonomy of pain. In: Bonica JJ. The management of pain. 2nd ed. Philadelphia: Lea \& Febinger; 1990. v.1, p.18-22.

17. Basbaum AI, Jessell TM. The Perception of pain. In: Kandel ER, Schwartz JH, Jessell TM. Principles of neural science. 4th ed. New York: McGrawHill; 2000. p.472-91. 
18. Price DD, Mao J, Mayer DJ. Neural mechanisms of normal and abnormal pain states. In: Raj PP. Current review of pain. Philadelphia: Current Medicine; 1994. p.1-16.

19. Ray BS, Wolff HG. Experimental studies in headache: pain-sensitive structures of the head and their significance in headache. Arch Surg. 1940; 41: 813-56.

20. Edvinsson L, Dahl E. Basic science aspect of headaches : anatomy of muscles, tendons, joints, blood vessels, and meninges. In: Olesen J, TfeltHansen P, Welch KMA. The Headaches. 2nd ed. Philadelphia: Lippincott Williams \& Williams; 2000. p.55-76.

21. Messlinger K, Burstein R. Basic science aspect of headaches: anatomy of central nervous system pathways related to head pain. In: Olesen J, TfeltHansen P, Welch KMA. The Headaches. 2nd ed. Philadelphia: Lippincott Williams \& Williams; 2000. p.77-86.

22. Rinkel GJ, Djibuti M, Algra A, van Gijn J. Prevalence and risk of rupture of intracranial aneurysms: a systematic review. Stroke. 1998; 29(1): 251-6.

23. Linn FH, Rinkel GJ, Algra A, van Gijn J. Incidence of subarachnoid hemorrhage: role of region, year, and rate of computed tomography: a metaanalysis. Stroke. 1996; 27(4): 625-9.

24. Locksley HB. Natural history of subarachnoid hemorrhage, intracranial aneurysms and arteriovenous malformations. Based on 6368 cases in the cooperative study. J Neurosurg. 1966; 25(2): 219-39. 
25. Longstreth WT Jr, Nelson LM, Koepsell TD, van Belle G. Clinical course of spontaneous subarachnoid hemorrhage: a population-based study in King County, Washington. Neurology. 1993; 43(4): 712-8.

26. Lanzino G, Kassell NF, Germanson TP, Kongable GL, Truskowski LL, Torner JC, Jane JA. Age and outcome after aneurysmal subarachnoid hemorrhage: why do older patients fare worse? J Neurosurg. 1996; 85(3): 410-8.

27. van Gijn J, van Dongen KJ. Computerized tomography in subarachnoid hemorrhage: difference between patients with and without an aneurysm on angiography. Neurology. 1980; 30(5): 538-9.

28. Velthuis BK, Rinkel GJ, Ramos LM, Witkamp TD, Berkelbach van der Sprenkel JW, Vandertop WP, van Leeuwen MS. Subarachnoid hemorrhage: aneurysm detection and preoperative evaluation with CT angiography. Radiology. 1998; 208(2): 423-30.

29. Kassell NF, Torner JC, Jane JA, Haley EC Jr, Adams HP. The International Cooperative Study on the Timing of Aneurysm Surgery. Part 2: Surgical results. J Neurosurg. 1990; 73(1): 37-47.

30. Linn FH, Rinkel GJ, Algra A, van Gijn J. Headache characteristics in subarachnoid haemorrhage and benign thunderclap headache. J Neurol Neurosurg Psychiatry. 1998; 65(5): 791-3.

31. Mohr JP, Caplan LR, Melski JW, Goldstein RJ, Duncan GW, Kistler JP, Pessin MS, Bleich HL. The Harvard Cooperative Stroke Registry: a prospective registry. Neurology. 1978; 28(8): 754-62. 
32. Bassi P, Bandera R, Loiero M, Tognoni G, Mangoni A. Warning signs in subarachnoid hemorrhage: a cooperative study. Acta Neurol Scand. 1991; 84(4): 277-81.

33. Becker LA, Green LA, Beaufait D, Kirk J, Froom J, Freeman WL. Detection of intracranial tumors, subarachnoid hemorrhages, and subdural hematomas in primary care patients: a report from ASPN, Part 2. J Fam Pract. 1993; 37(2): 135-41.

34. Kassell NF, Torner JC, Haley EC Jr, Jane JA, Adams HP, Kongable GL. The International Cooperative Study on the Timing of Aneurysm Surgery. Part 1: Overall management results. J Neurosurg. 1990; 73(1): 18-36.

35. Fontanarosa PB. Recognition of subarachnoid hemorrhage. Ann Emerg Med. 1989; 18(11): 1199-205.

36. Gorelick PB, Hier DB, Caplan LR, Langenberg P. Headache in acute cerebrovascular disease. Neurology. 1986; 36(11): 1445-50.

37. Linn FH, Wijdicks EF, van der Graaf Y, Weerdesteyn-van Vliet FA, Bartelds AI, van Gijn J. Prospective study of sentinel headache in aneurysmal subarachnoid haemorrhage. Lancet. 1994; 344(8922): 590-3.

38. Lledo A, Calandre L, Martinez-Menendez B, Perez-Sempere A, PorteraSanchez A. Acute headache of recent onset and subarachnoid hemorrhage: a prospective study. Headache. 1994; 34(3): 172-4.

39. Landtblom AM, Fridriksson S, Boivie J, Hillman J, Johansson G, Johansson I. Sudden onset headache: a prospective study of features, incidence and causes. Cephalalgia. 2002; 22(5): 354-60. 
40. Arboix A, Massons J, Oliveres M, Arribas MP, Titus F. Headache in acute cerebrovascular disease: a prospective clinical study in 240 patients. Cephalalgia. 1994; 14(1): 37-40.

41. Polmear A. Sentinel headaches in aneurysmal subarachnoid haemorrhage: what is the true incidence? A systematic review. Cephalalgia. 2003; 23(10): 935-41.

42. Okawara SH. Warning signs prior to rupture of an intracranial aneurysm. $J$ Neurosurg. $1973 ; 38(5):$ 575-80.

43. Ostergaard JR. Headache as a warning symptom of impending aneurysmal subarachnoid haemorrhage. Cephalalgia. 1991; 11(1): 53-5.

44. Leblanc R. The minor leak preceding subarachnoid hemorrhage. $J$ Neurosurg. 1987; 66(1): 35-9.

45. Ball MJ. Pathogenesis of the "sentinel headache" preceding berry aneurysm rupture. Can Med Assoc J. 1975; 112(1): 78-9.

46. Vega MG, de Sousa AA, Scarpelli M, Carvalho GT, Amaral A. Nevralgia paratrigeminal de Raeder como forma de expressão de aneurisma gigante intracavernous. Arq Neuropsiquiatr. 1994; 52(1): 69-73.

47. Smith WS, Messing RO. Cerebral aneurysm presenting as cough headache. Headache. 1993; 33(4): 203-4.

48. Hughes RL. Identification and treatment of cerebral aneurysms after sentinel headache. Neurology. 1992; 42(5): 1118-9.

49. Schubiger O, Valavanis A, Wichmann W. Growth-mechanism of giant intracranial aneurysms; demonstration by $\mathrm{CT}$ and $\mathrm{MR}$ imaging. Neuroradiology. 1987; 29(3): 266-71. 
50. Frankel K. Relation of migraine to cerebral aneurysm. Arch Neurol Psychiatry. 1950; 63(2): 195-204.

51. Day JW, Raskin NH. Thunderclap headache: symptom of unruptured cerebral aneurysm. Lancet. 1986; 2(8518): 1247-8.

52. Narbone MC, Rao R, Grugno R, Pellicano M. A late 'migraine': the only symptom of an intrasellar aneurysm. Headache. 1997; 37(8): 527-8.

53. McBeath JG, Nanda A. Sudden worsening of cluster headache: A signal of aneurysmal thrombosis and enlargement. Headache. 2000; 40(8): 686-8.

54. Witham TF, Kaufmann AM. Unruptured cerebral aneurysm producing a thunderclap headache. Am J Emerg Med. 2000; 18(1): 88-90.

55. Aneurysmal "thunderclap" headache without subarachnoid hemorrhage. Headache. 2002; 42(1): 82.

56. de Gray LC, Matta BF. Acute and chronic pain following craniotomy: a review. Anaesthesia. 2005; 60(7): 693-704.

57. Yasargil MG. Microsurgical anatomy of the basal cisterns and vassels of the brain, diagnostic studies, general operative techniques and pathological considerations of the intracranial aneurysms. New York: Thieme Stratton Inc.; 1984.

58. Tew JM, Scodary DJ. Basic techniques and surgical positioning. In: Apuzzo MLJ. Brain surgery: complication avoidance and management. New York: Churchill Livingstone; 1993. v.1, p.31-50.

59. Wen HT, de Oliveira E, Tedeschi H, Andrade FC, Rhoton AL. The pterional approach: surgical anatomy, operative technique, and rationale. Operative Techniques in Neurosurgery. 2001; 4(2): 60-72. 
60. Wen HT, de Oliveira E, Tedeschi H, Andrade FC, Rhoton AL. The pretemporal approach: surgical anatomy, operative technique, and rationale. Operative Techniques in Neurosurgery. 2001; 4(2): 73-81.

61. Verchere E, Grenier B. La douleur après une craniotomie et l'analgésie postopératoire. Ann Fr Anesth Reanim. 2004; 23(4): 417-21.

62. Dunbar PJ, Visco E, Lam AM. Craniotomy procedures are associated with less analgesic requirements than other surgical procedures. Anesth Analg. 1999; 88(2): 335-40.

63. Irefin SA, Schubert A, Bloomfield EL, DeBoer GE, Mascha EJ, Ebrahim ZY. The effect of craniotomy location on postoperative pain and nausea. J Anesth. 2003; 17(4): 227-31.

64. Goldsack C, Scuplak SM, Smith M. A double-blind comparison of codeine and morphine for postoperative analgesia following intracranial surgery. Anaesthesia. 1996; 51(11): 1029-32.

65. Guy J, Hindman BJ, Baker KZ, Borel CO, Maktabi M, Ostapkovich N, Kirchner J, Todd MM, Fogarty-Mack P, Yancy V, Sokoll MD, McAllister A, Roland C, Young WL, Warner DS. Comparison of remifentanil and fentanyl in patients undergoing craniotomy for supratentorial space-occupying lesions. Anesthesiology. 1997; 86(3): 514-24.

66. Gerlach K, Uhlig T, Huppe M, Nowak G, Schmitz A, Saager L, Grasteit A, Schmucker P. Remifentanil-propofol versus sufentanil-propofol anaesthesia for supratentorial craniotomy: a randomized trial. Eur J Anaesthesiol. 2003; 20(10): 813-20. 
67. Biswas BK, Bithal PK. Preincision $0.25 \%$ bupivacaine scalp infiltration and postcraniotomy pain: a randomized double-blind, placebo-controlled study. $J$ Neurosurg Anesthesiol. 2003; 15(3): 234-9.

68. De Benedittis G, Lorenzetti A, Migliore M, Spagnoli D, Tiberio F, Villani RM. Postoperative pain in neurosurgery: a pilot study in brain surgery. Neurosurgery. 1996; 38(3): 466-70.

69. Jackler RK, Pitts LH. Acoustic neuroma. Neurosurg Clin N Am. 1990; 1(1): $199-223$.

70. Schaller B, Baumann A. Headache after removal of vestibular schwannoma via the retrosigmoid approach: a long-term follow-up-study. Otolaryngol Head Neck Surg. 2003; 128(3): 387-95.

71. Mosek AC, Dodick DW, Ebersold MJ, Swanson JW. Headache after resection of acoustic neuroma. Headache. 1999; 39: 89-94.

72. Ruckenstein MJ, Harris JP, Cueva RA, Prioleau G, Alksne J. Pain subsequent to resection of acoustic neuromas via suboccipital and translabyrinthine approaches. Am J Otol. 1996; 17(4): 620-4.

73. Glasscock ME 3rd, Hays JW, Minor LB, Haynes DS, Carrasco VN. Preservation of hearing in surgery for acoustic neuromas. J Neurosurg. 1993; 78(6): 864-70.

74. Harner SG, Beatty CW, Ebersold MJ. Impact of cranioplasty on headache after acoustic neuroma removal. Neurosurgery. 1995; 36(6): 1097-9.

75. Soumekh B, Levine SC, Haines SJ, Wulf JA. Retrospective study of postcraniotomy headaches in suboccipital approach: diagnosis and management. Am J Otol. 1996; 17(4): 617-9. 
76. Catalano PJ, Jacobowitz O, Post KD. Prevention of headache after retrosigmoid removal of acoustic tumors. Am J Otol. 1996; 17(6): 904-8.

77. Feghali JG, Elowitz EH. Split calvarial graft cranioplasty for the prevention of headache after retrosigmoid resection of acoustic neuromas. Laryngoscope. 1998; 108(10): 1450-2.

78. Parving A, Tos M, Thomsen J, Moller H, Buchwald C. Some aspects of life quality after surgery for acoustic neuroma. Arch Otolaryngol Head Neck Surg. 1992; 118(10): 1061-4.

79. Martin HC, Sethi J, Lang D, Neil-Dwyer G, Lutman ME, Yardley L. Patientassessed outcomes after excision of acoustic neuroma: postoperative symptoms and quality of life. J Neurosurg. 2001; 94(2): 211-6.

80. Andersson G, Ekvall L, Kinnefors A, Nyberg G, Rask-Andersen H. Evaluation of quality of life and symptoms after translabyrinthine acoustic neuroma surgery. Am J Otol. 1997; 18(4): 421-6.

81. Weber PC, Gantz BJ. Results and complications from acoustic neuroma excision via middle cranial fossa approach. Am J Otol. 1996; 17(4): 669-75.

82. Vijayan N. Postoperative headache in acoustic neuroma. Headache. 1995; 35(2): $98-100$.

83. Hanson MB, Glasscock ME 3rd, Brandes JL, Jackson CG. Medical treatment of headache after suboccipital acoustic tumor removal. Laryngoscope. 1998; 108(8 Pt 1): 1111-4.

84. Lovely TJ, Lowry DW, Jannetta PJ. Functional outcome and the effect of cranioplasty after retromastoid craniectomy for microvascular decompression. Surg Neurol. 1999; 51(2): 191-7. 
85. Sataloff RT, Myers DL, Roberts BR. Pain following surgery of the skull base. Otolaryngol Clin North Am. 1984; 17(3): 613-25.

86. Driscoll CL, Beatty CW. Pain after acoustic neuroma surgery. Otolaryngol Clin North Am. 1997; 30(5): 893-903.

87. Cohen NL. Retrosigmoid approach for acoustic tumor removal. Otolaryngol Clin North Am. 1992; 25(2): 295-310.

88. Hendler N, Cashen A, Morrison C, Long D, Holliday M. Divalproex sodium and other medications for headache following craniotomy for acoustic neuroma. Headache. 1995; 35(8): 490-3.

89. Malis LI. Titanium mesh and acrylic cranioplasty. Neurosurgery. 1989; 25(3): $351-5$.

90. Fetterman BL, Lanman TH, House JW. Relief of headache by cranioplasty after skull base surgery. Skull Base Surg. 1997; 7: 1-4.

91. Silverstein H, Norrell H, Smouha E, Jones R. Retrolabyrinthine or retrosigmoid vestibular neurectomy: indications. Am J Otol. 1987; 8(5): 4148.

92. McKenna MJ, Nadol JB Jr, Ojemann RG, Halpin C. Vestibular neurectomy: retrosigmoid-intracanalicular versus retrolabyrinthine approach. Am J Otol. 1996; 17(2): 253-8.

93. Baldwin RL. Headache prevention in retrosigmoid vestibular nerve section. South Med J. 1996; 89(4): 375-9.

94. Levo H, Blomstedt G, Pyykko I. Vestibular schwannoma surgery and headache. Acta Otolaryngol Suppl. 2000; 543: 23-5. 
95. Levo H, Blomstedt G, Hirvonen T, Pyykko I. Causes of persistent postoperative headache after surgery for vestibular schwannoma. Clin Otolaryngol. 2001; 26(5): 401-6.

96. van Leeuwen JP, Braspenning JC, Meijer H, Cremers CW. Quality of life after acoustic neuroma surgery. Ann Otol Rhinol Laryngol. 1996; 105(6): 423-30.

97. Headache Classification Committee of the International Headache Society. Classification and diagnostic criteria for headache disorders, cranial neuralgias and facial pain. Cephalalgia. 1988; 8 Suppl 7: 1-96.

98. Dworkin SF, Huggins KH, LeResche L, Von Korff M, Hooward J, Truelove E, Sommers E. Epidemiology of signs and symptoms in temporomandibular disorders: clinical signs in cases and controls. JADA. 1990; 120: 239-34.

99. Von Korff A. Health services research and temporomandibular pain. In: Sessle BJ, Bryant PS, Dionne RA. Temporomandibular disorders and related pain conditions, progress in pain research and management. Seattle: IASP Press; 1995. v.4, p.227-36.

100. De Kanter RJ, Truin GJ, Burgersdijk RC, Van 't Hof MA, Battistuzzi PG, Kalsbeek H, Kayser AF. Prevalence in the Dutch adult population and a meta-analysis of signs and symptoms of temporomandibular disorder. $J$ Dent Res. 1993; 72(11): 1509-18.

101. McNeill C. Temporomandibular disorders: guidelines for classification, assesment, and management. The American Academy of Orofacial Pain. Chicago: Quintessence; 1993. 
102. Merskey H, Bogduk N. Classification of chronic pain. 2. ed. Seattle: IASP Press; 1994.

103. Hannerz J, Lindderoth B. Neurosurgical treatment of short-lasting, unilateral, neuralgiform hemicrania with conjunctival injection and tearing. Headache. 2003; 43: 429.

104. de Andrade Junior FC, de Andrade FC, de Araujo Filho CM, Carcagnolo Filho J. Dysfunction of the temporalis muscle after pterional craniotomy for intracranial aneurysms. Comparative, prospective and randomized study of one flap versus two flaps dieresis. Arq Neuropsiquiatr. 1998; 56(2): 200-5.

105. Piotrowski C. Assessment of pain: a survey of practicing clinicians. Percept Mot Skills. 1998; 86(1): 181-2.

106. Melzack R. The McGill Pain Questionnaire: major properties and scoring methods. Pain. 1975; 1(3): 277-99.

107. Melzack R, Terrence C, Fromm G, Amsel R. Trigeminal neuralgia and atypical facial pain: use of the McGill Pain Questionnaire for discrimination and diagnosis. Pain. 1986; 27(3): 297-302.

108. Hunter M, Philips C. The experience of headache pain--an assessment of the qualities of tension headache pain. Pain. 1981; 10(2): 209-19.

109. Jerome A, Holroyd KA, Theofanous AG, Pingel JD, Lake AE, Saper JR. Cluster headache pain vs. other vascular headache pain: differences revealed with two approaches to the McGill Pain Questionnaire. Pain. 1988; 34(1): 3542. 
110. Dumas JP, Arsenault AB, Boudreau G, Magnoux E, Lepage Y, Bellavance A, Loisel P. Physical impairments in cervicogenic headache: traumatic vs. nontraumatic onset. Cephalalgia. 2001; 21(9): 884-93.

111. Mongini F, Deregibus A, Raviola F, Mongini T. Confirmation of the distinction between chronic migraine and chronic tension-type headache by the McGill Pain Questionnaire. Headache. 2003; 43(8): 867-77.

112. Johnson PR, Thorn BE. Cognitive behavioral treatment of chronic headache: group versus individual treatment format. Headache. 1989; 29(6): 358-65.

113. Harden RN, Carter TD, Gilman CS, Gross AJ, Peters JR. Ketorolac in acute headache management. Headache. 1991; 31(7): 463-4.

114. Harden RN, Gracely RH, Carter T, Warner G. The placebo effect in acute headache management: ketorolac, meperidine, and saline in the emergency department. Headache. 1996; 36(6): 352-6.

115. Harden RN, Rogers D, Fink K, Gracely RH. Controlled trial of ketorolac in tension-type headache. Neurology. 1998; 50(2): 507-9.

116. Petit JH, Herman JM, Nagda S, DiBiase SJ, Chin LS. Radiosurgical treatment of trigeminal neuralgia: evaluating quality of life and treatment outcomes. Int J Radiat Oncol Biol Phys. 2003; 56(4): 1147-53.

117. Cohen MM, Tate RB. Using the McGill Pain Questionnaire to study common postoperative complications. Pain. 1989; 39(3): 275-9.

118. Haefner HK, Khoshnevisan MH, Bachman JE, Flowe-Valencia HD, Green CR, Reed BD. Use of the McGill Pain Questionnaire to compare women with vulvar pain, pelvic pain and headaches. J Reprod Med. 2000; 45(8): 665-71. 
119. Johns MW. A new method for measuring daytime sleepiness: the Epworth sleepiness scale. Sleep. 1991; 14(6): 540-5.

120. Johns MW. Reliability and factor analysis of the Epworth Sleepiness Scale. Sleep. 1992; 15(4): 376-81.

121. Zigmond AS, Snaith RP. The hospital anxiety and depression scale. Acta Psychiatr Scand. 1983; 67(6): 361-70.

122. Spinhoven P, Ormel J, Sloekers PP, Kempen GI, Speckens AE, Van Hemert AM. A validation study of the Hospital Anxiety and Depression Scale (HADS) in different groups of Dutch subjects. Psychol Med. 1997; 27(2): 363-70.

123. Herrmann C. International experiences with the Hospital Anxiety and Depression Scale--a review of validation data and clinical results. $J$ Psychosom Res. 1997; 42(1): 17-41.

124. Bjelland I, Dahl AA, Haug TT, Neckelmann D. The validity of the Hospital Anxiety and Depression Scale. An updated literature review. J Psychosom Res. 2002; 52(2): 69-77.

125. Mykletun A, Stordal E, Dahl AA. Hospital Anxiety and Depression (HAD) scale: factor structure, item analyses and internal consistency in a large population. Br J Psychiatry. 2001; 179: 540-4.

126. Hannah P, Jarman J, Glover V, Sandler M, Davies PT, Clifford Rose F. Kinetics of platelet 5-hydroxytryptamine uptake in headache patients. Cephalalgia. 1991; 11(3): 141-5. 
127. Jarman J, Davies PT, Fernandez M, Glover V, Steiner TJ, Rose FC, Sandler M. Platelet $[3 \mathrm{H}]$ imipramine binding in migraine and tension headache in relation to depression. J Psychiatr Res. 1991; 25(4): 205-11.

128. Devlen J. Anxiety and depression in migraine. J R Soc Med. 1994; 87(6): $338-41$.

129. Gale G, Nussbaum D, Rothbart P, Hann B, Leung V, Kanetz G. A randomized treatment study to compare the efficacy of repeated nerve blocks with cognitive therapy for control of chronic head and neck pain. Pain Res Manag. 2002; 7(4): 185-9.

130. Wenzel HG, Haug TT, Mykletun A, Dahl AA. A population study of anxiety and depression among persons who report whiplash traumas. J Psychosom Res. 2002; 53(3): 831-35.

131. Zwart JA, Dyb G, Hagen K, Odegard KJ, Dahl AA, Bovim G, Stovner LJ. Depression and anxiety disorders associated with headache frequency. The Nord-Trondelag Health Study. Eur J Neurol. 2003; 10(2): 147-52.

132. Wacogne C, Lacoste JP, Guillibert E, Hugues FC, Le Jeunne C. Stress, anxiety, depression and migraine. Cephalalgia. 2003; 23(6): 451-5.

133. Becker WJ. Assessing health-related quality of life in patients with migraine. Can J Neurol Sci. 2002; 29 Suppl 2: S16-22.

134. Solomon GD, Dahlof CGH. Impact of headache on headache sufferer. In: Olesen J, Tfelt-Hansen P, Welch KMA. The Headaches. 2nd ed. Philadelphia: Lippincott Williams \& Williams; 2000. p.25-31.

135. Solomon GD. Evolution of the measurement of quality of life in migraine. Neurology. 1997; 48(3 Suppl 3): S10-5. 
136. Colas R, Munoz P, Temprano R, Gomez C, Pascual J. Chronic daily headache with analgesic overuse: epidemiology and impact on quality of life. Neurology. 2004; 62(8): 1338-42.

137. Ertsey C, Manhalter N, Bozsik G, Afra J, Jelencsik I. Health-related and condition-specific quality of life in episodic cluster headache. Cephalalgia. 2004; 24(3): 188-96.

138. Lipton RB, Liberman JN, Kolodner KB, Bigal ME, Dowson A, Stewart WF. Migraine headache disability and health-related quality-of-life: a populationbased case-control study from England. Cephalalgia. 2003; 23(6): 441-50.

139. D'Amico D, Usai S, Grazzi L, Rigamonti A, Solari A, Leone M, Bussone G. Quality of life and disability in primary chronic daily headaches. Neurol Sci. 2003; 24 Suppl 2: S97-100.

140. Guitera V, Munoz P, Castillo J, Pascual J. Quality of life in chronic daily headache: a study in a general population. Neurology. 2002; 58(7): 1062-5.

141. Durham CF, Alden KR, Dalton JA, Carlson J, Miller DW, Englebardt SP, Neelon VJ. Quality of life and productivity in nurses reporting migraine. Headache. 1998; 38(6): 427-35.

142. Osterhaus JT, Townsend RJ, Gandek B, Ware JE Jr. Measuring the functional status and well-being of patients with migraine headache. Headache. 1994; 34(6): 337-43.

143. Essink-Bot ML, van Royen L, Krabbe P, Bonsel GJ, Rutten FF. The impact of migraine on health status. Headache. 1995; 35(4): 200-6. 
144. Michel P, Dartigues JF, Lindoulsi A, Henry P. Loss of productivity and quality of life in migraine sufferers among French workers: results from the GAZEL cohort. Headache. 1997; 37(2): 71-8.

145. Marcus DA. Identification of patients with headache at risk of psychological distress. Headache. 2000; 40(5): 373-6.

146. Marcus DA. Disability and chronic posttraumatic headache. Headache. 2003; 43(2): 117-21.

147. D'Amico D, Rigamonti A, Solari A, Leone M, Usai S, Grazzi L, Bussone G. Health-related quality of life in patients with cluster headache during active periods. Cephalalgia. 2002; 22(10): 818-21.

148. Wang SJ, Fuh JL, Lu SR, Juang KD. Quality of life differs among headache diagnoses: analysis of SF-36 survey in 901 headache patients. Pain. 2001; 89(2-3): 285-92.

149. Monzon MJ, Lainez MJ. Quality of life in migraine and chronic daily headache patients. Cephalalgia. 1998; 18(9): 638-43.

150. Meletiche DM, Lofland JH, Young WB. Quality-of-life differences between patients with episodic and transformed migraine. Headache. 2001; 41(6): $573-8$.

151. Magnusson JE, Riess CM, Becker WJ. Effectiveness of a multidisciplinary treatment program for chronic daily headache. Can J Neurol Sci. 2004; 31(1): 72-9.

152. Mannix LK, Solomon GD, Kippes CM, Kunkel RS. Impact of headache education program in the workplace. Neurology. 1999; 53(4): 868-71. 
153. Jhingran P, Cady RK, Rubino J, Miller D, Grice RB, Gutterman DL. Improvements in health-related quality of life with sumatriptan treatment for migraine. J Fam Pract. 1996; 42(1): 36-42.

154. Mannix LK, Chandurkar RS, Rybicki LA, Tusek DL, Solomon GD. Effect of guided imagery on quality of life for patients with chronic tension-type headache. Headache. 1999; 39(5): 326-34.

155. Vickers AJ, Rees RW, Zollman CE, McCarney R, Smith CM, Ellis N, Fisher P, Van Haselen R. Acupuncture for chronic headache in primary care: large, pragmatic, randomised trial. Bmj. 2004; 328(7442): 744.

156. Ware JE Jr, Sherbourne CD. The MOS 36-item short-form health survey (SF-36). I. Conceptual framework and item selection. Med Care. 1992; 30(6): 473-83.

157. Siqueira JTT, Teixeira MJ. Dor orofacial: diagnóstico, terapêutica e qualidade de vida. Curitiba: Maio; 2001.

158. Noether GE. Introduction to statistics: a nonparametric approach. New York: Houghton Mifflin Company; 1976.

159. Rosner B. Fundamentals of Biostatistics. 2 ed. Boston: PWS Publishers; 1986.

160. Senna ER. Estudo sobre a prevalência de doenças reumáticas na cidade de Montes Claros [dissertação]. São Paulo: Universidade Federal de São Paulo; 2002.

161. Hennekens $\mathrm{CH}$, Buring JE. Epidemiology in medicine. Philadelphia: Lippincott Williams \& Wilkins; 1987. 
162. Erskine A, Morley S, Pearce S. Memory for pain: a review. Pain. 1990; 41(3): 255-65.

163. Majani G, Tiengo M, Giardini A, Calori G, De Micheli P, Battaglia A. Relationship between MPQ and VAS in 962 patients. A rationale for their use. Minerva Anestesiol. 2003; 69(1-2): 67-73.

164. Frot M, Feine JS, Bushnell MC. Sex differences in pain perception and anxiety. A psychophysical study with topical capsaicin. Pain. 2004; 108(3): $230-6$

165. Feine JS, Bushnell MC, Miron D, Duncan GH. Sex differences in the perception of noxious heat stimuli. Pain. 1991; 44(3): 255-62.

166. Sarlani E, Greenspan JD. Gender differences in temporal summation of mechanically evoked pain. Pain. 2002; 97(1-2): 163-9.

167. Berkley KJ. Sex differences in pain [abstract]. Behav Brain Sci. 1997; 20(3): 371-80A.

168. Fillingim RB, Edwards RR, Powell T. The relationship of sex and clinical pain to experimental pain responses. Pain. 1999; 83(3): 419-25.

169. Ploghaus A, Narain C, Beckmann CF, Clare S, Bantick S, Wise R, Matthews PM, Rawlins JN, Tracey I. Exacerbation of pain by anxiety is associated with activity in a hippocampal network. $J$ Neurosci. 2001; 21(24): 9896-903.

170. Torrecilla Ortiz C, Rodriguez Blanco LL, Diaz Vicente F, Gonzalez Satue C, Marco Perez LM, Trilla Herrera E, Serrallach i Mila N. Litotricia extracorpórea por ondas de choque: ansiedad y perceptión del dolor. Actas Urol Esp. 2000; 24(2): 163-8. 
171. Jones A, Zachariae R, Arendt-Nielsen L. Dispositional anxiety and the experience of pain: gender-specific effects. Eur J Pain. 2003; 7(5): 387-95.

172. Klages U, Ulusoy O, Kianifard S, Wehrbein H. Dental trait anxiety and pain sensitivity as predictors of expected and experienced pain in stressful dental procedures. Eur J Oral Sci. 2004; 112(6): 477-83.

173. Cornwall A, Donderi DC. The effect of experimentally induced anxiety on the experience of pressure pain. Pain. 1988; 35(1): 105-13.

174. Bachiocco V, Morselli-Labate AM, Rusticali AG, Bragaglia R, Mastrorilli M, Carli G. Intensity, latency and duration of post-thoracotomy pain: relationship to personality traits [abstract]. Funct Neurol. 1990; 5(4): 321-32A.

175. Jones A, Spindler H, Jorgensen MM, Zachariae R. The effect of situationevoked anxiety and gender on pain report using the cold pressor test [abstract]. Scand J Psychol. 2002; 43(4): 307-13A.

176. Nguyen A, Girard F, Boudreault D, Fugere F, Ruel M, Moumdjian R, Bouthilier A, Caron JL, Bojanowski MW, Girard DC. Scalp nerve blocks decrease the severity of pain after craniotomy. Anesth Analg. 2001; 93(5): $1272-6$.

177. Ramadan NM, Keidel M. Chronic posttraumatic headache. In: Olesen J, Tfelt-Hansen P, Welch KMA. The Headaches. 2nd ed. Philadelphia: Lippincott Williams \& Williams; 2000. p.771-80.

178. Wiegand DA, Fickel V. Acoustic neuroma--the patient's perspective: subjective assessment of symptoms, diagnosis, therapy, and outcome in 541 patients. Laryngoscope. 1989; 99(2): 179-87. 
179. Moldin SO, Scheftner WA, Rice JP, Nelson E, Knesevich MA, Akiskal H. Association between major depressive disorder and physical illness. Psychol Med. 1993; 23(3): 755-61.

180. De Benedittis G, Lorenzetti A. Minor stressful life events (daily hassles) in chronic primary headache: relationship with MMPI personality patterns. Headache. 1992; 32(7): 330-4.

181. Mitsikostas DD, Thomas AM. Comorbidity of headache and depressive disorders. Cephalalgia. 1999; 19(4): 211-7.

182. Wang SJ, Liu HC, Fuh JL, Liu CY, Wang PN, Lu SR. Comorbidity of headaches and depression in the elderly. Pain. 1999; 82(3): 239-43.

183. Lyons RA, Lo SV, Littlepage BN. Comparative health status of patients with 11 common illnesses in Wales. J Epidemiol Community Health. 1994; 48(4): 388-90.

184. Jenkinson C, Coulter A, Wright L. Short form 36 (SF36) health survey questionnaire: normative data for adults of working age. Bmj. 1993; 306(6890): 1437-40.

185. Jenkinson C, Stewart-Brown S, Petersen S, Paice C. Assessment of the SF-36 version 2 in the United Kingdom. J Epidemiol Community Health. 1999; 53(1): 46-50.

186. Raj PP. Current review of pain. Philadelphia: Current Medicine; 1994. 